\title{
Understanding Pasifika Educational Aspirations and Conceptions of Development in Wainuiomata
}

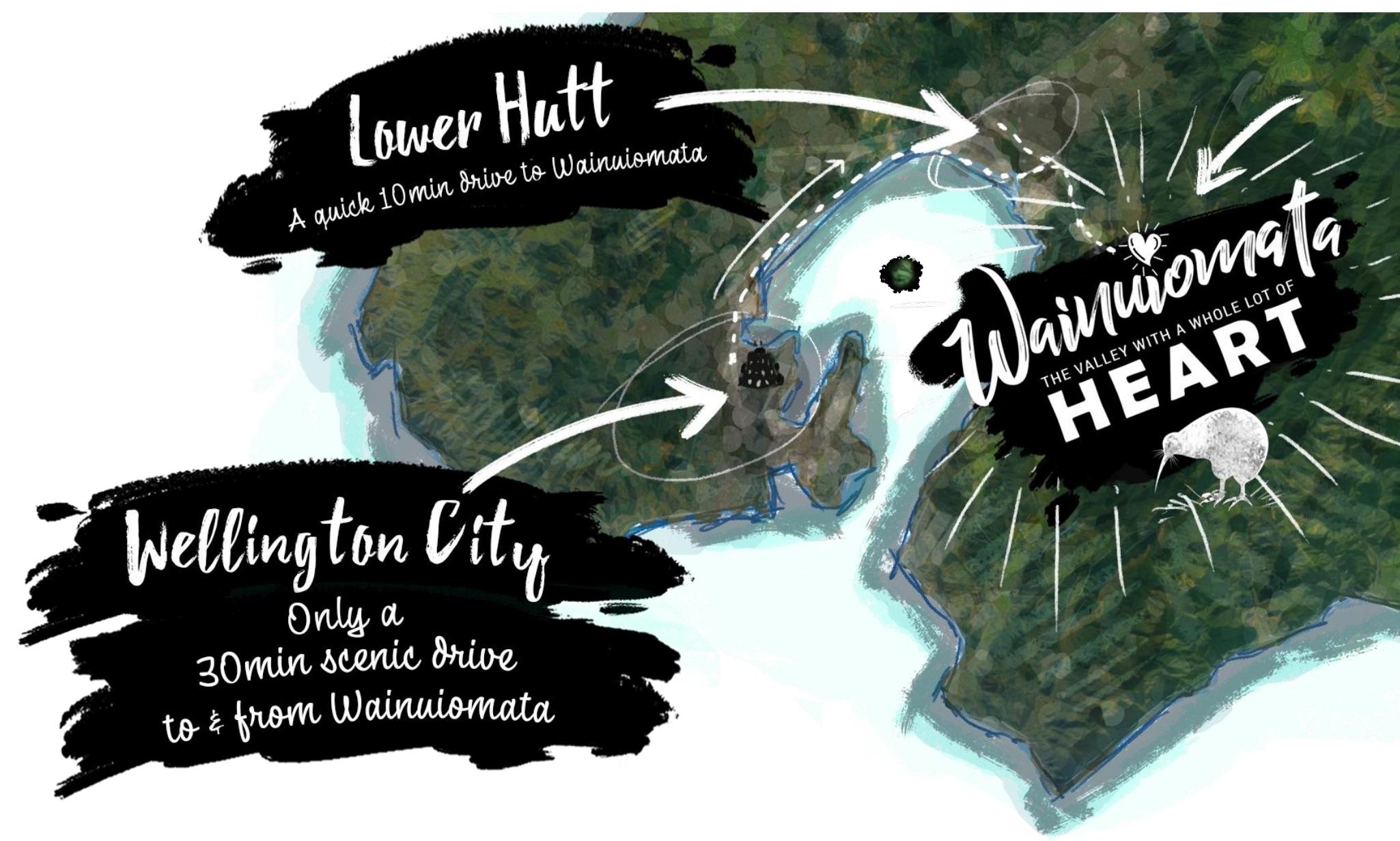

Holly McLeod

SID: 300253883

Supervisor: John Overton

School of Geography, Environment and Earth Sciences, Victoria University of Wellington

March 2020

120 point thesis submitted to Victoria University of Wellington in partial fulfilment of the requirements for the degree of Master of Development Studies. 


\section{Abstract}

Education is good for development. This positive relationship between education and development is often stated without challenge, resulting in education being posited at the forefront of global development strategies. Yet, within the subject of Development Studies, postdevelopment theorists have questioned the very basis of 'development', not only its definition but also the inherent assumption that it is necessarily desirable and positive. Instead, they point to examples such as Buen Vivir and argue that we should explore different ways of conceptualising what is a good life.

The present research has sought to examine the way the Pasifika community in Wainuiomata, Aotearoa perceives and engages with education to fulfil its own vision of development. Some 30 research participants contributed their valuable time and energy to this project through semi-structured interviews, offering insight into their own educational experiences and aspirations. Through employing a methodological approach informed by the ethos of talanoa and participatory research, this research has privileged the narratives of participants, giving voice to their experiences within an academic context.

This research has identified that while the experiences of these families within Aotearoa's education system have been frustrating and challenging, such adversity has not served to disenfranchise Pasifika families from engaging within this educational system. Rather, it has served as motivation to create better educational experiences for youth in this community today. Furthermore, the vision of development aspired toward by this community is one that draws both similarities and contrasts with mainstream conceptions of development. The existence of alternative conceptions of development supports post-development's call for development practise to examine local context and community aspirations, and to value community knowledge and action. In examining the way this community has engaged with education to progress their own vision of development, it was found that Pasifika families in Wainuiomata are taking ownership of their own development, and are actively involved in creating better educational outcomes for their youth. 


\section{Acknowledgements}

This research could not have happened without the support of some incredible people, who I would like to take the time to offer my sincere appreciation.

To my supervisor John: From my first encounter with you at university seven years ago, I knew that if I was going to embark on postgraduate study, I wanted it to be you guiding me; and I'm so grateful you have. Thank you for your endless positivity and belief in me, when I didn't believe in myself.

To the original DEVE crew: Chelsey, Katy, Matt, Michaela, Nadia, Neil, Prasanthi, Sarah, Thomas \& Vanessa. You have laughed with me, cried with me, supported me, challenged me and inspired me. I could not have hoped for a more passionate cohort to undertake this journey with, and I truly believe you all will change the world.

To WaiPESI: Thank you for welcoming me into your lives, and trusting me to give voice to your experiences. Your passion and commitment to creating a better future for your community inspires me.

To Gail and Trudy; the foundations of the Pasifika office at Vic. You both were instrumental in keeping this project moving, and it would not have progressed without you. I am beyond grateful for your support of me.

To the friends who are family, who have carried me through, I love you all. Thank you for the support.

Liz, I quite simply could not have done this without you. You have been my biggest cheerleader, a safe place and a constant reassurance. I could not wish for a better sister and friend.

Macleod, thank you for the love and support shown through your continuous, colourful reminders to 'finish that ... thesis'. That went well!

Megan, you have been the biggest supporter of my education for over eleven years now. Thank you for always lending an ear, taking an interest, and constantly showing you care. Pilot $P$ 500 's and post-it notes have been instrumental in the making of this thesis.

Che, 50 nautical miles away and yet somehow, you intuitively know when I need you. Thank you for the U-Mail, for the love and support, and for being my angel bell. 


\section{Table of Contents}

Understanding Pasifika Educational Aspirations and Conceptions of Development in

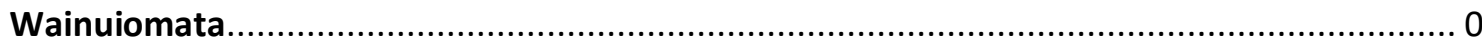

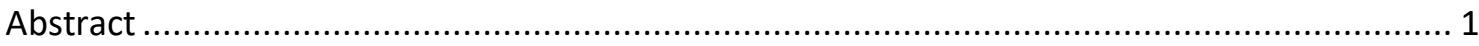

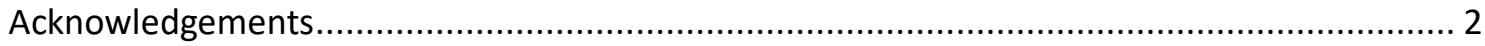

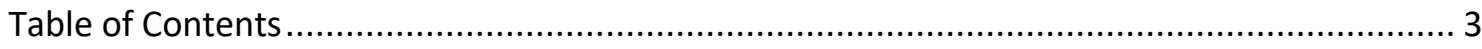

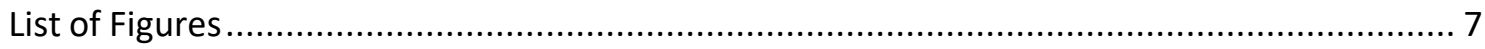

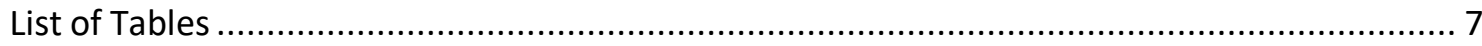

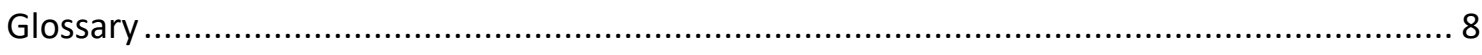

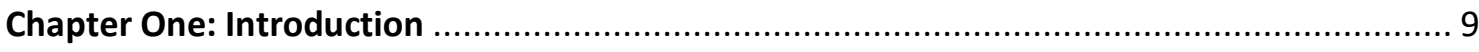

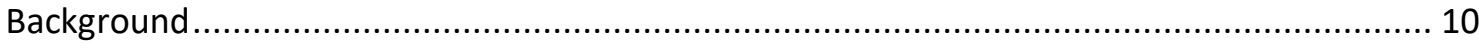

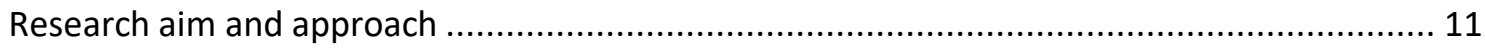

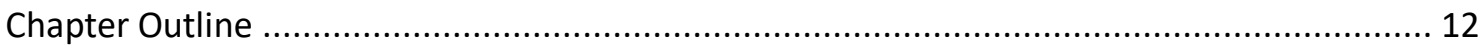

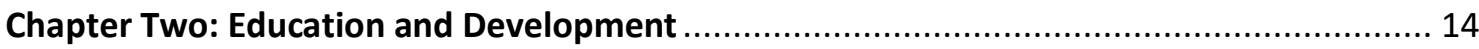

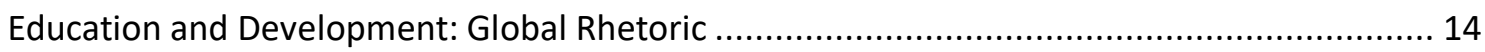

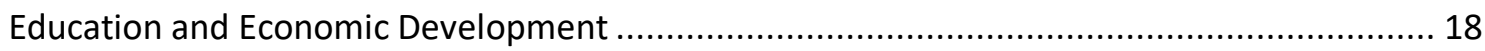

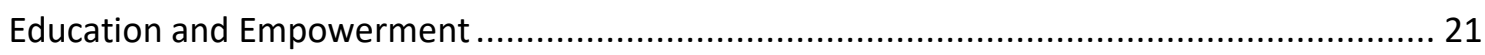

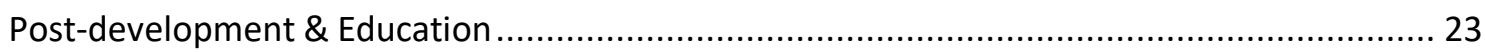

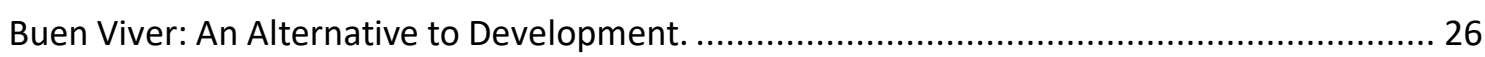

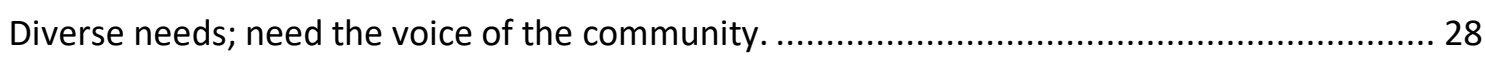

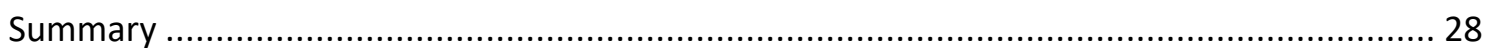

Chapter Three: Context: Pasifika \& Education in Aotearoa ................................................ 31

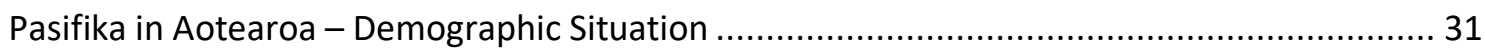

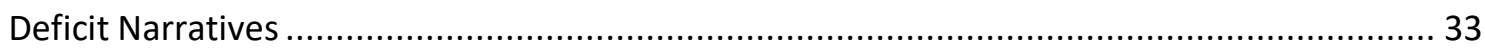

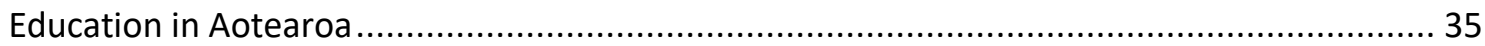

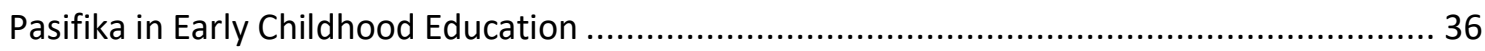

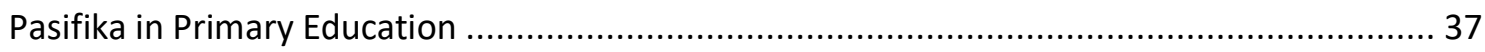

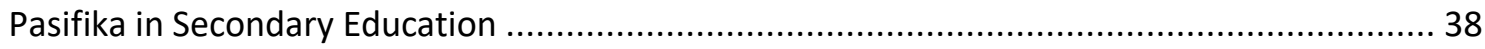

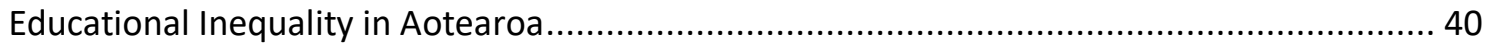

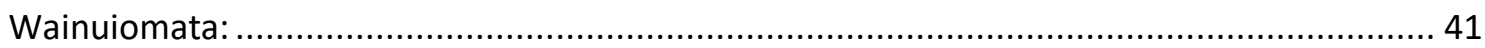

Introducing WaiPESI - the Wainuiomata Pasifika Education Success Initiative ........................ 43

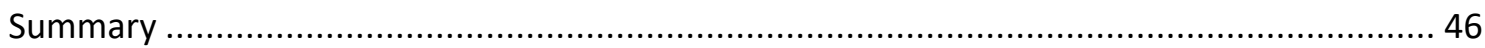

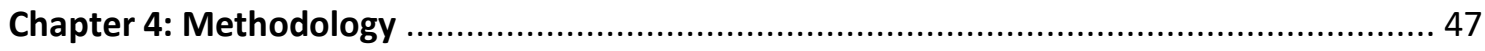

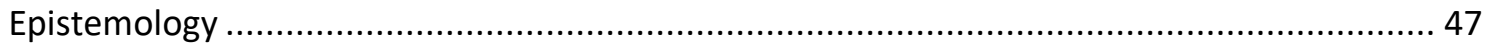




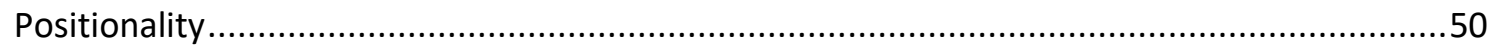

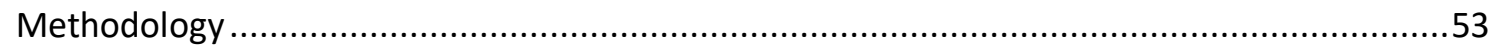

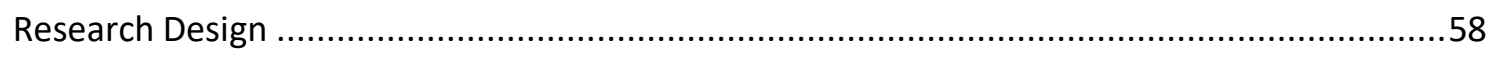

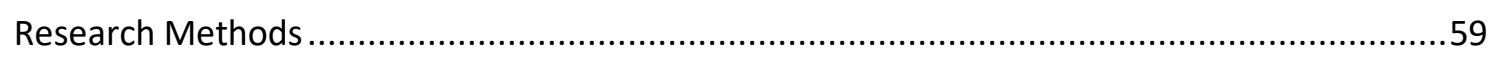

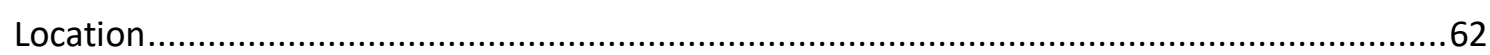

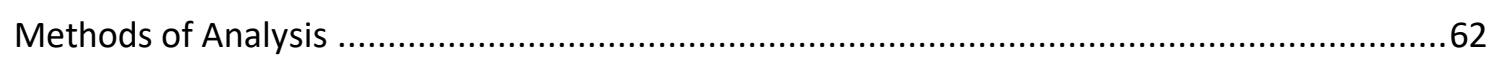

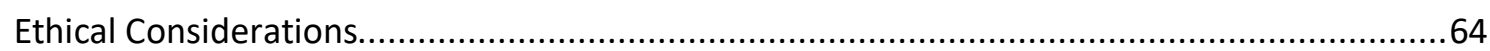

Chapter Five: What have been the educational experiences of Pasifika families in

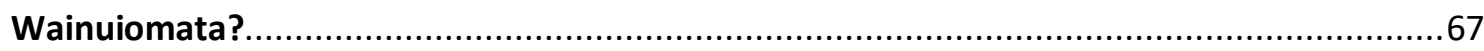

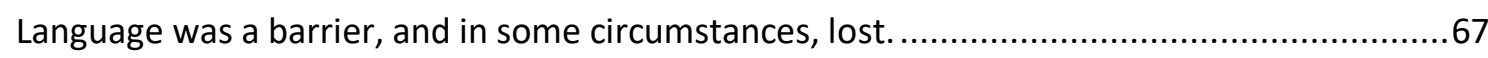

Encouragement to aspire high was lacking, but significant when present. ............................. 70

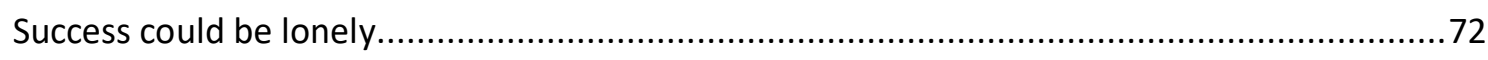

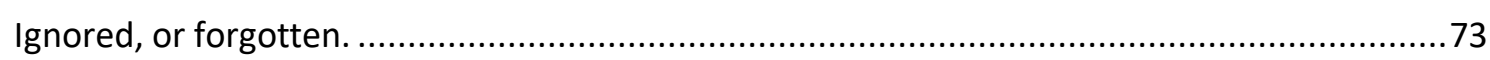

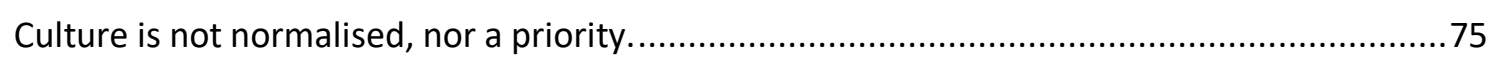

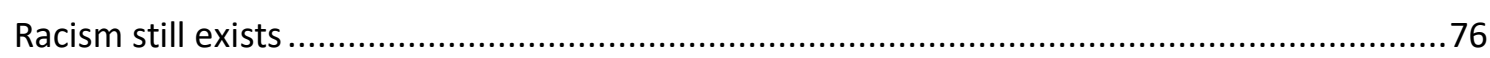

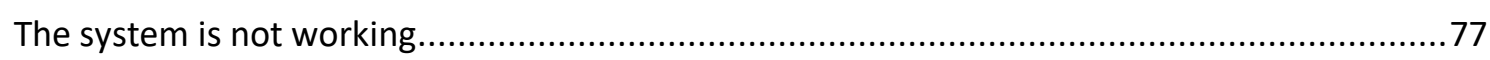

Chapter Six: What does a Good Life look like for Pasifika Families in Wainuiomata? .............80

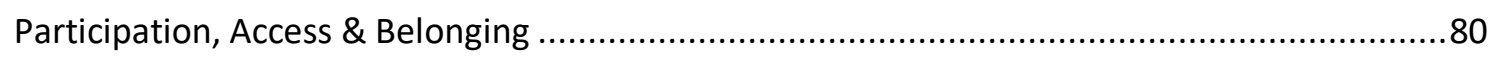

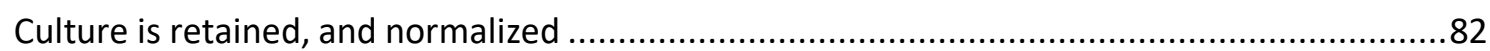

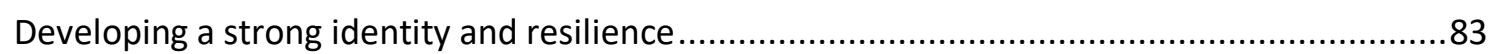

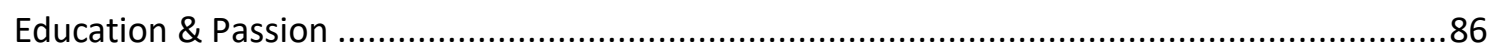

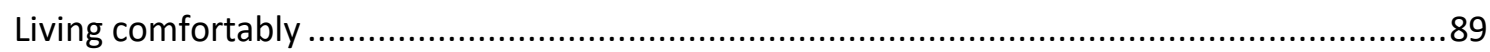

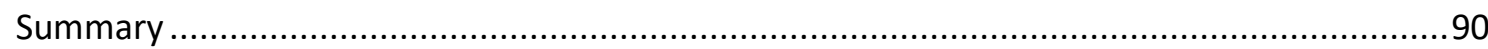

Chapter Seven: Thematic Analysis \#3: How can community involvement in education,

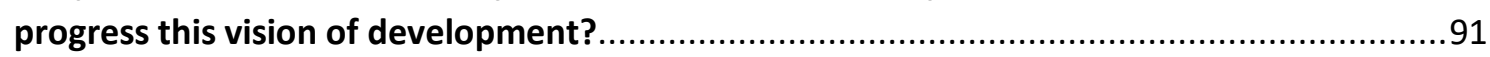

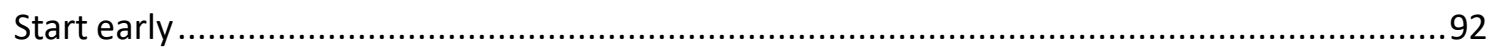

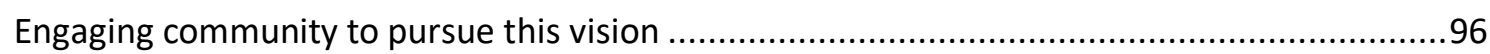

Support Pasifika youth to grow confident in their identity .....................................................98

Help education feel more safe, approachable and enjoyable ..............................................101

Support whanau to get involved - confidence to advocate, knowledge to question ...............103

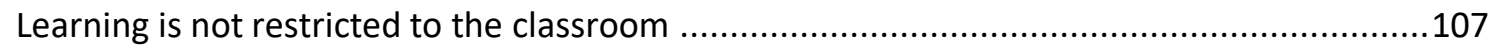

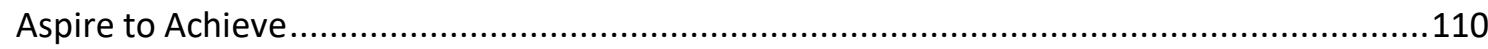

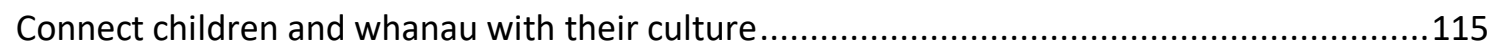

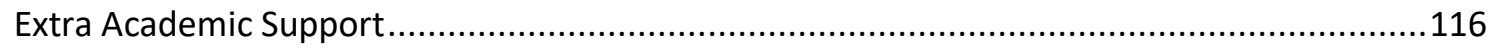

Connect whanau with other community opportunities ..................................................117

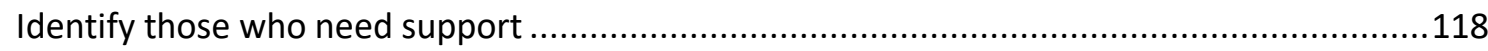

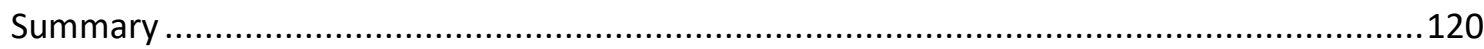

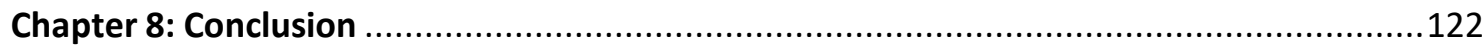




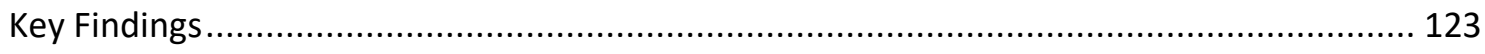

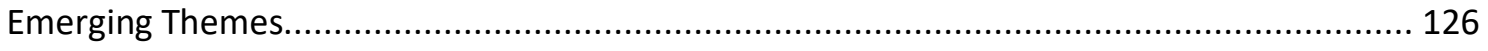

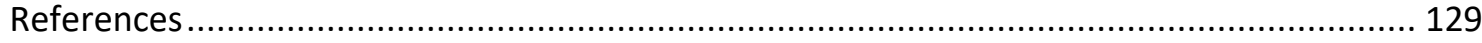

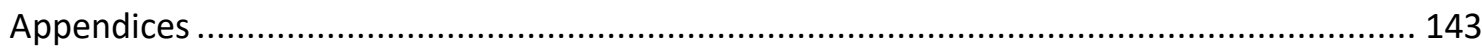

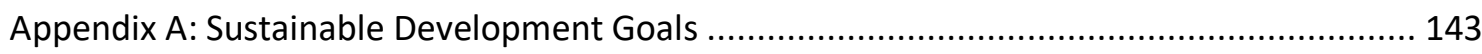

Appendix B: Participant Information and Consent Form .................................................... 144

144

145

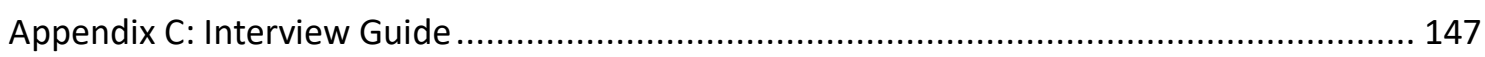

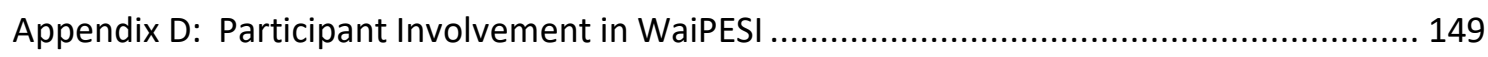




\section{List of Figures}

Figure 1: Education and the SDG's. ............................................................... 17

Figure 2. An artist's depiction of Wainuiomata. ................................................... 41

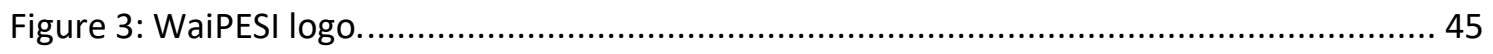

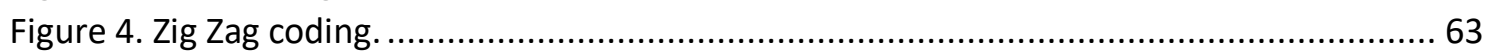

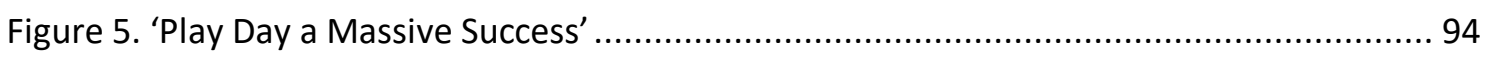

Figure 6. Careers Evening. ................................................................................ 111

\section{List of Tables}

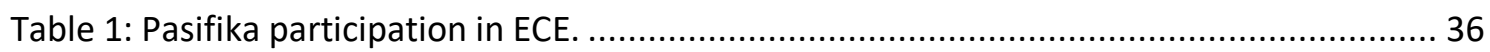

Table 2: Pasifika Achievement in Primary Education. .................................................. 37

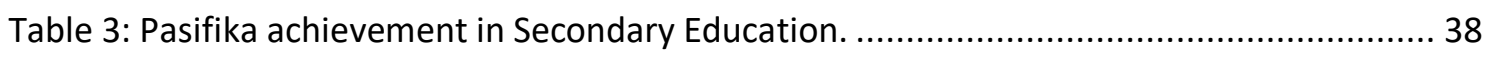

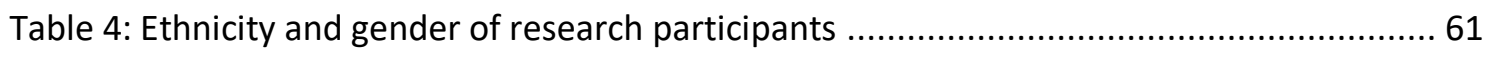

Table 5: Participants role within WaiPESI journey .................................................. 61 


\section{Glossary}

Anga Lelei Kind, calm, tolerant

Faka'apa'apa respectful, humble

Māfana Inwardly warm feelings

Mālie Energising of spirits to a positive state of enlightenment

Mateuteu Well-prepared, hard working, culturally versed

Noa

Anything or nothing in particular

'Ofa Fe'unga

Showing appropriate compassion, empathy, love

Poto He Anga

Knowing what to do, and doing it well

Tala

To tell or to talk

Talanoa

Talk/open informal or formal conversation

Definitions retrieved from Fa'avae, Jones \& Manu'atu (2016). 


\section{Chapter One: Introduction}

'Education is important for development, albeit in complex and sometimes contradictory ways ... development, also shapes education profoundly' (McGrath, 2018, p.13)

The notion that education is good for development is widely accepted by those entrusted to lead the drive for development across the globe. The importance of access to education underpins the global rhetoric voiced by development institutions striving for poverty alleviation and economic growth. Nowhere can this be seen more clearly, than in the significance of education in achieving each of the Sustainable Development Goals (SDG's), known as the '17 Goals to transform our world' (United Nations, n.d.a).

However, research is beginning to question the intricacies of the relationship between education and development. Scholars such as McGrath $(2010 ; 2018)$ point out that while universal access to education is a worthwhile goal, knowledge does not necessarily equate to years in a classroom. Rather, the quality, and objective of the education provided, must be taken into consideration.

Meanwhile, post-development theorists have brought the concept of development itself into question. These theorists assert that the concept of development is a western construct, that acts as an extension of western hegemony that imposes visions of progress and growth centred upon eurocentric values. In doing so, a vision of development that may be neither realistic nor desirable is imposed on a community that is inevitable positioned as 'undeveloped', and 'lesser than'. What is needed instead, they argue, are diverse forms of development that are anchored in local knowledge and resource, allowing communities to create their own futures (GibsonGraham, 2005; Escobar, 1995, as cited in Potter et. al, 2018). 
While highlighting that questions need to be asked of the relationship between development and education, scholars are yet to apply post-development critiques to education in an academic context. Nor, has education been approached in Aotearoa from a development studies perspective to question what vision of development our education system aligns with. Yet applying a post-development lens to education in Aotearoa suggests that rather than trusting that mainstream development and education holds the answers to living a good life, we must give voice to community visions of development, and see value in community-driven initiatives that are already underway.

\section{Background}

In embarking on this thesis, I knew only three things. One, I wanted my topic to be focussed at a community level in Aotearoa. Two, I wanted it to be participatory wherever possible. Three, I wanted it to be meaningful for the participants involved. Through discussions with Prof. John Overton, and AProf Hon. Luamanuvao Winnie Laban of Victoria University of Wellington ${ }^{1}$, I was introduced to WaiPESI - the Wainuiomata Pasifika Education Success Initiative. WaiPESI has been ingrained in the Wainuiomata Community since 2011, and was initiated by a small group of volunteers who were passionate about changing educational outcomes for Pasifika ${ }^{2}$ youth in their community.

The Pasifika community in Aotearoa is a vibrant, diverse and growing population that increasingly enriches the multicultural fabric of our country. However, this is also a community that faces many challenges. Pasifika groups are frequently ranked at the bottom of national socio-economic development indicators; particularly in the area of education.

\footnotetext{
${ }^{1}$ Hon Luamanuvao Dame Winnie Laban, DNZM, is the Assistant Vice-Chancellor (Pasifika) at Victoria University of Wellington. A founding member of WaiPESI and their patron to this day, Winnie is passionate about the educational outcomes for Pasifika youth and community empowerment. From here on, she will be referred to by her matai title; Luamanuvao.

${ }^{2}$ Pasifika is a term formally used by the Ministry of Education to describe the diverse group of Pacific Islanders living in New Zealand. It encompasses both those who have migrated from Pacific nations, and those who are New Zealand-born but identify with Pacific Island ancestry. (Education Counts, 2010)
} 
The purpose of WaiPESI is to engage the whole whanau ${ }^{3}$ in each students learning journey, encouraging students to raise their levels of aspiration, and empowering parents to ask questions of the education their child receives. Education is viewed as a partnership between families, schools, and the community. Through working in partnership, WaiPESI wants to see a Wainuiomata community where Pasifika and nonPasifika families view all levels of schooling, including university, as places where they can love learning, actively participate, and thrive.

WaiPESI was creating incredible change in the Wainuiomata community, that was yet to be documented outside of the local paper. However, WaiPESI Board members wanted their journey recorded. They were proud of what they had achieved as a small group of passionate volunteers, and wanted to be able to reflect on this. If their work could inspire other communities to develop similar initiatives; that was even better. As AVC Pasifika and Patron of WaiPESI, Luamanuvao was also aware that in order for the success of this community-driven initiative to be recognised within an academic context, research would need to be conducted that connected their journey to academic theory. Few researchers have sought to work with Pasifika communities in Aotearoa to understand what they perceive as 'development', and whether their aspirations for their communities are supported through the education system. It is out of this context that I was approached and employed by Luamanuvao in her capacity as AVC Pasifika at Victoria University of Wellington, to document the story of WaiPESI. This was to be achieved through two research outputs, both to be available to the Pasifika office as data for advocacy purposes. One would take the form of a report created for WaiPESI themselves, creating a tangible record of the journey they had undertaken thus far. The other, would constitute academic research in the form of the present thesis.

\section{Research aim and approach}

The current research aims to explore the ways that Pasifika communities might perceive and engage in education for their own vision of development.

\footnotetext{
${ }^{3}$ This research chooses to use the word 'whanau' when referring to family, in respect and acknowledgement of the New Zealand context in which this study is based.
} 
A case study design has been chosen in acknowledgement that a community's development aspirations are unique to that community, as will be their approaches to achieving these visions. This research seeks to honour that difference, advocating for community ownership of development. Embracing a social constructivist epistemology, and informed by both participatory and talanoa research methodologies, this research seeks to privilege participant narratives and give insight into the world as they experience it (Crang \& Crook, 2007).

The present research asks the question: How can education help fulfil a community's vision of development? In order to understand the Wainuiomata community's vision of development and the role of education in progressing this vision, three secondary research questions have been defined:

1) What have been the educational experiences of Pasifika families in Wainuiomata?

2) What does a good life look like for Pasifika families in Wainuiomata?

3) How can community involvement in education, progress this vision of development?

\section{Chapter Outline}

The following thesis is divided into 8 further chapters:

Chapter Two explores the relationship between Education and Development, providing a snapshot of the global rhetoric surrounding this positive relationship and a discussion of the literature underpinning these beliefs. Through an examination of post-development theory and emerging alternatives to development, it reminds us that it is important to question what vision of development we are striving for, and to ensure that education aligns with these visions.

Chapter Three situates the present research in the context of Aotearoa New Zealand, providing an overview of both the Pasifika demographic situation, and Pasifika educational achievement in New Zealand schools. It introduces Wainuiomata, and WaiPESI, as the present case study, before outlining research aims. 
Chapter Four outlines the methodological approach that has guided the present research, chosen with the intention of ensuring a diverse range of narratives were heard, giving voice to Pasifika experiences and aspirations. This chapter includes a discussion on positionality, and reflection on what will be termed here as Palagi paralysis.

Chapter Five presents the findings of the first research question, What have been the educational experiences of Pasifika families in Aotearoa?. It shares the narratives of Pasifika whanau whose own experiences as students, parents or teachers, inspired them to become involved in WaiPESI and create positive educational experiences for Pasifika youth today.

Chapter Six responds to the second research question, what does 'development' look like for Pasifika communities? Through discussions with participants around what they envisage as a good life for their whanau and community, this chapter illustrates the vision of development aspired towards by the Pasifika community in Wainuiomata.

Chapter Seven answers the third and final research question, How can community progress this vision of development? Through exploring what WaiPESI has already achieved, and the direction participants see it following in the future, this chapter demonstrates what can be achieved by a passionate community owning their own development vision.

Chapter Eight concludes this thesis, drawing together key themes that emerged throughout the journey of research. It highlights that while many Pasifika families have had frustrating experiences with the education system, they have not become disenfranchised. Rather, their experiences have inspired them to engage in their children's learning journeys, to ensure better educational outcomes for youth today. A good life, for this community, is one where they can live comfortably, while feeling strong in their identity and culture. Education is viewed as integral to achieving both of these aspirations. The work of WaiPESI demonstrates that an initiative aligned with community aspirations that is driven by the community itself, is a powerful force for development. 


\section{Chapter Two: Education and Development}

Education is good for development. This positive relationship between education and development is often stated without challenge, resulting in education being posited at the forefront of global development strategies. However, questions inevitably remain, around what kind of education is appropriate, for what vision of development?

This chapter will examine the literature surrounding the relationship between education and development, before posing questions regarding the nature of this relationship. It will firstly explore the global rhetoric around education and development that forms the basis of global development strategies. An overview is provided of the two distinct schools of thought that underpin this rhetoric, referred to here as education for economic growth, and education for empowerment. A discussion of post-development theory is then offered, before examining the indigenous philosophy Buen Viver and it's 'good life' outlook as an emerging alternative to the western construct of mainstream development. Finally, this chapter will consider the value in applying a post-development lens to approaches to education, arguing that to do so creates an opportunity to promote local answers to what a community perceives as a good life for them.

\section{Education and Development: Global Rhetoric}

Despite decades of debate as to what the purpose, means and definition of development itself should be, the positive relationship between education and development has been largely undisputed. Indeed, this rhetoric is frequently repeated by those entrusted to lead the drive for development across the world:

'Education is fundamental to development and growth'

(King, 2011, as cited in World Bank Group, 2011, para.1 ) 
'Education is one of the most powerful and proven vehicles for sustainable development'

(United Nations Development Programme, n.d., para. 2)

'All countries, regardless of their national wealth, stand to gain ... stunning economic and social benefits ... if they ensure that every child not only has access to education, but through that education, acquires at least the baseline level of skills needed to participate fully in society.

(OECD, 2015, para. 1)

The underlying belief here is that education provides children with the basic skills necessary to enter the workforce, and that this is more than a moral obligation; it is an investment in a country's prosperity and economic growth (World Economic Forum, 2015).

This widespread belief in the positive influence education has on development outcomes is reflected in its prominence throughout the Sustainable Development Goals (SDG), the '17 Goals to transform our world' (United Nations, n.d.a). The 2030 Agenda for Sustainable Development was adopted in 2015 by all United Nations Member States, acting as both a plan and universal call to action to eliminate poverty, strive for a sustainable earth, and ensure better quality of life is enjoyed by all (United Nations Development Programme, 2018.

Within these, education is a goal in itself: 'Goal 4: Ensure inclusive and quality education for all and promote lifelong learning' (United Nations, 2019), yet also underlies the success of the majority of SDG's, as depicted in Figure 1.

The below infographic demonstrates that access to quality education is integral to the success of all Sustainable Development Goals. For example, Goal 1: 'End poverty in all its forms everywhere', and Goal 8: 'Promote inclusive and sustainable economic growth, employment and decent work for all' are reliant on the upward socioeconomic mobility of individuals, which in turn is influenced by the level of education they receive. With substantial investment in access to, and participation within, education, generational poverty cycles can be broken. It is also recognised that 
education increases greater acceptance of diversity and tolerance of differences within societies (United Nations, n.d.b), and will therefore be critical to the achievement of Goal's 16 'Promote just, peaceful and inclusive societies'; and 10, 'Reduce inequalities within and among countries'. Moreover, research has indicated that environmental concern rises with levels of education obtained (Global Partnership for Education, 2015), while education that fosters environmental consciousness will increases human ability to research, innovate and develop clean technologies. Such consciousness and abilities will be crucial in the success of goals $7,12,13,14 \& 15$, which focus on an environmentally sustainable world. A summary of all 17 Sustainable Development Goals can be found in Appendix A. 


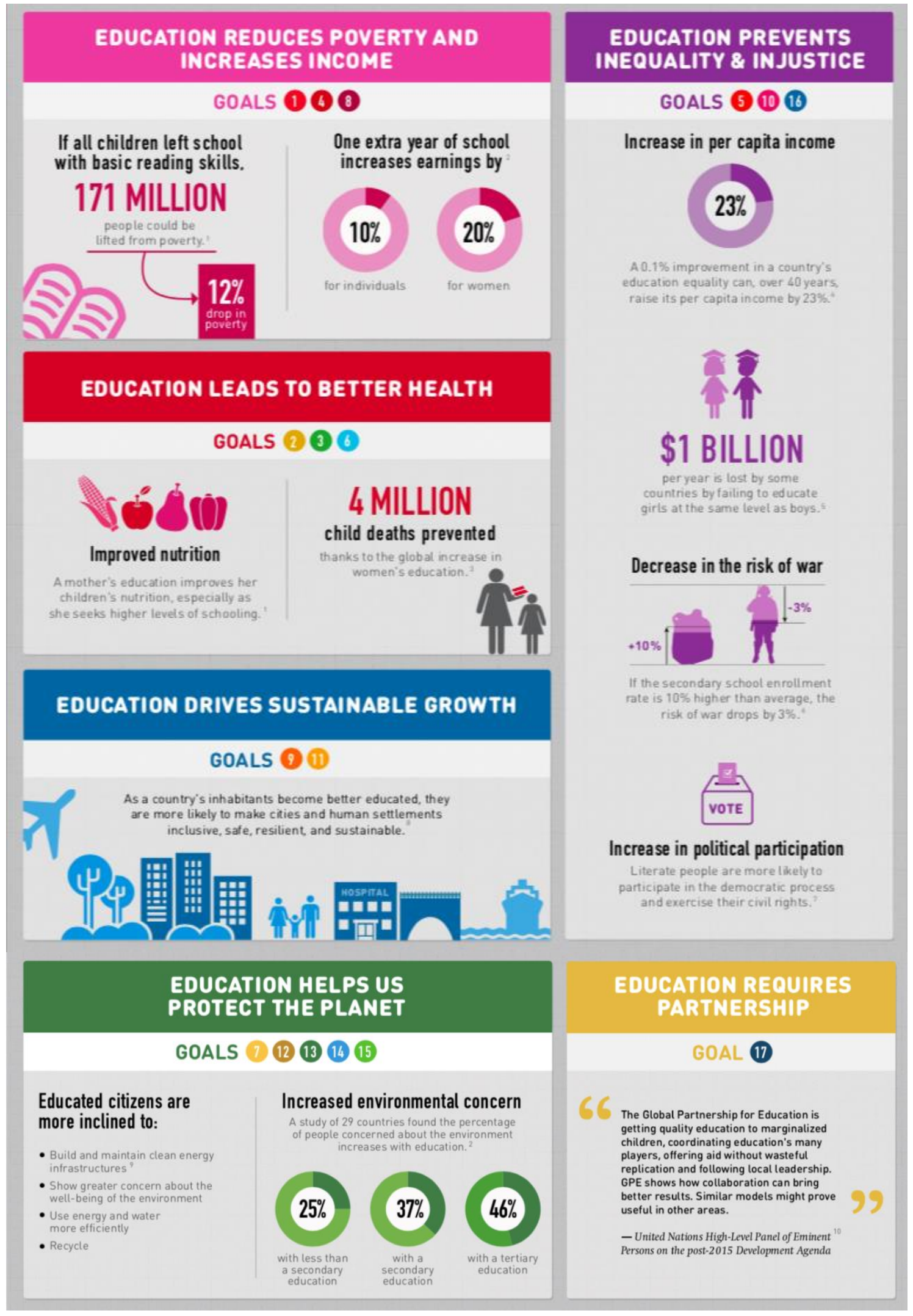

Figure 1: Education and the SDG's. Infographic depicting Sustainable Development Goals 2015-2030, and the way in which education underpins the achievement of each goal. Data sources can be found in Appendix A (Global Partnership for Education, 2015). 
While the positive relationship between Education and Development is frequently stated without challenge, questions inevitably arise around what model of education, supports what form of development. In a broad sense, literature surrounding this topic can be distilled into two distinct schools of thought: education for economic prosperity, and education for individual empowerment. The beliefs underpinning both approaches will be explored below.

\section{Education and Economic Development}

'The human mind makes possible all development achievements... For countries to reap these benefits fully, they need to unleash the potential of the human mind. And there is no better tool for doing so than education.'

(King, 2011, as cited in World Bank Group, 2011, para. 4)

The influence of human capital in creating and sustaining economic growth underpins much of the literature surrounding education for economic development. In the 1960's, economists such as Gary Becker (Becker, 1993, as cited in Sweetland, 1996) and Theodore Shultz theory (Schultz, 1971, as cited in Sweetland 1996) recognised that investing in education could increase productivity, resulting in the emergence of human capital. Human Capital Theory argues that the economic prosperity of a country is significantly influenced by its level of human capital, and ultimately, that an educated population, is a productive population (Sweetland, 1996; Olaniyan \& Okemakinde, 2008). Individual human capital constitutes skills, knowledge and experience held by individuals, which can be supported by investments in education and training. Therefore, a human capital approach can be defined as the belief that 'education improves the overall skills and abilities of the workforce, leading to greater productivity and improved ability to use existing technology, and thus contributing to economic growth.' (Earle, 2010).

From a economists point of view, literature indicates that the economic benefits of a well-educated population are virtually endless. The greater the knowledge and skill an 
individual can bring to their employment, the more likely they are to be able work efficiently, innovate, and adapt to technological advances throughout their career (Earle, 2010). Resultantly, their productivity as an employee increases, with the potential to influence overall business productivity and outputs, country exports, and ultimately, a country's GDP (Olaniyan \& Okemakinde, 2008). Convincingly, the Organisation for Economic Cooperation and Development (OECD) estimates that equipping every child with the necessary education and skills to be an active member of society would increase GDP by approximately $28 \%$ per year in lower-income countries, and $16 \%$ in higher-income countries (OECD, 2015). This education also enables individuals to access higher-paid employment, which, through consumer spending, contributes back to the growth of the economy. Together, productivity and economic growth drive trade performance and competitiveness in markets, leading scholars such as Olaniyan \& Okemakinde (2008) to conclude that a nations ability to compete in global markets is directly influenced by their investment in human capital.

As the world shifts towards more sustainable service-focussed economies, the importance of establishing a work force with strong educational foundations becomes increasingly vital to a countries economic growth. In the words of Borge Brende, President of the World Economic Forum, 'In today's knowledge-driven economies, access to quality education and the chances for development are two sides of the same coin' (Brende, 2015, para.6) Providing the necessary education to increase an individual's human capital, increases the likelihood that these individuals will go on to adapt to new knowledge and technologies, innovate further advancements, and create opportunities for countries to capitalise on these (Olaniyan \& Okemakinde, 2008; Van Den Berg, 2001). It has been identified that countries at the forefront of technological advancement are also those who have invested in building human capital (Van Den Berg, 2001, as cited in Olaniyan \& Okemakinde, 2008). The case of the 'Asian Tigers'4 exemplifies the influence investment in human capital can have on a countries growth. Challenged by a lack of natural resources and difficulty in breaking exports into western markets, these countries rose by capitalising on the knowledge and innovation of their well-educated populations, who in turn used modern technologies

\footnotetext{
${ }^{4}$ Hong Kong, Singapore, Taiwan and South Korea constitute the 'The 'Four Asian Tigers', who 'rose to prominence in the boom years of the 1960s by taking advantage of emerging technology and globalization, and they have held onto their position as economic leaders ever since' (Gaw, 2016, para.1)
} 
to their advantage. Once comparable to the poorest countries in the world, today these countries remain amongst the wealthiest nations, holding some of the strongest economies around the globe (Gaw, 2016).

Other scholars have examined the relationship between education and economic development at a more individual level, and agree that this relationship is positive, based on the belief in the ability of education to equip individuals with the skills and knowledge to break poverty cycles (Harris, 1996; Tilak, 2002; Corak, 2006). The logic here is that a family who is impoverished will struggle to break out of a generational cycle of poverty unless an intervention occurs, such as gaining of financial capital or education. 'Lack of access to education is one of the most certain ways of transmitting poverty from generation to generation.' (Global Partnership for Education, 2020, para.2). Receiving an education can provide an individual with the skills necessary for employment, which in turn can increase financial capital, and the resources to support their family (particularly children) to stay healthy and also gain an education, thus breaking cycles of poverty (Tilak, 2002).

An economic-growth focussed perspective of development in turn requires a specific approach to education, favouring educational strategies that develop the skills needed to successfully participate in an evolving workforce (Overton, Stupples, Murray, Gamlen \& Palomino-Schalscha, 2020). The nature of the workforce itself, is ultimately dictated by the direction of the market at the time, which a country must succeed within if it is to achieve economic growth. As argued by Overton et al. (2020), 'Overall, it is the market, not the state nor communities, that develops educational institutions and determines educational outcomes.' (Overton et al., 2020, p. 4)

It is evident then, that there is a strong case for education fuelling economic development, both at an individual and state level. Literature has indicated that investment in human capital through means of access to quality education leads to enhanced economic growth, and is supported by OECD predictions of GDP rising with increased access to education. Proponents of economic growth as the objective of development, perceive education as performing an economic function in the overall drive for development. As a result, the form education that is supported is driven primarily by market conditions, and much less the vision of a community. 
However, it is important to acknowledge this is but one perspective on the positive influence education can have on development. Others have focussed on the power education has to make individuals aware of their circumstances, and empower them to use their own agency to create a better life for themselves. It is this potential for individual empowerment and realising both personal and local conceptions of development, that we turn our attention to now.

\section{Education and Empowerment}

Identifiable in the vast literature surrounding education and development is a second distinct theme; that of educations influence on development at an individual level. This work focusses on the potential education offers for helping individuals to free themselves from oppression, and participate in their own development, or alternatives to development; as equals.

Much of this literature stems back to the work of Paulo Freire (2017), the Brazilian philosopher and educationalist who brought the concept of 'conscientización' to prominence in the realms of both education and development.

\footnotetext{
'As an educationalist, Freire was convinced that formal education, as practised in schools and universities the world over, was (and indeed, remains) an instrument of oppression rather than an instrument of liberation' (Blackburn, 2000, p. 6)
}

Freire's belief in the oppressive nature of formal education was explained in his writing by what he termed 'banking education'. In Freire's eyes, formal education operated in the same manner as a banking system, whereby students are considered the depositories and teachers the depositors (Blackburn, 2000; Gadotti \& Torres, 2009). Students are reduced to passive receivers of 'deposits' which constitute approved knowledge, which they are then expected to receive, and store. In this way, formal education maintains an 'oppressive social order' (Blackburn, 2000, p.6), where the 
more students are encouraged to focus on receiving and memorising the knowledge given to them, the less they can develop critical thinking, or critical consciousness.

Development of critical consciousness, Friere (2017) felt, was essential to releasing one from the oppression of western hegemonic structures, and crucially, enabling the oppressed to liberate themselves rather than imposing further power structures upon them. What was needed, and what education needed to encourage, was the process of 'conscientización'. Conscientización has been defined at its most basic level as 'the process by which humans become more aware of the sources of their oppression' (Blackburn, 2000, p.7), and is deemed more than an intellectual process. Instead, it is dynamic and involves components of both action and reflection, wherein 'action leads to further reflection, and so on, in a dialectical path of increasing liberation' (Blackburn, 2000, p.7).

Conscientización is viewed as a critical tool for the oppressed, who are deemed disadvantaged by the fact that they may not have the confidence to engage in seeking change, believing this to be their fate, or at worst; having internalised the values of their oppressor (Blackburn, 2000). To achieve conscientización, and also to reduce oppression within education, Freire argued that education must encourage dialogue. Dialogue, in Freirean terms, involves genuine discussion and reciprocity whereby the educator acknowledges that they too can learn from participants in learning, and that their knowledge is as valuable as their own (Blackburn, 2000). The role of the educator is not to deliver approved knowledge, but rather, to act as an animator, creating a space where participants in learning teach themselves, and each other (Blackburn, 2000; Gadotti \& Torres, 2009). When dialogue, and conscientización occurs, so too can action, and the potential for oppressed to liberate themselves emerges. 
In the context of development then, education that raises critical consciousness, encourages participation, and empowers individuals to be active in creating their own futures, is good for development. Education for empowerment rhetoric suggests that education's value is not found in prescribing and developing the skills necessary for countries to succeed in the global economy, nor countering this homogenisation by returning solely to forms of traditional knowledge.

Rather, the value of education lies in its ability to facilitate conscientización through dialogue, and in turn, encourage social change (Overton et al., 2020). Such education has the potential to result in empowered communities, who can draw on their own ideals and knowledge of local context to progress own vision of a better life for themselves; for their own development. These Freirean ideals have also informed recent evolutions in development theory, with the paradigms of grassroots and participatory development, for example, drawing directly from the concepts of conscientisation, participation, and empowerment (reference). The work of Freire, remains a compelling influence amongst emerging alternatives to mainstream development (and in some cases, development itself), today.

\section{Post-development \& Education}

However, on the other side of the debate are those that question the steadfast belief in education's positive role in development. These are the people who ask what kind of education are we referring to, for what kind of development?

Two different approaches to education have been outlined above. The first, education for economic development, focusses on developing national strategies to achieve universal standards of literacy and numeracy in education, in order to build human capital and help sustain the nation's economy. The second, education for individual development, seeks education that empowers the individual by helping them develop a critical consciousness and conscientisation, encouraging them to develop local answers to oppressive structures that exist around them. Although distinctly different, and by no means conclusive, these two approaches indicate that education supports development in different ways. 
The question that must now be asked, is what do we mean by 'development'? Is it always desirable, and beneficial?

In recent decades, the concept of one homogenous, vision of development for all has come into question. Vanhulst \& Beling describe this vision as one that 'seemed to describe a universal horizon modelled on Western standards, and [was] then disseminated globally' (Vanhulst \& Beling, 2014, p.54).

Post-Development theorists in particular, have questioned mainstream development rhetoric, opening up new ways of thinking about development in doing so. As a school of thought, Post-Development emerged in the late 1980's as a response to increasing dissatisfaction and concern with development practise and thinking.

Post-development asserts that development is a western construct that imposes visions of progress and growth centred upon western values, upon those the West deems as 'undeveloped'. In positioning Western societies as being the utopian vision of development other countries should aspire towards, these societies are normalised, while all those who are not at such standards are therefore inferior, and 'underdeveloped' (Potter et al., 2018). Such discourse then becomes a regime of truth (Hall, 1992) that in the perspective of post-development theorists, creates both the 'problems' of the global south and 'solutions' that justify the neo-colonial mission of the global north to bring all societies to the same universal standard of development, underpinned by western values. Pieterse (2000), goes as far as to state that 'Development ... is the "new religion" of the west' (Pieterse, 2000, p.175) Early post-development scholars have been critical of development to the point of rejecting the concept entirely, believing 'the time is ripe to write its obituary' (Sachs, 2010, p. xv) perceiving it as both a disappointment and a destructive failure. Wolfgang Sachs perhaps phrased this most eloquently, when he stated 'The idea of development stands like a ruin in the intellectual landscape. Delusion and disappointment, failures and crimes, have been steady companions of development' (Sachs, 2010, p. xv). As theory has progressed, these staunch proponents of rejecting development in its entirety were criticised for neglecting to acknowledge the uneven, yet positive outcomes development had achieved (Ziai, 2014). Post-development was also criticised for its lack of ability to offer a realistic and significant alternative to development (Fleming, 2015) 
However, work by post-development scholars has indicated a shift in focus of postdevelopment theory, from transcending development, to seeking new ways of responding to community needs that are anchored in community knowledge and resource (Escobar, 1995, as cited in Potter et. al, 2018). While remaining true to its core belief that not one universal way of conceiving and practising development can exist, it can be argued that post-development now assumes a less revolutionary position, striving to encourage diverse forms of development (Gibson-Graham, 2005). What remains important, is that this development is not oppressive and built through Western values, but instead, on community visions for their future.

It is evident then, that a post-development view of 'ideal' development, is one that rejects western-imposed development structures that prioritise the values and philosophies associated with Western modernity. Instead, post-development supports the exploration of alternative ways of understanding, perceiving and achieving human well-being. In doing so, this school of thought acknowledges that not one homogenous conception of well-being exists, and implies that to achieve wellbeing, governments and development workers alike should look to local answers.

While post-development has extensively critiqued the concept of development, such critiques focus less on examining the means of development itself, tending only to identify them as neo-colonial in their objectives. As a result, a post-development lens has yet to be applied to approaches to education, and inform new thinking around education for development. The work of Fleming (2015) has taken up this opportunity, with her research into diverse education for diverse economies in the Solomon Islands opening up a space for post-development and education discussions. Through applying a post-development lens to education, her research recognises that within different contexts, visions of development differ, and approaches to education must adjust to align with local conceptions of development. Therefore, in order for education to have a genuinely positive relationship with development, the vision of development must be that of the communities, and the education of the community must support this vision. However, aside from the work of Fleming (2015), literature that applies a postdevelopment lens to education remains scarce, providing a space for new research to explore how local conceptions of development can inform approaches to education. 


\section{Buen Viver: An Alternative to Development.}

As post-development theory has progressed, so too has the ways that development is conceptualised. Indigenous understandings of wellbeing in particular, have entered the sphere of development thinking, offering alternative ways to conceptualise both development and wellbeing (Gegeo, 1998; Bulloch, 2014).

One such alternative to modern conceptions of development, is the indigenous understanding of wellbeing: Buen Vivir. Whilst emerging at different points in the evolution of development theories, Buen Vivir is considered by some to be a postdevelopment concept, or at the least, sharing many commonalities (Ziai, 2014). The concept of Buen Vivir in Latin America has offered both a philosophy and theoretical lens that rejects the notion of development in a western sense, where economic growth is the main objective, and instead argues that good development is equivalent to living what people deem a good life.

Buen Vivir is a Spanish term, used 'to describe alternatives to development, focused on the good life in a broad sense' (Gudynas, 2011, p.54). Whilst it is difficult to translate the richness of this term into an explicit English definition without falling to reductionism, Gudynas \& Acosta (2011, as cited in Vanhulst \& Beling, 2014) make a commendable attempt to do so, defining Buen Vivir as:

'An opportunity to build a different society sustained in the co-existence of human beings in their diversity and in harmony with nature, based on the recognition of the diverse cultural values existing in each country and worldwide'

(Gudynas \& Acosta, 2011, as cited in Vanhulst \& Beling, p.56)

Emerging as a discourse in the late 1990's, Buen Vivir captured the attention of critical thinkers, social movements and governments, since its inception (Guynas, 2011). However, the cultural values and beliefs upon which Buen Vivir is based have existed for centuries, despite only recently being considered in development discussions. Extrapolated predominantly from the Quechua concept 'Sumak Kawsay', but 
analogous to the beliefs of many indigenous cultures ${ }^{5}$ in Latin America, Buen Vivir synthesises these beliefs into one principle; that of living in harmony 'and in balance, with every form of existence in a state of permanent respect' (Huanacuni Mamani, 2010, as cited by Vanhulst \& Beling, 2014, p.56).

Breaking down the above definition, to live in harmony and unity with others, requires respect for the differences and complementarities that exist amongst the collective (Vanhulst \& Beling, 2014). In showing respect for the diversity that is not only assumed, but valued, each individual is therefore expected to recognise the inherent dignity of others, and honor what it is that makes them, them; life experiences, values and perspectives (Gudynas, 2011). Buen Vivir holds that when internal balance is prioritised, and found within the individual, only then can larger-scale balance and change occur. Inherent in this belief, is the idea that diversity is natural; individuals have the power to improve themselves, and collectively, to improve the lives of their community. While ultimately seeking quality of life, Buen Vivir is also a reaction to the prioritisation of economic value and commodification that dominate society today, and instead orients toward a more austere lifestyle that acknowledges that value can be found in many places for different communities ${ }^{6}$. As a result, the philosophy of Buen Vivir does not seek universal application, for this opposes it's appreciation of diversity and recognition of the significance of local context (Cerdan, 2013). Such ideas represent a radical shift from the values of capitalism and consumerism that underpin western conceptions of development; thus deconstructing developments cultural foundations.

It is important to note that Buen Vivir should not be thought of as a development paradigm, but rather, an alternative to development that proposes living by priorities that communities deem essential to their conception of a good life; rather than what is considered integral for good modern 'development'. (Gudynas, 2011). It represents an idea, rather than a concept, and is open to incorporating knowledge from other paradigms in order to respond effectively to local challenges (Viteri, 2004, as cited in Cerdan, 2013).

Today, Buen Vivir continues to evolve, offering an opportunity for communities to build local answers as to what constitutes a good life for them. While yet to be applied

\footnotetext{
${ }^{5}$ Buen Vivire is by no means a homogenous philosophy, exclusive to one indigenous group, or culture. Similar beliefs have been identified in the idea of gurani (Bolivia), of shiir waras or the good life (Ecuador), and harmonious living or küme mongen (Chile) (Gudynas, 2011)

${ }^{6}$ E.g spiritual value, environmental value, cultural value (Gudynas, 2011)
} 
directly to education in a theoretical sense, the philosophy of Buen Vivir infers that to achieve diverse conceptions of what constitutes a good life; education must be localised and involve communities in both planning and delivery.

\section{Diverse needs; need the voice of the community.}

Applying the philosophy of Buen Vivir to education, reinforces the importance of localising education to fit diverse conceptions of what constitutes a good life, for diverse communities. To understand a communities vision of development and establish an appropriate educational response, the voice of the community is key. When examining what is considered inequality in universal education systems, literature has identified community participation as critical to developing effective educational strategies that raise educational performance and recognise the aspirations communities hold for their youth (Gregson et al., 2004; Tucker et al., 2006; Tupper, 2001). The benefits that emerge from community participation are numerous, and include improving community relations and connections within communities, improving school programs and culture, supporting local knowledge and skill, and raising the capacities of parents, teachers and communities through collective learning in partnership (Epstein, 2010; Kendall, Kaunda \& Friedson-Rideneur, 2015).

Partnerships focussed on the collective goal of helping children succeed in education and later in life have the ability to make a child feel cared for and identify with the goals of their education, meaning they are more likely to work to achieve their potential and build positive attitudes towards their schooling (Epstein, 2010). However, Epstein (2010) notes that while parents care about their child's education and want to connect with educators to form partnerships, they frequently lack the confidence or knowledge to establish these connections independently (Epstein, 2010).

\section{Summary}

It is evident from the literature examined, that a global rhetoric exists stating that education, is good for development. This rhetoric is predominantly underpinned by 
two different ways of perceiving the relationship between education and development.

The first school of thought examined, referred to here as 'education for economic growth' argues that building a countries human capital through education, results in economic prosperity for both the country and the individual. In order to achieve economic growth, education embodying this vision of development seeks to equip the population with the necessary skills for participation in the workforce, the shape of which is dictated by the market. Proponents of this perspective believe that an educated population, is a productive population, thus resulting in a countries economic development.

The second school of thought examined is that of 'education for empowerment', which is largely driven by the work of Paulo Freire (2017). This perspective argues that education that facilitates the process of conscientisation, encourages social change driven by community visions. Conscientisation is believed to empower individuals and communities to emancipate themselves from the development ideals of their neocolonial 'oppressors'.

However, this steadfast belief in the positive relationship between education and development has not gone unchallenged. Post-development theorists have brought mainstream development rhetoric into question, rejecting the idea of development as a western construct that serves to impose a utopian ideal of progress and growth grounded in western values. In doing so, post-development has opened up new ways of thinking about development, creating space for alternatives such as Buen Vivir to emerge. Although grounded in Latin-American indigenous philosophies, Buen Vivir offers an alternative way to conceptualise development, broadly defined as living a 'good life', as defined by the community it is applied to. The application of Buen Vivir in other contexts creates an opportunity to consider development as a vision of a good life that a community aspires towards, as opposed to a western ideal.

Literature has seldom applied post-development to education (with the exception of Fleming, 2015), yet one can infer that in doing so, post-development would argue that one universal model of education would not support the diverse conceptions of development. Rather, approaching education with a post-development outlook raises the questions: What kind of education is appropriate for a communities development? 
And what vision of development is aspired toward by this community? To answer these questions, the voice of the community is key. 


\section{Chapter Three: Context: Pasifika \& Education in Aotearoa}

'By 2030, 30\% of New Zealanders will be Māori or Pasifika, and right now many of them are under-served by the education system'

- Tim Fowler, Chief Executive of the Tertiary Education Commission (Fowler, 2018).

The Pasifika community in Aotearoa is a diverse, youthful and growing population that represents $8.1 \%$ of Aotearoa's population (Statistics New Zealand, 2019). However, this is also a community that faces many challenges. The following chapter will outline the demographics of Pasifika in Aotearoa, before offering a snapshot of the socioeconomic challenges currently faced by Pasifika whanau. In acknowledging that education is considered integral to development, and overcoming such challenges, it will then examine Aoteroa's education system, and the performance of Pasifika students within this. This chapter will then conclude by introducing us to WaiPESI and Wainuiomata, the case study and location of the present research, before outlining the questions this research seeks to answer.

\section{Pasifika in Aotearoa-Demographic Situation}

The Pasifika community in Aotearoa is a vibrant, diverse and growing population that increasingly enriches the multicultural fabric of our country. Comprising of at least 13 distinct ethnic groups and languages, each individual brings unique histories, cultures and knowledge to Aotearoa's shores (Ministry for Pacific Peoples, 2016). Together, these groups form a population of 381,642 'Pasifika'7 people that has increased by approximately 86,000 people over the past five years: $8.1 \%$ of the total New Zealand population. (Statistics New Zealand, 2019).

This community is incredibly youthful, and growing. In 2013, it was estimated that the median age of the Pasifika population was a mere 22.1 years of age, sixteen years

\footnotetext{
7 'The term Pasifika is used collectively to refer to the people or students from the islands of the Pacific have identified as coming from or having their ethnicity originate from there' (Nakhid, 2003, p.297)
} 
younger than the median age of 38.0 for the total New Zealand population (Statistics New Zealand, 2014a). Just under half (46.1\%) of the Pasifika population is under 20 years of age, with 55\% under the age of 25 (Statistics New Zealand, 2013, as cited in Pasefika Proud, 2016) By 2038, it is expected that the Pasifika population will form 10.9\% of Aotearoa's total population, while almost one-fifth of all New Zealand children will be of Pasifika descent (Statistics New Zealand, 2013, as cited in Pasefika Proud, 2016).

However, this is also a community that inherently knows struggle. Whilst wary of constructing a deficit-based narrative, it is important to paint a realistic image of the challenges Pasifika whānau face in order to fully appreciate the successes outlined in the following chapters.

Behind these children are whanau working hard to make ends meet; many having arrived in Aotearoa with the vision of giving their whanau better educational and employment opportunities than those available back at home (Frankel, 2012). Fijian Soneel Kumaran surmised the optimism felt by her fellow island migrants when she stated 'You know those people that have American dreams? New Zealand is pretty much like America, for all the Pacific Islands' (Roy, 2018).

However, making ends meet often requires whanau to work long hours on low wages, with minimal financial security, merely to maintain a roof over their heads (Sin \& Ormsby, 2019). Limited English proficiency and/or minimal educational qualifications also impact the deemed employability of migrants, making whanau attempting to settle in Aotearoa particularly susceptible to unsecure employment and fluctuations in economic conditions. Pasifika unemployment rates sat at 7.7\% in 2017, significantly higher than the national rate of 4.5\% (MBIE, 2017a), while Pasifika average weekly income of \$584 in 2017 was \$227 lower than the national average (Education Counts, 2016d). As a result of both low and insecure incomes, just $18 \%$ of Pasifika families reported owning or partially owning their own homes at the time of the 2013 census, meaning $71 \%$ of this population (Pasifika Proud, 2017) work hard to pay rent for a home they cannot enjoy the luxury of owning themselves. $43 \%$ of Pacific people report they are often or always cold in such living situations, whilst $15 \%$ also indicate that these homes are damp; a precursor to many avoidable health conditions (Pasifika Proud, 2017) 
Together these figures illustrate the realities faced by many Pasifika families: living on a week-by-week budget, unable to afford opportunities outside of essentials, and struggling to progress into opportunities that could alter their situation - such as home ownership, self-employment, tertiary study, and so on. Long or irregular hours may mean not being at home at appropriate times to help a child with their reading or to encourage them to complete their homework, or not having the energy when they are.

As outlined in the previous chapter, education is widely perceived as the answer to precarity, the key to development and to breaking cycles of poverty. Durie (2006, as cited in Van Der Meer, 2011, p.1), eloquently surmised its powerful potential when he stated 'Education is the key to the realization of Pasifika and Māori potential'. Yet, gaining a quality education in a eurocentric system is the very thing these youth are struggling to succeed in; through little fault of their own.

\section{Deficit Narratives}

A further challenge faced by Pacific peoples in Aotearoa, is that of prejudice and discrimination, built on stereotypes and negative assumptions fueled by society and media representations. Together, these stereotypes and assumptions lead to a practice called deficit theorizing. Deficit theorising can be understood as the practise of considering someone, or something, in terms of what they lack; rather than what they do have (Berryman, Kerr, Hikairo Macfarlane, Penetito \& Smith, 2012)

Studies have demonstrated that portrayal of Pasifika people within New Zealand media creates an image of lazy, dumb, and violent individuals, who are dependent on Palagi to get by (Loto, 2006; Human Rights Commission, 2016; Allen \& Bruce, 2017). This image normalizes the positioning of Pasifika in Aotearoa as different, and inferior to Palagi (Allen \& Bruce, 2017)

These inaccurate, discriminatory portrayals are of serious concern for two separate, yet equally important reasons. Firstly, media representation has been shown to have significant influence on how groups are perceived (Spoonley \& Butcher, 2009), therefore creating real prejudice in New Zealand society. Secondly, such 
representations have a detrimental impact on Pasifika families and particularly youth, who are aware of the deficit narratives surrounding them. Research has argued that Pasifika youth are more likely to take greater offence to racism than their parents, owing to the fact they are often New Zealand-born citizens (Allen \& Bruce, 2017)

Research has indicated that such thinking around Pasifika students and their learning potential is a key contributor to poor learning outcomes for Pasifika, with teachers implicit beliefs and understandings proving to be one of the greatest barriers to improving learning outcomes (Spiller, 2012). Spiller found that educators often attributed low Pasifika achievement levels to poor behaviour, that resulted from cultural values. For example; teachers considered discipline in the Pasifika home to be inappropriately strict or otherwise too relaxed, and believed students were resultantly unable to behave appropriately within the independent setting school provided (Spiller, 2012). Consequentially, they employed teaching strategies that were repetitive, over-simplified, and less complex than tasks set for other students. When speaking to students however, Spiller (2012) found that students were aware of the invisible barrier that was teachers low expectations of them, and attributed their poor behaviour to their frustration and resentment towards teachers attitudes.

In the opposite manner, it has also been argued that stereotypes and assumptions that result from media portrayals of Pasifika, can result in unrealistic expectations of Pasifika students. The work of the Ministry of Education (n.d) found that Pasifika secondary students frequently are assumed to have talents associated with being Pasifika, such as being a natural at sports, or being good and singing and dancing. These students wanted to be recognized and identified for the skills they have, rather than being reminded of the skills they lack, much like any other culture.

The research above, coupled with the socio-economic challenges that Pasifika families often face, suggests that Pasifika youth are being met with invisible barriers to succeeding in education, without even entering the classroom. 


\section{Education in Aotearoa}

The Ministry of Education, the lead advisor on Aotearoa's education system, outlines their purpose as being '[to] shape an education system that delivers equitable and excellent outcomes' (Ministry of Education, 2018). This focus on equity, aligns with a standardised approach to education in Aotearoa that ensures all students have access to government owned, state-funded schooling, are guided by the same national curriculum, and are subject to the same national framework of assessment; NCEA. Whilst state-integrated schools and private schools are also available in most regions, the majority of Aotearoa youth enrol in state-funded education, where it is expected that through the National Curriculum a child 'will develop a range of values and key competencies, or capabilities, that they need to succeed in life' (Ministry of Education, 2010.

However, as noted in the previous chapter, equality of access does not necessarily equate to equality of achievement, or opportunity to succeed. In reality, Aotearoa's education system is currently failing its own vision of equitable outcomes for New Zealand youth,

Research by UNICEF released in 2018 found that New Zealand holds one of the highest rates of educational inequality in the world, ranking $33^{\text {rd }}$ out of 38 countries in the OECD (UNICEF, 2018). This inequality persisted across all three schooling levels, with the gap between the highest and lowest performing pupils identifiable as early as preschool, and widening thereon. Additional New Zealand-specific analysis commissioned by UNICEF (Berenston-Shaw, 2018) highlighted that Māori and Pasifika youth in particular were disproportionately impacted by hardship that therefore impacted their educational opportunities, and are largely educated in a system that does not align with their needs.

These claims have been inadvertently supported by Ministry of Education data in New Zealand's standard assessment framework for all. Pasifika are found to be 'trailing' behind Pākeha across all three education levels, in terms of both completion and achievement. 


\section{Pasifika in Early Childhood Education}

Participation in early childhood education (ECE), be it through early childhood centres or home-based educators, is considered critical to a child's development and future achievement (Wylie et al., 2008). Pasifika and Māori participation in ECE has long lagged behind that of NZ European children, for a variety of reasons. Parents who are unable to see their values and aspirations reflected in the values of an early childhood centre, are unlikely to feel a sense of belonging for both themselves and their children in this environment, preferring instead to keep their children at home engaged with their own whanau and culture. Financial challenges ${ }^{8}$ may also pose a barrier to engaging with these services, with food, transport and clothing additional costs that are often unacknowledged by government ECE incentive schemes.

Despite these barriers, the number of Pasifika children participating in ECE grown rapidly in recent years, with Pasifika recording the greatest growth over the past five years when compared to other major ethnic groups (see Table 1). As a result, early childhood education is perhaps the area where greatest equality can now be seen between Pacific children and other ethnic groups in the education sector.

Furthermore, Pacific Island Early Childhood Centres are increasing in both quantity and popularity, with Statistics New Zealand (2018) reporting that only 59\% of children attending these ECE centres were of Pacific ethnicity.

Prior Participation in Early Childhood Education rates, 2012-2017

\begin{tabular}{|l|c|c|c|c|c|c|c|}
\hline & $\mathbf{2 0 1 2}$ & $\mathbf{2 0 1 3}$ & $\mathbf{2 0 1 4}$ & $\mathbf{2 0 1 5}$ & $\mathbf{2 0 1 6}$ & $\mathbf{2 0 1 7}$ & Overall Change \\
\hline NZ European & $97.9 \%$ & $98.2 \%$ & $98.1 \%$ & $98.0 \%$ & $98.1 \%$ & $98.3 \%$ & $0.4 \%$ \\
\hline NZ Māori & $90.9 \%$ & $92.3 \%$ & $92.9 \%$ & $94.0 \%$ & $94.9 \%$ & $95.2 \%$ & $4.3 \%$ \\
\hline Pasifika & $86.7 \%$ & $88.4 \%$ & $90.2 \%$ & $91.2 \%$ & $92.7 \%$ & $92.4 \%$ & $\mathbf{5 . 7 \%}$ \\
\hline Asian & $95.8 \%$ & $96.7 \%$ & $96.8 \%$ & $97.3 \%$ & $97.5 \%$ & $97.7 \%$ & $1.9 \%$ \\
\hline Total & $94.9 \%$ & $95.6 \%$ & $95.9 \%$ & $96.2 \%$ & $96.6 \%$ & $96.8 \%$ & $1.9 \%$ \\
\hline
\end{tabular}

Table 1: Pasifika participation in ECE. Percentages of children participating in ECE in the six months prior to schooling beginning, by year and ethnicity. (Education Counts, 2017).

\footnotetext{
${ }^{8}$ Whilst Aotearoa has a 20 -hour free scheme that is a huge incentive to enrol in ECE, an unintended consequence of this scheme is that fees outside of the 20 hours can be significantly higher to compensate, or centres request a minimum number of days weekly enrolment
} 


\section{Pasifika in Primary Education}

Few publicly-available measures exist by which achievement in primary education can be measured in Aotearoa. The introduction of the controversial National Standards in 2008 offered a narrow, but flawed snapshot of primary student achievement, as outlined in Table 2, but were discontinued from $2018^{9}$.

Pasifika achievement in National Standards (Primary), 2013-2016

\begin{tabular}{|c|c|c|c|c|c|c|c|c|c|}
\hline & \multicolumn{2}{|c|}{2013} & \multicolumn{2}{c|}{2014} & \multicolumn{2}{c|}{2015} & \multicolumn{2}{|c|}{2016} & \multirow{2}{*}{$\begin{array}{c}\text { Overall change } \\
\text { (Pasifika) }\end{array}$} \\
\hline & PASI & ALL & PASI & ALL & PASI & ALL & PASI & ALL & $1.7 \%$ \\
\hline Reading & $64.3 \%$ & $77.9 \%$ & $65.0 \%$ & $78.0 \%$ & $66.1 \%$ & $78.1 \%$ & $66.0 \%$ & $77.8 \%$ & $2.9 \%$ \\
\hline Writing & $57.6 \%$ & $70.5 \%$ & $59.7 \%$ & $71.1 \%$ & $60.6 \%$ & $71.5 \%$ & $60.5 \%$ & $71.2 \%$ & $2 \%$ \\
\hline Mathematics & $60.9 \%$ & $74.6 \%$ & $61.9 \%$ & $75.2 \%$ & $63.3 \%$ & $75.5 \%$ & $62.7 \%$ & $75.4 \%$ & $1.8 \%$ \\
\hline
\end{tabular}

Table 2: Pasifika Achievement in Primary Education. Percentage of Pasifika students at or above the standards for each subject measured in Primary, compared to national totals (Education Counts, 2016a, 2016b \& 2016c)

The results from these standards over the past three years do not make for encouraging reading when we look at the progress of Pasifika children. Overall change has been minimal, and the achievement gap has remained wide. Whilst these figures should be considered with caution given the controversial nature of these standards, they do provide a significant indication that Aotearoa's education system is leaving Pasifika children behind as early as Primary level, signalling the creation of an uneven playing field as these children progress through the education system.

\footnotetext{
${ }^{9}$ These standards were introduced to improve results in the three R's (reading, writing and arithmetic) and provide some indication to the MoE as to the progress of schools and students in achieving these. They have since been scrapped by the Labour government, who argue that these standards encourage a narrow curriculum focus and pressure on children to achieve in all areas at the same rate as others, ignoring a child's individual aptitude and the progress that has been made.
} 


\section{Pasifika in Secondary Education}

Achievement in NCEA has long been a site of struggle for Pasifika students, whom have had to contend not only with the aforementioned socio-economic barriers, but with not seeing themselves represented in Aotearoa's education system; a challenge discussed further in the following section. Yet, it is achievement in this very system that will dictate the future employment opportunities for all cultures that pass through it. With this in mind, it is encouraging to see that Pasifika students (nationally) have had the largest increases in attainment of NCEA L1-L3 from 2012-2017, as illustrated in Table 3 below.

NCEA L1 Achievement by Ethnicity

\begin{tabular}{|l|c|c|c|c|c|c|c|}
\hline & $\mathbf{2 0 1 2}$ & $\mathbf{2 0 1 3}$ & $\mathbf{2 0 1 4}$ & $\mathbf{2 0 1 5}$ & $\mathbf{2 0 1 6}$ & $\mathbf{2 0 1 7}$ & Overall change \\
\hline NZ European & $75.4 \%$ & $78.7 \%$ & $80.3 \%$ & $81.7 \%$ & $82.5 \%$ & $81.8 \%$ & $6.4 \%$ \\
\hline NZ Māori & $50.5 \%$ & $55.5 \%$ & $59.1 \%$ & $63.5 \%$ & $65.6 \%$ & $64.2 \%$ & $13.7 \%$ \\
\hline Pasifika & $58.4 \%$ & $64.8 \%$ & $66.9 \%$ & $71.9 \%$ & $73.2 \%$ & $73.3 \%$ & $\mathbf{1 4 . 9 \%}$ \\
\hline Asian & $79.4 \%$ & $82.0 \%$ & $84.2 \%$ & $87.9 \%$ & $92.8 \%$ & $93.2 \%$ & $13.8 \%$ \\
\hline
\end{tabular}

NCEA L2 Achievement by Ethnicity

\begin{tabular}{|l|c|c|c|c|c|c|c|}
\hline & $\mathbf{2 0 1 2}$ & $\mathbf{2 0 1 3}$ & $\mathbf{2 0 1 4}$ & $\mathbf{2 0 1 5}$ & $\mathbf{2 0 1 6}$ & $\mathbf{2 0 1 7}$ & Overall change \\
\hline NZ European & $77.4 \%$ & $78.6 \%$ & $82.2 \%$ & $83.0 \%$ & $84.0 \%$ & $84.5 \%$ & $7.1 \%$ \\
\hline NZ Māori & $59.0 \%$ & $62.0 \%$ & $67.1 \%$ & $70.6 \%$ & $74.9 \%$ & $74.4 \%$ & $15.4 \%$ \\
\hline Pasifika & $62.5 \%$ & $67.8 \%$ & $74.5 \%$ & $76.6 \%$ & $79.5 \%$ & $80.7 \%$ & $\mathbf{1 8 . 2 \%}$ \\
\hline Asian & $85.9 \%$ & $85.1 \%$ & $87.2 \%$ & $89.7 \%$ & $93.9 \%$ & $97.8 \%$ & $11.9 \%$ \\
\hline
\end{tabular}

NCEA L3 Achievement by Ethnicity

\begin{tabular}{|l|c|c|c|c|c|c|c|}
\hline & $\mathbf{2 0 1 2}$ & $\mathbf{2 0 1 3}$ & $\mathbf{2 0 1 4}$ & $\mathbf{2 0 1 5}$ & $\mathbf{2 0 1 6}$ & $\mathbf{2 0 1 7}$ & Overall change \\
\hline NZ European & $62.1 \%$ & $63.7 \%$ & $66.4 \%$ & $69.0 \%$ & $70.1 \%$ & $70.4 \%$ & $8.3 \%$ \\
\hline NZ Māori & $42.6 \%$ & $44.3 \%$ & $46.5 \%$ & $51.5 \%$ & $54.4 \%$ & $56.7 \%$ & $14.1 \%$ \\
\hline Pasifika & $44.2 \%$ & $47.8 \%$ & $51.6 \%$ & $57.5 \%$ & $60.4 \%$ & $65.3 \%$ & $\mathbf{2 1 . 1 \%}$ \\
\hline Asian & $70.5 \%$ & $69.6 \%$ & $71.1 \%$ & $75.4 \%$ & $79.2 \%$ & $82.3 \%$ & $11.8 \%$ \\
\hline
\end{tabular}

Table 3: Pasifika achievement in Secondary Education. Roll-based ${ }^{10}$ attainment rates of NCEA L1,L2 \& L3, by ethnicity (NZQA, 2016; NZQA, 2018)

\footnotetext{
${ }^{10}$ Roll-based cohorts = students in Years 11-13 on the school roll as at 1 July, summed over all the secondary schools (NZQA, 2018)
} 
Even more pleasing to note, is that these results suggest that the achievement gap between Pasifika students and NZ European students is narrowing, particularly in attainment of NCEA L2. NCEA Level 2 is usually deemed the minimum requirement for entry into the workforce as it provides the foundational skills required for many jobs, whilst opening doors to other training opportunities (CareersNZ, 2017). In 2017, Pasifika achievement rates for NCEA L2 sat only 3.8\% behind NZ European students (NZQA, 2018).

Despite this success in earlier levels, university entrance ${ }^{11}$ for Pasifika students remains an area of concern. University Entrance attainment rates for Pasifika youth have fluctuated over the past six years, yet remain relatively unchanged. National UE attainment rates for Pasifika students in 2017 remained 25\% lower than those of NZ European students (NZQA, 2018).

Youth aged 15-24 then who are not engaged in education, employment and training $\left(\mathrm{NEET}^{12}\right)$, are considered to be at risk for poor future employment opportunities and outcomes - which in 2017, was 12,300 of Pasifika youth (MBIE, 2017). Poor employment opportunities will not only affect the economic and social realities of these youth, but their future families, perpetuating cycles of poverty.

These youth are expected to be the faces of Aotearoa's future, who will inevitably shoulder the responsibility of guiding us through the immense global challenges faced - climate change; food security, overpopulation and dwindling resources, to name a few. Yet these faces are those of the same youth who are struggling today, in a public education system designed according to western values and practices (Hook, 2006; Mahuika, 2011.

\footnotetext{
${ }^{11}$ University Entrance requirements were changed in 2014 and since doing so, NZQA reports that achievement rates have generally decreased from 2013 results. This does not however, influence the UE achievement gap between Pasifika and other students.

12 NEET is an acronym for 'Not engaged in education, employment and training', and is described as a measure of youth disengagement (MBIE, 2016). It takes into consideration the current employment status of 15-24 year olds throughout the country, those defined as youth and at an age where they can be engaged in either the workforce or further education/training. Youth who are not engaged in such activities are considered to be at risk for poor future employment opportunities and outcomes
} 


\section{Educational Inequality in Aotearoa}

There is an increasing body of literature in Aotearoa that recognises that our own public education system is designed according to eurocentric norms to cater for the dominant Pākehā culture (Hook, 2006; Mahuika et al., 2011). Decades of indigenous Māori scholarship and activism have drawn attention to this issue, and have sought to transform outcomes for Māori youth being left behind in a eurocentric, universal education system. It is out of this context that Kaupapa Māori theory emerged as a theoretical dimension to this struggle to revive Te Reo and regain autonomy over education for Māori youth (Smith, 2009). Kaupapa Māori is a complex term, and 'at its simplest, means the Māori way of doing things' (Durie, 2012, p.21), informing a framework which can be applied within various contexts- academic research, policies and strategies, community initiatives, and so on. Actions informed by a Kaupapa Māori framework tend to be created by Māori, and reflect Māori aspirations, values and principles (Ahukaramu and Royal, 2012). Māori language, knowledge, and culture are both legitimised and validated, and to be Māori is simply taken for granted (Cram, 2016). As a theory, Kaupapa Māori holds a political dimension in that it critiques and challenges Pakeha hegemony, questioning the right of Pakeha to oppress and exclude Māori interests (Pihama, Cram and Walker, 2002).

These insights from Māori scholars regarding educational disparities and the need to recognise different ways of learning and different learning objectives have been mirrored by Pacific educationalists. Scholars such as Helu Thaman $(1993,2003)$, Sanga (2001, Sanga and Taufe'ulungaki 2005) and Teaiwa (2011) (see also Tolley 2008) have been influential in the rise of Pacific-oriented and managed curricula and the critique of educational models and content imported from metropolitan countries, often through aid programmes. However, this work, whilst arguing persuasively for pedagogy and curricula that reflect Pacific knowledge, aspirations and culture, has been largely focused on educational reforms in Pacific Island countries, and has been largely ignored in the New Zealand and Australian contexts. 


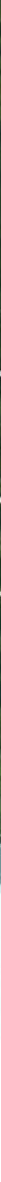

Figure 2. An artist's depiction of Wainuiomata. Image retrieved from Love Wainuiomata (2016a)

\section{Wainuiomata:}

'Community wise, there is nothing like it - nothing like Wainui'

$\left[\mathrm{Vai}^{13}{ }^{13}\right.$, past WaiPESI Board Member and deputy principal at Wainuiomata Intermediate]

Today, Wainuiomata is affectionately referred to as 'Wainui' by locals, who are identifiable by their passionate pride in their tight knit community; a visual expression of which can be seen in Figure 2.

Wainuiomata is home to 17,970 people, nestled in a valley separated from both the Hutt \& Wellington regions by the Wainui Hill (Love Wainuiomata, 2016b). Settlement in this area was avoided until after 1855 , when a significant earthquake in the Wairarapa rose the dense forest and immense swamps that filled the valley, that would later become known as Wainuiomata. This movement encouraged European settlement, and Wainuiomata became a small sawmilling and farming community until after the Second World War (Maclean, 2016). Affordable housing soon attracted many

\footnotetext{
${ }^{13}$ Vai is a former assistant-principal at Wainuiomata Intermediate School who was considered by other WaiPESI leaders to be instrumental in the genesis of WaiPESI
} 
young couples, transforming the area into a working-class suburb of Lower Hutt that would come to be nicknamed 'Nappy Valley' (Maclean, 2016), due to the rapid growth of young families living in the suburb. Wainui's working-class status has prevailed over the years, with nearly two-thirds of households earning less than $\$ 70,000$ (Love Wainuiomata, 2016b) annually.

While Wainui was perceived as a 'rough' area for some time, it is now shaking off the reputation that precedes it, and rapidly. A past Stuff article quoted a community member as saying 'Everybody's more aware of what our kids need and it's all about looking towards the future and giving them the best shot we can .... The area may not have the best reputation, but it's got the most heart' (Dominion Post, 2010). This perspective was also supported by Vai, a former deputy principal at Wainuiomata Intermediate when she advised

'New Zealand culture is beautiful, and Wainui was a typical Kiwi community: friendly, close, caring about one another ... it's so much more transcendent now because of housing, but it's also such a great range of people'.

[Vai] 
Introducing WaiPESI - the Wainuiomata Pasifika Education Success Initiative

'We wanted to empower our kids because we knew that education opens up the door for choice and opportunity'

[Louana ${ }^{14}$, former WaiPESI Chair]

It is out of this context of educational inequality that WaiPESI has emerged, as a community response to growing concern for the educational achievement of Pasifika youth. WaiPESI was formed in 2011 by a small yet passionate group of Pasifika educators based in Wainuiomata, who wanted to create better educational outcomes for Pasifika youth in their community.

Pasifika whanau have long-established roots in Wainuiomata, with the first wave of Pacific migrants settling in this community in the early 1960's. Today, this large Wellington suburb is home to a small, diverse and youthful Pasifika population, with Love Wainuiomata (2016) estimating that $13 \%$ of the total Wainuiomata population identify as Polynesian.

As this research progressed, it became evident that passion lies at the heart of WaiPESI's conception. The initiative emerged from a partnership between three key groups of people.

1) Passionate teachers who were ready to make changes to improve Pasifika education success in Wainuiomata.

2) A passionate, Wainuiomata-raised Assistant Vice Chancellor at Victoria University, who could see the low numbers of Pasifika students enrolling in University, and a high attrition rate in those who arrived.

3) A close-knit community who were passionate about the future of their tamariki, and have great heart.

The purpose of WaiPESI is to empower Wainuiomata's Pasifika families and community to achieve their aspirations and best educational outcomes for their children, and supply them with the tools to help them stand alongside their children in this journey

\footnotetext{
${ }^{14}$ Louana is a current WaiPESI trustee and former Board Chair. Louana's connections as an ECE teacher and energy were integral in the initiating of WaiPESI's Play Days to encourage participation in Early Childhood Education.
} 
of achievements. Their logo, as shown in Figure 3, offers a visual representation of this vision. WaiPESI wants to see a Wainuiomata community where Pasifika and nonPasifika families view all levels of schooling, including university, as places where they can love learning, actively participate, and thrive.

In order to achieve this vision, WaiPESI has established four core programmes that occur on an annual basis:

Play Days aimed at connecting parents and community members with early childhood education centres, providing a space to share learning tips and resources, and encouraging Pasifika participation in ECE

Growing Stronger Together, an 11-week program engaging and supporting Pasifika students in the areas of literacy, numeracy and mentoring, as well as empowering the families and community that supports these students.

Pasifika Passion, a careers-expo style event that seeks to improve communication with Pasifika parents on high school subjects and available support to help their children choose and follow their desired pathways.

Pasifika Ignite, an event celebrating Pasifika community successes to inspire Pasifika student achievement. 


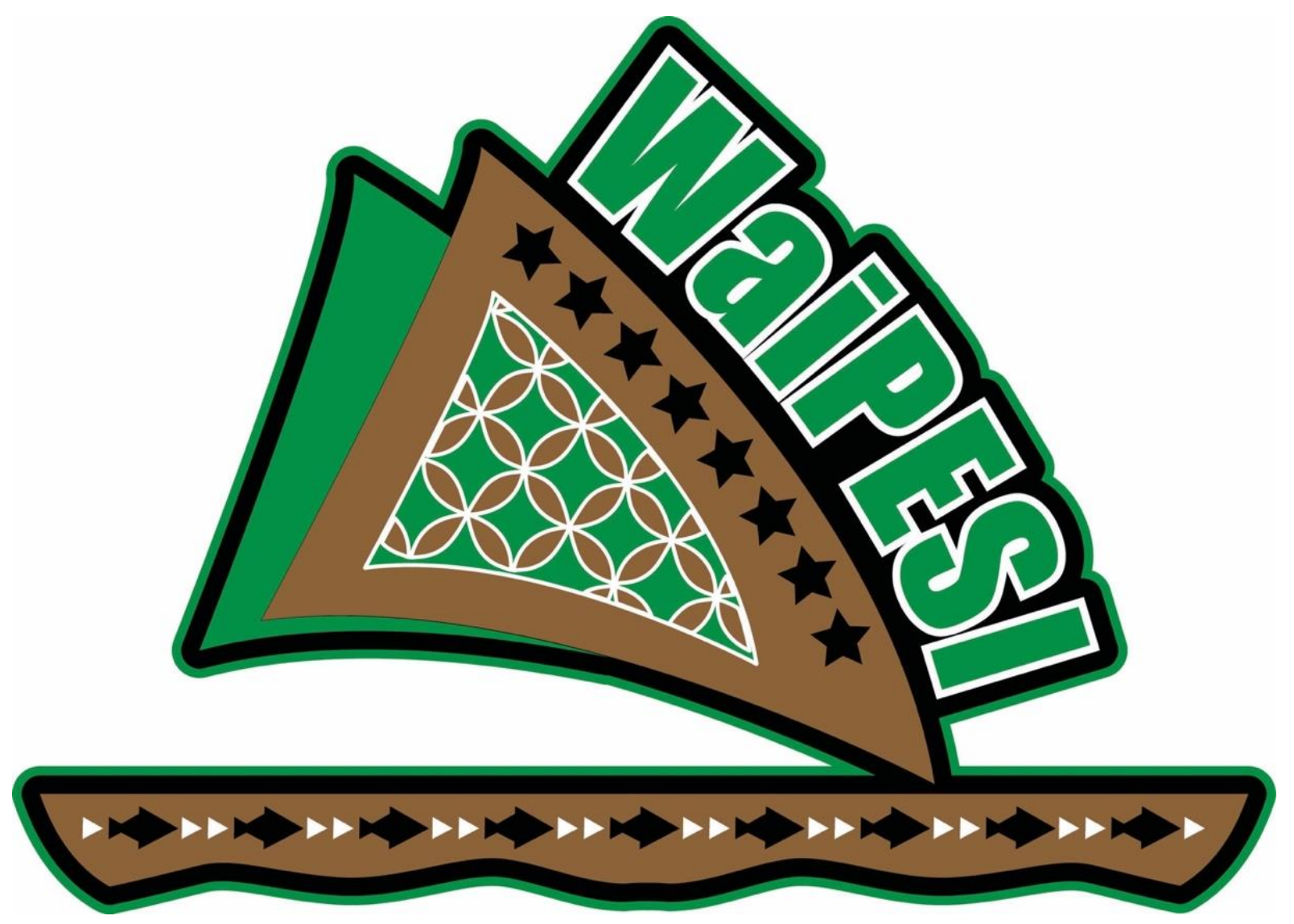

Figure 3: WaiPESI logo. Designed by local artist Ramese Malaetasi (WaiPESI, 2016), this artwork embodies the spirit, values and culture of WaiPESI.

The WaiPESI logo, reflects a vision of empowerment through supporting whanau to be the masters of their own destiny. 'WaiPESI' is attached to the mast of the vaka, the solid structure upon which the sails can rely, signalling the groups intention to be a supportive foundation for whanau and community whilst they direct their own journey. The Vaka itself embodies what unites the people of the Pacific - beliefs, cultures and traditions. It is the vessel that Pacific ancestors used to journey through life. Stars that once guided these journeys, represent the knowledge and self-skill whanau hold to now navigate their own destinies. 


\section{Summary}

The image painted in the chapter above, is one of a vibrant, youthful population, who face many challenges in Aotearoa society.

It is important to note that the population being discussed here is not of 'migrants', as deficit narratives so often infer. $65 \%$ of Pasifika in Aotearoa are now $2^{\text {nd }}$ or $3^{\text {rd }}$ generation New Zealanders, with migration now contributing less than natural increase to the growth of the Pasifika population in New Zealand (Tanielu \& Johnson, 2014). These are predominantly New Zealand-born citizens, and their right to obtain a quality education and live comfortably is equal to the right of any other ethnic grouping.

In the context of education being vital to development, the statistics provided are harrowing, and indicate that something needs to change within Aotearoa education to avoid intergenerational reproduction of educational disparity. Applying a postdevelopment lens to this situation encourages us to look beyond the statistics and question whether the universal approach to education, embodied in the country's education system, is appropriate. It also reinforces a need to turn to the Pasifika community and understand this situation from a local context. It prompts us to ask what the educational experiences of Pasifika families have been, what they perceive as the objective of education, and how they are engaging with this vision. 


\section{Chapter 4: Methodology}

'We are obligated in our work to do everything we can to further our understanding of others perspectives, at least as one human being to another' [Farrelly \& Baba, 2012, p.18]

In a single sentence, Farrelly \& Baba have reflected the belief of the present research, and a belief that 'understanding' is intrinsic to any methodology. In research, the journey of data collection and connecting with participants at a human level is as important as the completion of research itself. With these beliefs in mind, each section of this research methodology has been carefully considered.

This chapter will outline the methods employed in this research, which were chosen with the intention of ensuring a diverse range of narratives were heard and that participant voices would be privileged, and amplified. It will firstly explore the epistemological foundations of this study as this research employs social constructivism and appreciative inquiry. Secondly, this chapter examines the researchers positionality and offers a discussion on the concept of Palagi paralysis. Details of research design and methods of data analysis will then be outlined, giving particular focus to the methodologies of talanoa, and participatory research. Finally, a reflection on ethical considerations will explore the challenges faced and decisions made in order to ensure that this research was conducted in the most ethical manner possible.

\section{Epistemology}

Social Constructivism. The present research adopts a social constructivist epistemology, a term used interchangeably-albeit not always correctly-with social constructionism. A social constructivist worldview holds that 'knowledge and truths are created; not discovered' (Schwandt, 2003, as cited in Andrews, 2012, p. 40). Here, there is a preference for analysing narratives grounded in lived experience, as opposed 
to viewing them through what is deemed expert knowledge. Such a worldview sees reality as being created through interactions. Different realities exist for each individual, with meaning being constructed and attributed through interactions with others (Andrews, 2012). The objective of research founded in social constructivism then, is to 'understand the world of lived experience, from the perspective of those who live in it' (Andrews, 2012, p.40)

With this in mind, social constructivism was a natural fit for this research, with its emphasis on personal experiences and the existence of multiple realities in the Pasifika education space. The ability to explore the potential of multiple realities, encourages a variety of perspectives and individual experiences to come forth, enhancing the ability of this research to share the voices of a vibrant and diverse group of people.

Social constructivism also holds that throughout the research journey, engagement occurs between researcher and participant, thereby positioning the researcher as inherent within the research process (Cresswell, 2014). Therefore, social constructivism acknowledges that objectivity is not possible within research; nor would objectivity be preferable within this research context. The goal of the present study is for the researcher to work alongside participants, understanding their experiences as seen through their eyes, and to give voice to these within an academic context in a way that values these participants experiences. In this sense, researcher and participant work together, as a collective, to honour the collective.

While acknowledging that a key critique of social constructivism is its refusal to recognise the existence of an objective reality, the discovery of 'fact' is not sought in the present research. In this instance, this thesis seeks to give voice to diverse experiences, privileging the understanding of individual experiences over consensus and the discovery of objective 'truth'.

Appreciative Inquiry. The ethos of an Appreciative Inquiry (AI) approach has also informed the journey of the current research. At its heart, Appreciative Inquiry is about believing in the best in people and their communities, and exploring the opportunities their strengths provide alongside them. Participants in Al research are considered to be part of the inquiry; not the subject of enquiry' (Towsin, 2019) 
An Appreciative Inquiry philosophy focuses on what is working, rather than concentrating on barriers. It acknowledges that focussing on issues or challenges can create barriers in itself, and unintentionally reinforce harmful discourses. Like social constructivism, Al believes in the existence of multiple realities, and takes this further in arguing that what we concentrate on, becomes our reality (Hammond, 1996, as cited in Hammond, 2013). Resultantly, in research a positive framework is adopted that aims to 'identify, anticipate and heighten positive potential' (Shuayb, Sharp, Judkins, \& Hetherington, 2009). Interviews, for example, encourage reflection on participants best moments, capabilities and future ideals, asking questions that elicit narratives, examples and self-reflection.

Research informed by an Appreciative Inquiry methodology then, seeks to 'open up new ideas and thinking so that participants can be empowered to develop themselves beyond the present study' (Reed, 2011). This philosophy is consistent with the intentions of the present research, to share the strengths and voices of a passionate community who are creating their own path to their vision of development. As previously discussed, harmful discourses that label Pasifika people 'fat, dumb and violent' already exist in Aotearoa society (Human Rights Commission, 2016). By aligning with the philosophy behind $\mathrm{Al}$, the present research seeks to counter such assumptions not through focussing on them, but by sharing the enthusiasm, hope, and motivation for change by a Pasifika community seeking a better future for their youth.

It is also important to note that Al does not ignore the challenges faced by a community to emphasise focus on the positive. Rather, helping the reader understand the obstacles and challenges faced by a community, as this research has sought to do, highlights the significance of successes achieved by this community thus far, and is a testament to their passion and perseverance. 


\section{Positionality}

Reflecting upon, and acknowledging, one's own positionality is critical to understanding the influence researchers have on the research process. To understand our positionality, is to explore our identity in relation to that of our participants, and acknowledge how privileges and oppressions on both sides have the ability to significantly influence researcher-participant relations, interactions, and subsequent research findings (Sultana, 2007).

Whilst a researcher may have the best of intentions, it is critical to recognise that power is both inherent (Kapoor, 2005) and inescapable (Chambers, 1997) in the role of the researcher, an idea that is discussed in greater depth later in this chapter. Reflecting on positionality is therefore integral to conducting ethical research, as it is only with recognising the degree of power we hold that we can seek to level power between the researcher and participants (Sultana, 2007).

Mere acknowledgement of the researchers positionality on commencement and conclusion of the research is not enough. Our positionality is fluid, altering as we change, as our relationships develop, as our participants connect with us, and as the insider-outsider distinction becomes blurred (Sultana, 2007). It is for this reason that our identity in relation to others must continually be revisited, and critical reflexivity practised, to ensure a levelling of power between the researched, and the researcher.

My identity as a young, female, pālagi ${ }^{15}$ researcher, was an identity I feared would inhibit interactions with my participants from the outset. Being Palagi was of particular concern for me, and perhaps the part of my identity I was least confident in, due to many years in academia spent questioning western hegemonic discourses and exploring the concept of decolonisation. Uncertainty plagued me. Did I have the right to do this research? Would participants trust me? What would I be able to give to them? Would I be viewed as a naive Palagi researcher who took, but didn't give back? Who never truly understood the experiences they researched, and perpetuated tokenism, yet selfishly gained their qualification?

${ }^{15}$ The term 'pālagi' is a Samoan term that refers to something 'of or relating to Europe, and it's inhabitants', and is a common phrase in the Aotearoa Pasifika community (Collins Dictionary, 2020) 
These persistent doubts led me to believe that my Palagi status would negatively influence my interactions far more than I believe has actually occurred. I do not deny, that these interactions have not been influenced by my identity. I do however, believe that my fear of 'being Palagi', had greater potential to do damage than being Palagi itself has done, for it almost stopped me doing the research itself. Had it not been for the support of my supervisor and some wise words from a close friend, I believe I would have.

Tolich (2002) speaks of a similar experience many postgraduate students - and even senior academics - encounter when seeking to conduct research with Māori. He terms this experience 'Pākeha paralysis'. For Tolich, Pākeha paralysis refers to the uncertainty and apprehension that pākeha postgraduate students frequently face when researching topics relevant to the general population of Aotearoa; thereby requiring ethical approval that covers all ethnic groups. It is not uncommon for these students, lacking confidence, to deliberately exclude Māori from their research, in an attempt to minimise unintentional harm. What they instead achieve, may be the opposite, and tantamount to discrimination (Tolich, 2002).

While Tolich (2002) is relatively specific in his context in which pākeha paralysis may emerge, a broader and more recent depiction of this of this phenomenon is offered by Hotere-Barnes (2015):

'Emotional and intellectual difficulties that Pākehā can experience when engaging in ... relations with Māori because of: a fear of getting it wrong; concern about perpetuating Māori cultural tokenism; negative previous experiences with Māori; a confusion about what the course of 'right' action may be'

(Hotere-Barnes, 2015, p.41)

Replacing 'Pākeha' with 'Palagi' in the above, and 'Māori' with 'Pasifika' describes an experience not dissimilar to my own. Perhaps then, my initial apprehension could be described as 'Palagi paralysis'. 
Ultimately, it was my realisation that there was no pre-determined 'right' way to go about this research, that convinced me to proceed with this research topic. The only way I was going to learn was to try.

I proceeded with caution. I was initially too reserved. I learned to trust my own empathetic nature to guide me, it was that above all else that created emotional connection as I listened to trials, and triumphs. At one point, a participant told me she was proud I had taken this on. At that point, I knew I was too.

A close friend also reminded me, that taking responsibility for the sharing of others voices, representing them in a respectful way, and carrying the weight of their hopes for your research on your shoulders, was integral to the very nature of Development Studies. If I was not prepared to take on that responsibility, then Development Studies was not for me. Truer words could not have been spoken, and I am immensely grateful for that.

Hotere-Barnes (2015) makes several convincing arguments for Pākeha involvement in Māori research, which can be equally applied to Palagi-Pasifika research. He points out that for the 'dominant' group to let go of power, experiencing discomfort and uncertainty is inevitable, whilst temporarily experiencing research paralysis allows us space for self-reflection and to engage in reflexivity. To not act, in order to avoid opening ourselves up to criticism, is a further expression of dominance and privilege (Margaret, 2013, as cited in Hotere-Barnes, 2015). But perhaps most importantly of all, as humans it is crucial that we engage with our skills and visions where we can, to enhance educational capabilities for a transformed future. To not share our creative potential and strengths, is a disservice to each other as neighbours in Aotearoa. 


\section{Methodology}

Qualitative Research. Qualitative research, with its focus on exploring and understanding phenomena or experience, was the natural choice of approach for the current research topic. Qualitative research seeks to inductively understand the value and meaning participants have given to their experience, and to build a holistic, indepth view of this experience derived from multiple perspectives. As such, research design in qualitative research is described as 'emergent' (Cresswell, 2014) for as the researcher learns and understands more about the experience from their participants, the better they are equipped to identify and apply research methods that will help to understand the experience or phenomena further. Depth of understanding, is valued over breadth of data. Critically, given the post-structuralist foundations of this research, qualitative research also allows space for the researcher to reflect upon their own positionality, and to employ reflexivity in both recognising and acting upon the impact this may have on the study.

Participatory Research. Participatory Research has emerged out of an academic desire to interrogate power relations in the production of knowledge. As a research methodology, it seeks to circumvent traditional power structures by sharing power and maximising participation in the research process (Kindon, Pain, \& Kesby, 2007; McIntyre, 2007; Whyte, 1991). 'Action' is integral to successful participatory research, which aspires for research to be part of an activist process and result in meaningful, positive change in the lives of those involved.

To achieve this, practitioners undertaking PAR must engage in critical self-reflection throughout the research process. Reflexivity, or constant reflection of self, and renegotiation of actions, is a key part of this. In addition to acknowledging subjectivities in research, reflexivity requires a constant consideration and renegotiation of research relationships, subject matter, and thought to the consequences of research (Cunliffe, 2003; England, 1994).

Whilst valuable as a methodology, it is important to acknowledge as a practitioner that despite the noble intentions of PAR, power is inescapable. Participants, research methods, and methods of analysis, are all predominantly chosen by the facilitator of 
the research. Without recognition of this, participatory research risks replicating the power structures it seeks to challenge. Such criticisms should not be perceived as failings however, but as opportunities to evolve research to achieve the highest levels of positive development and capacity building we can reach, for the sake of those PAR seeks to empower.

While resonating with the ethos of PAR, I was forced to acknowledge at the outset of my research that conducting research considered worthy of PAR, was likely to fall outside both the time and academic constraints a master's thesis allows. Although I wanted my research to be as participant-driven as possible, there was much I could not let go of and still fulfil the requirements of a thesis. In light of this, I have chosen not to describe this as 'participatory research', but rather, research undertaken with the principles of PAR consistently in mind.

Fortunately, in some ways this research has naturally aligned itself with PAR methodology. I had been approached to do research that told the story of WaiPESI, by the patron of the group itself. Attending the group's 2018 AGM at her request allowed me to assess whether other leaders were equally enthusiastic to have their story told, and to check that what I sought to discover, was also what they deemed important elements in their journey. While documenting the story of what they and their community had achieved was their priority, they were also highly supportive of having 'academic' research conducted. In the words of one Luamanuvao 'Nobody listens to you here unless you have the "data" to back it up' (Personal communication, May 15, 2018).

While I was able to design the report output of this research in consultation with several key leaders in WaiPESI, the focus of the thesis itself has unfortunately been largely dictated by myself and the interests of Development Studies. In attempting to share ownership of this research with WaiPESI where I could, I sought to allow participants to dictate who should be involved in both outputs of this research project. This was a offer they took up enthusiastically, with the result being an unusually large 'sample' size for a Master's thesis, given I wanted to avoid restricting them as little as possible. As outlined above, PAR also calls for critical self-reflection at all stages of the research process, something I can confidently say I engaged in. Such reflections can be found in the Positionality and Ethical Considerations sections of this chapter. 
Talanoa Research Methodology. Talanoa Research Methodology (TRM), compliments a participatory approach to research and naturally aligns as a methodology that reflects the lived realities of Pasifika research participants (Fa'avae, Jones \& Manu'atu, 2016). Talanoa as a research method, emerges from the oratory tradition of talanoa that is steeped in cultural practises across the Pacific Island region, and is integral to the way Pacific people relate to each other (Vaioleti, 2006). The literal translation of the word talanoa in Tongan perhaps offers the most simple understanding of this broad cultural concept. To 'tala' is to tell, or talk, whilst 'noa' is anything, or nothing specific (Otunuku, 2011, as cited in Fa'avae, Jones \& Manu'atu, 2016). To talanoa then, at its most basic level, is to have an open, informal conversation.

The use of talanoa in the research context derives from the work of Halapua and Vaioleti, who are recognised as leaders in developing the concept of talanoa as both a practical and theoretical approach to research (Fa'avae, Jones \& Manu'atu, 2016). Halapua describes TRM as involving 'an open informal dialogue where people can speak from their hearts, where they are not guided by a "pre-determined agenda"' (Halapua, 2008, as cited in Fa'avae, Jones \& Manu'atu, 2016). Vaioleti offers a similar description, stating that TRM is 'a personal encounter where people story their issues, their realities and aspirations, [allowing] for more mo'oni (pure, real, authentic) information to be available for Pacific research than data derived from other research methods' (Vaioleti, 2011, as cited in Fa'avae, Jones \& Manu'atu, 2016). To talanoa then, aligns well with the intent of the researcher to give voice within a research context, to participants lived experiences and visions for their future.

It is suggested by Vaioleti (2006) that five values are vital to respectful and ethical research talanoa in Tonga, and interactions outside a research setting. These values are: faka'apa'apa (respectful, humble), anga lelei (tolerant, kind, calm), mateuteu (hard-working, culturally-versed, professional) poto he anga (knowing what to do, and doing it well), and 'ofa fe'unga (showing appropriate compassion and empathy for the context). The quality of knowledge gained in the research process is said to be dependent on the level to which these values are embodied by the researcher, and without them, the research interaction will amount to little more than a typical interview in a western academic context. In this way, talanoa differs from standard 
interviewing techniques because the researcher is not only present, but responsive. Knowledge is created together, through a mutually constituted-process. Empathy is not only encouraged, but vital, as surmised eloquently by Farrely and Baba (2012, p.319) 'Emotion and empathy are vital to valid talanoa and should be critical in research methodologies, yet are absent'. This ethos of a talanoa approach to research informed my own approach to the research process.

With the aim of 'open conversation' at the forefront of my mind, I attempted to set as few restrictions as possible on my research interactions. I described these interviews to participants as an informal chat over coffee, my 'interview' questions were limited to a simple five, and if concentrating on asking all these questions would interrupt the flow of conversation, I did not interject. Instead, I chose to interview more participants to gather the data I needed, rather than restricting topics of conversation with the ones I had, in hope that participants would feel they could speak freely about what was important to their stories.

Where possible, interviews were also organised without any pre-determined end point. While most participants had other commitments to attend that would inevitably restrict their time with me, all interviews lasted for an hour and a half minimum. The majority of participants indicated to me they felt they were 'waffling', yet could still have spoken at greater length about the topics we discussed. They not only welcomed me to contact them again, but expressed enthusiasm at talking further.

Fa'avae et al. (2016) suggest that being an 'outsider' who adheres the previously mentioned values of talanoa can be a more advantageous position for inciting genuine talanoa than being positioned as an insider; an opinion I initially treated with scepticism. Reflecting now, I believe this was emulated in my research interactions. It became evident that despite the many successes of WaiPESI, politics and personalities resulted in much friction between those involved. Because of my positioning as an outsider, who was not aligned with any personalities involved, I was fortunate enough to have honest, yet diverse perspectives on WaiPESI's journey shared with me.

As a researcher, the most gratifying output of this research was recognising that the majority of those I spoke to, genuinely enjoyed being participants in the research process; something I attribute solely to the ethos of talanoa. The longer we talked, or in some cases; the longer I listened, the more honest and raw these stories became. 
These interviews gave participants an opportunity to express not only their pride and future aspirations, but frustrations and anger at past circumstances. The simple act of listening to understand, and empathising, gave validation to these participants experiences that I believe they had not previously felt. However, these conversations also allowed them to reflect on the moments they cherished, feel pride at the changes they had helped make in their community, and to smile at fond memories. Manu'atu (2000, as cited in Fa'avae, Jones \& Manu'atu, 2016 ), terms this feeling 'mālie'; an energising and uplifting of ones spirits as a result of talanoa that connects and enlights both researcher and participant. The warmth and contentedness also felt as a result of good talanoa is referred to as 'māfana'. Together, the mālie and māfana experienced by my research participants led them to express their pride in me for seeking to give voice to their experiences, and excited anticipation for the report that would follow. Anecdotal evidence during follow-up emails also indicated that some participants sought to reconnect with each other, after years apart.

Challenges faced in engaging in Talanoa. Despite best intentions of the researcher, it would be naive to argue that a talanoa methodology had been employed in its entirety. Farrelly \& Baba (2012) remind us that true talanoa requires time, mutual trust and genuine emotional connections that the restricted research time period of a Master's thesis does not allow to develop freely. Indeed, Fa'avae et al. argues that 'To properly engage in talanoa might take years of learning ... the popular idea of talanoa as a research method is often idealized' (Fa'avae, Jones \& Manu'atu, 2016, p. 143). A cultural connection, or connection within a cultural vā is also suggested in some cases to be necessary for talanoa to occur (Vaioleti, 2006). Without a reciprocated trusting and respectful relationship, the level of talanoa that takes place can only reach fakatalanoa - that of an informal conversation that is polite and friendly. (Vaioleti, 2011)

Others have pointed out that despite the skill of the researcher and nature of the research itself, talanoa cannot be used as a method in qualitative research for the use of talanoa as a tool implies a fixed purpose and structure that contradicts the nature of talanoa itself (Fa'avae, Jones \& Manu'atu, 2016). The participant information sheets and interview guides required for ethical approval express an agenda to the 
participant, sometimes prior to their first face-to-face interaction with the researcher, and undoubtedly stifle the level of open conversation achieved. Prescott (2008) also argues that talanoa cannot result in open conversation, as a researcher always seeks specific information. With my own experiences in mind here, I would alter this idea slightly and argue that while the conversation cannot be entirely unstructured, it can be open in terms of the level of honesty shared with the researcher.

Despite the obstacles faced in engaging in talanoa, particularly as an outsider, it is important to recognise the value in embodying the ethos of talanoa alone. What was produced, was solid ethical research, research that my participants appeared to enjoy, because of the ethos of talanoa that informed my approach.

'We have to use elements and principles of talanoa in our research unevenly, in patches or without ambivalence, without feeling inadequate. What is most important is that we openly explore our experienced difficulties when we write our research'

(Fa'avae \& Manu'ato, 2016, p.147)

\section{Research Design}

Case Study. A case study design was selected for the current research due to the ability of this design to explore the experiences of individuals, whom are bound by time and activity (Cresswell, 2014). This binding or connecting thread is particularly important given the context of this research. Across many Pacific cultures it is believed that a person exists not as an individual, but instead in relation to others; both living and deceased (Tamasese, Peteru, \& Waldegrave, 1997). Their identity is the embodiment of their relationship with others, the earth, and the spiritual world. Significant value is therefore placed on placed on the wellbeing of the collective; and to study Pasifika individuals across Aotearoa would have contradictory to the very nature Pacific cultures. To instead work alongside a Pasifika community to understand their experiences, aligns more closely with a Pasifika worldview .

Analysing the Pasifika community in Wainuiomata provided the case study for this research, involving a segment of the population that is estimated to be over 2,000 
strong and comprised of over ten different ethnicities (Love Wainuiomata, 2016b). This community was chosen for its strong Pasifika base, the existing connections between community and VUW through WaiPESI, and the opportunity to begin my experience in 'development' at home, looking at the aspirations of one of Aotearoa's own communities.

Whilst the most common critique of case studies is the lack of transferability their results offer, the unique nature of this research is considered to be its strength. To argue that these voices speak for all Pasifika in Aotearoa, would be to blur the very myriad of experiences and aspirations that this research seeks to promote at an academic level.

\section{Research Methods}

Semi Structured Interviews. Semi-structured interviews were chosen as the primary research method for this project due to their ability to explore lived-realities in depth, thereby gaining an understanding of a diversity of meaning and personal experiences (Dunn, 2005). The flexible nature of this approach to interviewing offers balance between discussing topics that are fundamental to the research, and allowing the participant to discuss other ideas or experiences that are relevant to their stories, or of interest to the researcher (Crang \& Crook, 2007). Face-to-face interaction also offers a greater opportunity to develop a genuine connection with participants, essential to talanoa; and to allow the researcher to demonstrate both respect for the participant and value in their worldview (Dunn, 2005). Appendix C: Interview Guide outlines the questions that formed the foundation of these interviews, yet did not limit the topics of discussion. Each interview was audio-recorded with the participants permission, to minimise note-taking and allow both participant and researcher to give their full focus to each other.

Focus Group. Focus Groups are valued for the opportunity they offer a researcher to gather data from a wide range of participants in a short space of time, and are widely practised in the field of participatory research. 
My original intention when planning this research project was to conduct a focus group at the Wainuiomata Library for the children of parents already interviewed, aged $10+$. Ethical approval was sought, and obtained for this component of the research (Reference \# 0000026492). Understanding not only perspectives of Pasifika adults, but what young Pasifika people envisaged to be a 'good life' for them, was a perspective I felt was important to this research. The voices of Pasifika youth were literally, the voices of the future, that would tell stories of experiences and dreams as important as their elders. Part of WaiPESI's vision was also to raise the level of aspiration in these Pasifika youth. I hoped that I could be of service to this in introducing them to the idea of 'research' in a fun, friendly atmosphere, and demonstrating that university does not equate to the popular vision of remaining stuck in a classroom.

Unfortunately, this focus group never came to fruition due to the time constraints of a Master's thesis, and logistical support falling through. This is a potential direction for future research, as student perceptions and experiences in Aotearoa's education today, would give a more holistic picture of Pasifika educational experiences.

Participants, Sampling \& Recruitment. As is consistent with qualitative research methodology, participants for this study were purposefully selected with the intention of answering the research questions in depth, encompassing a variety of experiences and perspectives.

A total of 30 participants contributed to this research project, each over the age of 18 . All participants had considered themselves part of the Wainuiomata Community at some time, and had been involved in the WaiPESI journey.A further breakdown of their role within WaiPESI can be found in Table 5, with a list of participants and their associated roles available in Appendix D. A summary of gender and ethnicity can be found in Table 4. 


$\begin{array}{cccc}\text { Ethnicity } & \text { Female } & \text { Male } & \text { Total } \\ \text { Samoan } & 10 & 2 & 13 \\ \text { Tongan } & 2 & \mathrm{X} & 2 \\ \text { Tokelauan } & \mathrm{X} & 1 & 1 \\ \text { Indo-Fijian } & 1 & \mathrm{X} & 1 \\ \text { Fijian } & 1 & \mathrm{X} & 1 \\ \text { Niuean } & 1 & \mathrm{X} & 1 \\ \text { Māori } & 5 & 1 & 6 \\ \text { Pakeha } & 2 & 4 & 6 \\ \text { Total } & 22 & 8 & 30\end{array}$

Table 4: Ethnicity and gender of research participants. While the present study cannot be deemed representative of all Pacific Island cultures, and does not seek to be, this table demonstrates the ethnic diversity of participants involved in this study.

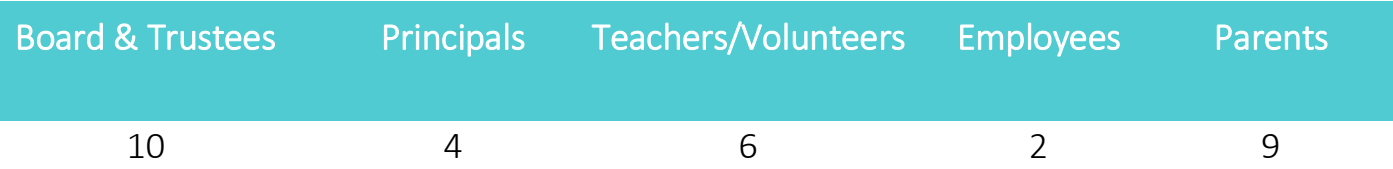

Table 5: Participants role within WaiPESI journey. While 30 participants took part in this research, many wore multiple hats, as Appendix D demonstrates. As a result, these figures total a number greater than 30

Initial participants were established when attending a WaiPESI Board Meeting to discuss my research ideas in 2017. I write with some pride that the WaiPESI Board were unanimously supportive of the research I intended to carry out, and volunteered both their time to be interviewed and to connect me with other Pasifika whanau.

Whilst 'snowball' sampling had been envisaged as an ideal recruitment method at the outset of this research, I could not have predicted how enthusiastically this request would be received by my initial participants. Snowball sampling refers to the process by which research participants connect the researcher with further potential 
participants, increasing the sample size as the study progresses and increasing connections are made (Noy, 2008). The premise of snowball sampling is to build on natural social networks and allow participants to have choice in whom they connect the researcher with, aligning well with the intention for this research to be participatory where possible.

To illustrate, my first interview took place with the ever-welcoming Bruce and Annie, both trustees on the WaiPESI Board. A mere two days later, from a hospital bed, Annie had suggested a further ten participants for me and introduced me via email to seven of these. Her level of support was reflective of that which I received throughout the entire research journey. Such support for the research being conducted was as equally humbling as it was daunting, and on a personal level reinforced my desire to reciprocate their efforts, by producing work that they would be proud of.

\section{Location}

While all participants had been part of the Wainuiomata community at some point, as time has shifted so too have the whanau involved. Out of respect for participants time and comfort, on initial contact each person was asked to nominate a time and place that worked for them. As a result, I found myself travelling around the Wellington region conducting interviews in a variety of public spaces, including schools, cafes, and participant workplaces. With Wainuiomata Public Library frequently being home to WaiPESI events, many participants also chose this familiar space for their interview location.

\section{Methods of Analysis}

Inductive thematic analysis was the primary method of analysis employed while conducting this research. An inductive approach to research allows codes, and later, themes, to be derived from the data itself, rather than collecting data and categorising this into pre-established themes that literature and theories have offered. The researcher becomes familiar with interview transcripts before beginning to 'code' the data, examining the underlying meaning of each quote, then assessing themes that emerge both within and across participant narratives. This method of analysis is 
valuable in that it allows the full diversity and detail of participant experiences to be explored, before establishing what connections lie between these. As key themes emerge, so too does new knowledge, and new meaning from these experiences.

The present research was informed by what Seale (2017) refers to as the zigzag approach to coding, as illustrated in Figure 4. Rather than a standard inductive approach to coding, which involves the completion of all data collection prior to coding and thematic analysis taking place, a zigzag approach allows the researcher to begin data collection and coding simultaneously. Collecting and coding at the same time offers the researcher the opportunity to alter interviews with participants to explore new or unexpected ideas that emerge in the coding process, or to emphasise discussion in areas where data has not been immediately forthcoming.

\section{Data Gathering}

Data collection finishes (few new codes appearing, thorough understanding of the experience has been gained)

Themes become saturated (fewer new codes appearing)

Further data collection (explore new ideas, fill gaps)

Initial data collection

\section{Data Analysis}

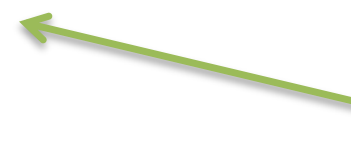

More refined themes

(coding becomes more succinct)

Refined thematic coding

Preliminary thematic coding

(first codes established)

Figure 4. Zig Zag coding. Image adapted from Seale (2017) 
Being informed by the zigzag approach to coding meant I was able to being coding interviews from the first day of data collection, and continued to do so as soon as they were transcribed. Doing so highlighted to me that while I received enthusiastic responses to my questions around progressing development in the Wainuiomata community, I was receiving less explicit narratives surrounding what good development looked like for this community. To my surprise, I was also hearing from many participants about how important community participation was in achieving change, and this was a belief I wanted to hear more about.

As such, I was able to reorganise the interview structure to position questions I felt I needed to hear more about, to better understand my participants experiences, at the start of the interviews. This reduced the likelihood of time constraints or lowering energy cutting the interview and potentially crucial questions short at the end.

As the number of themes grew, this process inevitably became more 'deductive' in style, as frequently occurring codes naturally slotted in to those themes already established. Indeed, it is impossible for research to ever be entirely inductive, for the researchers prior knowledge will always influence interpretation.

\section{Ethical Considerations}

Ethical approval for this research was granted by the Victoria University of Wellington Human Ethics committee (Reference \#0000026040). In accordance with the guidelines of this ethics committee, signed, informed consent was received prior to conducting all research interviews. Templates for both Participant Information Sheets and Consent to Participation forms can be found in Appendix B. Interviews were audio-recorded with the permission of participants, with the option given to receive and examine a verbatim transcript following the interviews conclusion; an offer many participants enthusiastically took up.

As with any research project, obtaining ethical consent does not signal the end of ethical considerations. Several of these ethical complexities have already been discussed in both the Positionality and PAR sections of this chapter. 
A situation that required particular ethical consideration on the part of the researcher was that of participant anonymity. When obtaining informed consent, all participants were given the option of being identified by their name or a pseudonym, in both the report and thesis to follow. The majority of participants indicated that they were happy to have their name used in both outputs, with the exception of one, who sought a pseudonym. This initially posed an ethical dilemma for me as a researcher, as I was concerned that by only having one pseudonym, it would be evident to other participants who was not named. Alternatively, if I was to remove this participant from the study, it would be unethical in that their choice to participate had been taken away from them. I made the decision to continue with this participants involvement, and made all attempts to remove identifying factors, including gender, and any reference to the role in which they engaged with WaiPESI. Fortunately as the research progressed, several participants who had been suggested to me for participation could not be contacted, and I realised that this increased the number of possible identities that Participant A could be, supporting their anonymity.

However, one of the greatest challenges faced in this research was the balancing of expectations; those of my participants, the WaiPESI leadership group, my employer Luamanuvao in her capacity at Victoria University of Wellington, and academia. Although Luamanuvao had been generous in her requests, with the only explicit request being to 'Tell WaiPESI's story', I was aware that this story was anticipated to be a positive one, that would highlight what a successful initiative the university had supported. The current WaiPESI trustees, to whom I wanted to offer as much ownership as possible, were somewhat unconsciously divided in their expectations. Some harboured the same positive outlook as the university, while others recognised there had been considerable room for improvement, and viewed both the report and thesis I was writing as an opportunity to highlight this.

As interviews began, I quickly became aware that there were many perspectives of the journey WaiPESI had taken, within past and present members. Some stories told of a grassroots initiative in a community with beautiful spirit, that was influential in the lives of Pasifika youth. Others were more cautious in their observations, suggesting that while WaiPESI had made positive steps forward in the community, there was much more they could achieve. A small, but nevertheless significant group, were 
unflinchingly honest about their experiences with WaiPESI, suggesting that personality had got in the way of the group reaching its full potential.

These differing perspectives posed an ethical dilemma for me. While my employers, and indeed, some WaiPESI leaders, were anticipating a perfect story of success, other participants were honouring me with sharing their honest experiences, trusting me to represent them truthfully. Balancing these expectations seemed impossible, particularly given the degree of ownership I wanted the WaiPESI leadership group to have. Ultimately, I came to the conclusion that while it may be difficult to explain to both the university as my employer and some WaiPESI members, the space for improvement that had been suggested, it would be unethical to distort participant voices. The best approach I could take was to make it clear that the beauty of WaiPESI's journey, was the diversity of people involved, who would inevitably have differing perspectives of this journey; yet, they all shared the same dream of success for their Pasifika youth. 


\section{Chapter Five: What have been the educational experiences of Pasifika families in Wainuiomata?}

In order to understand the influence education may have in setting up a 'good life' for Pasifika whanau, it is imperative to first understand their current experiences in Aotearoa's education system. This chapter will seek to understand the experiences the Pasifika community in Wainuiomata have had with education, as voiced from the perspectives of parents and educators.

As stated throughout this thesis, education and development are intrinsically linked. However, lived experiences of Pasifika in education systems are not as clear-cut as the link between education and development would make it out to be. This chapter reinforces the experiences of Pasifika students facing challenges within Aotearoa's eurocentric, universal education system. In keeping with the methodological approaches guiding this research, an exploration and understanding of such experiences is warranted through a social constructivist lens.

\section{Language was a barrier, and in some circumstances, lost.}

When asked to reflect on their time as a student in Aotearoa, the loss of one's first language emerged as a common experience between participants. Such experiences, though devastating, are unsurprising. The dominance of Pākehā settlers from the 1860 's and consequential pre-eminence of the English language led to the speaking of Te Reo being officially forbidden in education, ${ }^{16}$ in an attempt to ensure the assimilation of Māori youth into a now, predominantly Pākehā, society.

By the time immigration from the Pacific was encouraged to meet labour demands in the 1960's \& 1970's, Te Reo was still suppressed in schools by formal or informal means, and was often met with punishment. Like Te Reo however, languages of these south Pacific migrants were no longer perceived as relevant in a Pākehā-dominated world, and they too would be discouraged.

\footnotetext{
${ }^{16}$ This restriction on Te Reo was a result of the 1867 Native Schools Act, which dictated that English would be the only language to be used in New Zealand education (Te Taura Whiri I te Reo Māori, n.d)
} 
'As a student I did not have preconceptions in my mind about my limitations as a learner, although I did realise that being born in a thatched hut did put me somewhat behind the proverbial 8-ball in NZ. I put this down mostly to the language barrier. I think I believed that if I could speak English and understood the contexts such as history, farming, business, trade etc I could do well.'

[loane, former principal]

loane's ${ }^{17}$ beliefs as a student, reflects the attitude of Pākehā society at the time. While he did not consider his background a disadvantage, he did perceive learning the English language to be advantageous, the key to 'getting ahead' in this world; as did many other whanau in Aotearoa (Ministry for Culture \& Heritage, 2017). For many students, learning English would become their priority, at the expense of their native tongue.

‘l lost my language because when I started school, my parents friends suggested that I try and speak more English, but also my teacher at the time visited my parents ... I didn't realise it, but we were only really speaking Samoan in the home. Put it this way, I was fluent in Samoan. Or understanding it. But I was struggling at school. So she asked my parents if they could drop the language. At that time, this is the 70's, they don't know that kids are sponges and they could pick 2-3 languages up. So frustrated with that, that I've lost it. It's been a struggle to actually get that language back you know' [Annie \#1, WaiPESI Board member]

Annie $^{18}$ acknowledged that her lack of English language contributed to struggles in the classroom, but expressed her frustration at this resulting in Samoan being removed from her home environment completely. She now faces the challenge of re-learning the language; no small feat when attempting to fit around work and home obligations,

\footnotetext{
${ }^{17}$ Ioane is a former WaiPESI trustee and former deputy-principal at Wainuiomata High School, and was considered by other WaiPESI leaders to be instrumental in the genesis of WaiPESI

${ }^{18}$ Annie \#1 is a current WaiPESI Trustee and Acting Board Chair
} 
and not least, find people to practise with regularly. These sentiments are echoed by Lisa below:

'And but ... do you know in terms of culture we're a snob country. In terms of culturally. Because what we do is, even within my own culture, and I know it's alive and well in other Pacific cultures but if you don't speak the language, who are you? But actually learning - I tried, I tried to go learn Niuean, but unless I'm speaking with someone every day it's nothing. I attended this thing, and young people were denigrating us because we couldn't speak Niuean and they could, so we weren't Niuean's.'

[Lisa, grandparent and teacher]

Like Annie, Lisa also referenced how challenging it can be to learn one's own language. However in her experience, incredible emphasis is placed on being able to speak her own language to be considered a true Niuean. This suggests that proficiency in one's native language has the ability to influence perceived cultural identity in the eyes of others.

'I find that speaking Samoan, it's quite challenging. Because I don't speak it a lot now. But there's something about a deep spiritual connection that occurs with speaking your own language.'

[Hon Luamanuvao Dame Winnie Laban]

Luamanuvao's reference to a spiritual connection that arises when speaking her first language, is a key component of what research terms a strong cultural identity. The ability to understand or speak one's native tongue is often considered intrinsic to the expression of culture, thereby fostering cultural identity. Chomsky surmises this relationship between language and culture eloquently when he states: "Language embodies the world view of a culture and is unique to the culture that created it. It reflects values and concepts that are deemed to be the most important by a culture. $A$ language describes the culture it comes from." (Chomsky, n.d, as cited in Kamehameha Schools, 2014). Language also has a strong social function in its ability to communicate 
shared beliefs and values, and thereby cultivate a sense of group identity or solidarity (RacismNoWay, 2015).

A strong understanding of one's own language therefore, can contribute to a stronger sense of cultural identity. For people like Luamanuvao who can still speak their first language, this cultural identity can positively influence their spiritual and emotional wellbeing. For others, like Annie and Lisa who have struggled to regain their language, a sense of cultural identity may be more difficult to develop and maintain, or in Lisa's experience, be negated by outsiders.

However, for all of these participants who have struggled to retain their language, their ability to pass this knowledge on to their families and students is limited. In children, a strong cultural identity is particularly important in developing self-esteem and a sense of belonging, both critical influences on mental health and wellbeing. Understanding their cultural history and traditions assists children in creating a positive cultural identity for themselves that builds self-esteem, and illustrates where they belong in the world (Kids Matter, 2013). These parents and educators are aware of this, from their own experiences in. a monocultural education system, and it is for this reason that they seek the assistance of WaiPESI to share Pasifika culture with youth today. This will be explored further in Chapter 7.

\section{Encouragement to aspire high was lacking, but significant when present.}

'I didn't go to uni or anything but I look back and wish someone really did push me to go and do something after school. '

[Leah, parent]

While Leah's experiences of education in Aotearoa were not ones she deemed negative, she did acknowledge support was lacking around her to aspire high and continue to tertiary education.. The limited encouragement she received as a student unfortunately mirrors the experiences of many Pasifika youth today. While deficit thinking around Pasifika learners remains in the classroom, these students are unlikely to be encouraged by their educators to raise their level of aspiration. Significantly, the annual average NEET rate sat at $16.4 \%$ in June 2019 for Pasifika, indicating that approximately 12,100 Pasifika youth who had left school were not engaged in 
education, employment or training (MBIE, 2019). With experiences such as those of Leah, and Vai (below) in mind, one cannot help but wonder how many of these students have not been imbued with confidence, encouraged to aim high, and seek to achieve to their full potential.

'I wanted to have that impact on learning. Because my own experience of learning was that no one cared about me enough. I was always at the back, or the side, and I never really had a teacher care about me until I got to college. And the first thing that teacher said to me was: have you considered teaching? I was sixth form, and that was the first time in my school life someone said to me, I could do something. And I didn't want that for kids. I wanted kids to have that, way before they get to college.'

[Vai, former teacher and parent]

When discussing what prompted her to not only continue her education, but to enter the education system as a teacher herself, Vai reflected on her own experiences with learning. Like Leah, encouragement to aspire high and pursue tertiary education was non-existent, prompting a lack of self-belief until the age of 15 when a teacher finally showed belief in her. As a result, she turned her own focus to education, and dedicated her teaching career to supporting Pasifika youth, culminating in the creation of WaiPESI.

'I do not re-collect evaluations of the system but I do remember some really awesome teachers and some downright frightful ones... One thing I will always be grateful for were the number of people who helped me along the way simply because they could.'

[loane]

In a similar manner, in loane's experience it was the supportive teachers that would prove the most memorable and influential, despite the presence of some that were 'downright frightful'. His narrative demonstrates that like Vai, it didn't take many teachers to help him along his way; just a couple that genuinely cared. It was not necessarily about being told to widen their horizons and seek higher education; rather, being shown it was possible. 
It is worth noting that the significance of an encouraging teacher for Pasifika students fifteen to twenty-five years ago remains unchanged, with the presence of supportive teachers still considered a crucial factor in educational success today. Narratives in the recent Children's Commissioner report mirror the above, signalling that a positive teacher can make the single greatest difference to whether the learners educational journey is disappointing, or inspiring.:

\footnotetext{
"'Teachers focus on those they think can achieve and not the other. Focus on those who don't want to as they need it the most as they are probably going through something." (Student in learning support unit, Tongan / New Zealander / Samoan / British)'
}

(NZSTA, 2018)

" "If my teacher believes in me, sees potential in me and teaches me in the way I learn best, I will achieve more." (Secondary school student, undisclosed ethnicity)'

(NZSTA, 2018)

\section{Success could be lonely}

Despite being a success story in the eyes of his whanau and Tokelauan home, having learned English and succeeded in his schooling, loane spoke of it being lonely at the top.

'In contrast to my early days in Tokelau, my New Zealand experiences were very lonely. Along with many others considered to be the best and brightest in Tokelau, I was offered a government scholarship to complete my compulsory schooling in New Zealand. A great many of my contemporaries failed to advance to tertiary studies, university studies was the stuff of rarefied air as far as Tokelau students were concerned in my time as a student' 
[loane]

Collectively, these participants have offered a small snapshot of Pasifika experiences in education in 1960's and 70's Aotearoa. These narratives show that they began their studies unaware of any differences that could set them behind in the classroom, untainted by deficit thinking around their ethnicity. English was the language of instruction in school, and the learning of this would take priority over their first language, sometimes resulting in loss of this language altogether. Encouragement to aspire towards tertiary education was largely lacking, and influenced the self-belief of learners. However, the difference one genuinely supportive teacher could make to their self-confidence and future goals, was inspiring. These experiences did not disenfranchise them from education, but instead, inspired them to work towards better learning experiences in the future for both their own whanau, and other Pasifika youth.

While participants were asked to reflect on their own experiences as students in Aotearoa, conversation naturally flowed to the challenges they now observed their whanau facing in their own education journey.

Ignored, or forgotten.

'When I was Minister of Pacific Islands affairs, when I was in politics, the Ministry of Pacific peoples showed me some research that showed that despite all the training that teachers had, there was still an attitude that brown kids, Pacific kids, are not university material. So there are invisible barriers that still happen'

[Luamanuvao]

Luamanuvao's recognition of invisible barriers for non-Pākehā students implies a continued presence of deficit thinking and stereotypical views in Aotearoa classrooms. 
'They [teachers] focus on those that can. That's what I see, they focus on those that can and push those ones... leaving all the ones that are struggling and can't in the background, to either catch up or get hoha ${ }^{19}$ and drop out.'

[Traci, parent]

Traci's observations as a parent also reflect the idea of invisible barriers remaining in the classroom. Her perception of her children's experiences describe a situation where teachers have higher expectations of those already achieving, and seek to extend their knowledge; while those who are struggling may be subject to lower expectations, and thus given less time and energy.

'I think people make way for us [Pasifika]. I don't feel it's like ... it's not embedded in anyway. Like we're always like an afterthought, that's how I feel.' [Vai]

Vai's comments take Luamanuvao and Traci's perceptions that Pasifika youth are being ignored, a step further, to being forgotten. Despite confronting achievement statistics, and a MoE aim to produce 'demanding, vibrant, dynamic, successful Pasifika learners', this Pasifika educator feels as though their youth remain an afterthought; insignificant. Such poignant observations prompt the question: How can Pasifika realities can be transformed, if they are not perceived as a priority?

${ }^{19}$ Hoha means to be fed up, exasperated, annoyed (Māori Dictionary, 2020) 


\section{Culture is not normalised, nor a priority.}

Whatever the reason for the perceived insignificance of Pasifika youth - being ignored, forgotten or an afterthought - participants also suggested they felt the culture of these youth received the same treatment.

'It seemed to me that institutionalising education had separated the child from the village. It became a cycle where parents did not know how they could be part of their child's education. Education became the business of schools and teachers. Contrary to their DNA and cultural norms, PI children were being brought up as non-PI. Some made it but far too many just could not cope on their own.'

[loane]

Over time, loane has observed that education has become the work of schools, and teachers, as opposed to the role of whanau and community. In doing so however, the practise of teaching cultural customs, values and expressions, has been neglected. For schools, these traditions would be seemingly irrelevant in a monocultural system. The cultural identity of these youth therefore, has had less opportunity to be developed. The distance created between parents and the provision of education, has also created uncertainty around what role parents are expected to play, and what authority they have when it comes to their children's education.

The experiences of Annie and Lisa described earlier in this chapter, have already demonstrated that it was difficult to retain one's language. Now, loane's narrative implies children are still growing up without knowing being strong in their cultural identity; knowing who they are, and where they belong.

'No, it [education] strangles it [culture]. Conformity, you know. Because when they say Māori success is Māori, everyone judges it on numbers, their pass grades. For me, I judge it on their ability to be able to say I am whatever Iwi I am, I know the boundaries of my land, I know all the landmarks, I know my history. That success is Māori. We're so removed from our areas and Pasifika even more so. They need, strength in their identity' 
[Charmaine, teacher and parent]

Charmaine's comments further demonstrate how the teaching and valuing of culture can be overlooked in the education system. As she points out, success is education measured in literacy and numeracy scores, in NCEA credits, or in scholarships attained. It is not measured in knowing your culture, your identity, or your whakapapa. Understanding and identifying with one's own culture does not enter the education systems vision of success and as a result, is given minimal attention. However, a strong sense of identity and belonging do enter parent's hopes for a good life for their whanau, which will be discussed further in the next chapter.

'There are some schools that are unfortunate. For example my two daughters going to Sacred Heart, they don't have Samoan. So I'm so sad, because $60 \%$ of Pasifika is Samoan at that school, and they don't have the language there. So I push the principal when I was having a conversation with her and say hey, this is one of the approval subject. And she says they will have it in Year 12 and Year 13 , but they miss some of the steps you know?'

[Reverend Aneterea, parent]

Rev. Aneterea's experience with his daughter's principal, although disappointing, does suggest there are now more opportunities for children to connect with their culture than in recent years. However, the knowledge that a school that has a strong Samoan population is unable to provide teaching Samoan language in students formative years, indicates that it is either not a priority or unable to be funded. The teaching and expressing of culture then, is not yet a priority, and is not yet normalised as a result.

\section{Racism still exists}

For other participants, racism remained an invisible barrier to supporting their child's education. Yvonne shared her experience with trying to identify her son's learning difficulty, and the challenges she faced in having this diagnosed and supported below: 
'And you don't know, even for us we didn't know what was wrong for our son, we just knew it was a processing thing. And that could be anything, and people would go is there a drug issue, is there an alcohol issue, is there domestic violence issues ... and seriously, that's your go to? And it is, and that's what annoyed me the most, because it's absolutely racial profiling. And I don't care what anybody says. They wouldn't ask a person in the same neighbourhood living two houses down from me if their child's learning challenges were the result ... they would actually get assistance, and get tested. So what I found was it doesn't matter how you speak English, where you work, how much you get paid, whether you are dealing with the health system the education system or the justice system, you are absolutely put in a box because of the color of your skin. Absolutely.'

[Yvonne]

Yvonne's comments demonstrate that racism prevails within Aotearoa's communities, and is noticed by those it is directed against. Whilst some would consider her experience to include subtle racism, what is important is that it is seen, and felt. Her experiences are sadly aligned with the deficit theorising surrounding Pasifika in Aotearoa, as discussed in Chapter 3, and reflective of the demoralising experiences Pasifika families frequently encounter. Such encounters indicate an invisible barrier within education; working with the system, is hard.

\section{The system is not working}

Ultimately, the experiences and observations of participants shared thus far have suggested that in many ways, the education system is not working to help Pasifika students achieve their full potential. Some people, like Yvonne, explicitly expressed their disbelief at this reality.

'There are a number of education challenges. And you think how does that even ... how is that still acceptable in this day and age? We've got increased access to technology, supposedly more teachers, MoE is improving schools as they go over time, they've got more support supposedly if you read the media, but then you get inside. And you realise it's not true.' 
[Yvonne]

'Education is a must. But I'm not happy with the education system. I like to see the kids learning, what they are interested in doing. And not being forced to do something they're not interested in doing. Not all children learn the same, and want to learn the same. That's what I think.'

[Trevor, uncle]

As a caregiver, Trevor too pointed out he believes the education system is flawed. He would rather see children being able to pursue their interests than conforming to a prescribed curriculum, implying that the aim of the education system does not align with his vision of success for the children in his care. His acknowledgement that not all children are interested in the same things or learn the same way, indicates that his own vision of success is based on the wellbeing of the learner, not on their pass-grades or ability to conform in the school environment.

'I always think those kids are in there [trouble] not because of anything to do with them, but because our system failed to support them in navigating their way through the education system'

[Tute, deputy principal and parent ${ }^{20}$ ]

Tute's comments reflect a sad reality. Ultimately, it is the students that are being deprived of the opportunity to succeed to their full potential, and their future prospects that are being limited, owing to inequalities in our schools that they have little control over.

It is important to note that a tone of frustration and anger underlies these narratives; not one of resignation or resentment. Despite these experiences, whanau have not waivered in their belief that education will help their children lead what they deem a good life. Rather than becoming disenfranchised and disheartened, these parents and educators have stayed motivated. They have been inspired to seek change in the education system either by becoming educators themselves or participating in WaiPESI

\footnotetext{
${ }^{20}$ Tute is the current Deputy Principal at Wainuiomata Primary School, and a former WaiPESI trustee. Tute was considered by other WaiPESI leaders to be instrumental in the genesis of WaiPESI
} 
as a parent, because they want to see a better future for Pasifika youth today. Osuvale eloquently surmises his perspective on this below:

'That is the reason we come to New Zealand. For the education. That's why most of the Pacific Island people came here, because of the standard of education. In Samoa it is good, but the good school, most of them can't afford to pay the bill to go to the good school. That is why most of the families are moving here, education for their children.'

[Osuvale, parent] 


\section{Chapter Six: What does a Good Life look like for Pasifika Families in Wainuiomata?}

The work of scholars such as Gegeo (1998), Bulloch $(2014 ; 2017)$ and the emergence of Buen Vivre (Gudynas, 2011) has demonstrated that the vision of 'development' a community aspires toward, ought to be reflective of their community needs and align with their perceptions of what a good life should be.

This chapter seeks to examine what a good life looks like, for the Pasifika community of Wainuiomata. It draws together responses from questions such as 'What does a good life look like for you and your whanau?', or 'What does a good life look like for your community?' to illustrate what positive development looks like for this community in particular. From these discussions, five clear themes emerged: a feeling of belonging, a strong sense of identity, the celebration of culture, achieving in one's education, and ultimately, living a comfortable life. Throughout this chapter, these themes will be discussed in detail, while exploring the underlying idea that connects them: the importance of successful education.

\section{Participation, Access \& Belonging}

The ability to participate fully in one's community, and feel they belong there, emerged as a critical component of what these participants deemed a good life for their whanau and community. Luamanuvao shared her own view on this, with a strengths-based ethos underpinning her thoughts:

'You know, it [a good life] is about participation, it's about access, it's about feeling valued, feeling you belong, feeling you have something to contribute. But building a sense that I also know where to go if I need support, but also I can give support. So, respect, relationship, and reciprocity are the three fundamental values of the Pacific.'

[Luamanuvao]

What is striking about Luamanuvao's narrative, is the emphasis not only on what someone deserves as part of the good life vision, but what they can contribute. Her comments highlight a belief that while someone deserves to be able to participate in 
their community and feel they belong there, they also deserve to be empowered to recognise they have something to contribute too. Community and reciprocity then, are central to her perception of what a good life entails. These beliefs align with values of relationship and reciprocity, which she affirms are strong within Pacific cultures.

'Access to information. That's the primary thing... Support, access, and drive.' [Alexia, Teen Librarian at Community Hub]

'I think it's [life] without struggle. And that's always been on the back foot. It's not necessarily... yes, it's all about the economics, but also access to services, knowing where to go, just being well-informed about trustworthy organizations or people. There's lots of things out there and that's just being scammed away by a bunch of you know, quick [cash]? But I think a good life is when you are comfortable in your space, and knowing that you can get help when you want it. And knowing that your kid has the best education, they have the best access within that school, so they are performing at their best'

[Gail, WaiPESI Board member ${ }^{21}$ ]

The narratives of Alexia and Gail above agree that access to information and services in the community, is also a vital component of leading a good life. Having access to these services allows whanau to be able to reach out when they are struggling, and receive support that will not make decisions for them, but instead fuel them with the knowledge to make choices themselves. This way, whanau are empowered to make decisions that are in line with their own vision of a good life for themselves and their whanau.

'So I mean it's fundamentally, I think about belonging, about feeling that you ... you're essence of being a human being and some sense of dignity. Feeling that you're being heard, feeling that you can participate.'

[Luamanuvao]

Luamanuvao's narrative here, eloquently surmises the vision shared by participants above. Ultimately, a good life is about having a sense of belonging in your community. This sense of belonging, is derived from feeling one can participate, contribute, and

${ }^{21}$ Gail is a current WaiPESI Trustee who acts as both Treasurer and Secretary. 
seek support when they need it. Belonging in this community, means feeling you are a valuable member of it, and that you belong in this place.

\section{Culture is retained, and normalized}

Central to a sense of belonging, is a feeling of validation in who you are - your identity. As has already been discussed, an understanding of ones culture is key to identity development. These participants suggest that retaining and affiliating with ones culture, with an end goal of having it normalised within society, is a key component of their vision of a good life.

'On a whanau/community level [a good life is] that we achieve that bottom line and retain the values, customs and norms which makes us distinctively us, people from Tokelau'

[loane

For loane, a good life involves maintaining a strong sense of cultural identity, and being proud of the culture that makes you unique, but also connects you to your past and whanau. Preserving and sharing cultural traditions and values then, is essential to loane's vision of a good life for his community.

In Jay's vision of a good life, she points out that it is important Pasifika whanau affiliate with their culture and feel comfortable 'walking in both worlds confidently, you know, free from bias', but also emphasises that freedom from racism or stereotyping would be integral to her perception of a good life for her community.

'That they [Pasifika] are spoken with, and spoken to, as you would speak to anyone, respectfully as you would speak to anybody else, regardless of their skin color or their accent, or how they look really.'

[Jay, former WaiPESI employee]

Louana's conception of a good life, encompasses both of the perspectives above. She spoke both to the necessity of retaining and uplifting PI cultures and languages, but also, to these cultures being welcome in both 'worlds'. 
'One really good thing would be that their culture and language is uplifted, the mana is hooked to who they are, who they are is important to their children, and they don't have to hide it when they go out to any institution because they do. They don't want to say they're Samoan or speak their Samoan language, but when they go somewhere and someone greets them with Talofa, they're like wow ... so they don't feel less than. I suppose that's the one big thing, that they don't feel 'less than'.'

[Louana]

Underlying Louana's narrative is a desire to see the culture of Pasifika families normalised; as evidenced by her hope that families would not feel the need to hide their culture, and instead, would be greeted with familiarity.

Collectively, these participants have illustrated that an integral part of a good life for their community, is remaining connected to the customs and values of their culture, and to have this culture welcomed in the wider community.

\section{Developing a strong identity and resilience}

Other participants suggested that a good life for their families, was more than retaining and normalising their culture. Rather, supporting youth in their own families and communities to develop a strong cultural identity was their focus. While several reasons lay behind these narratives, the underlying belief remains the same: a strong sense of cultural identity is integral to a good life for Pasifika youth.

'So my kids, that's my goal for my kids. To remember their culture, who they are, that is your identity. Your language. I told them you can come home and we can speak Samoan, if you go out, English all the time. But you need to keep those, because we have our own way of talking to them, to discipline them, and help them out.'

[Rev. Aneterea] 
For Rev. Aneterea, a good life for his children is one where they are strong in their cultural identity and particularly, language. In his whanau, being able to switch between both English and Samoan allows you to walk in both worlds, as Jay referred to earlier in her vision of a good life for her community. However, for Rev. Aneterea, retaining Samoan is not only significant in terms of keeping his children connected to their culture, but in terms of communication in his home.

When reflecting on her own vision of a good life, Lisa also drew attention to the importance of developing strong cultural identities in youth today:

'I want my Pacific Island children in this school, and my Māori children and my Fijian Indian children to have a strong sense of themselves, that I want for my own children. I want them to be fiercely proud of that. I don't want for my own Mokos, what I don't want for every child I come across... I don't think that as a NZ country, we give our children - our Māori children have it, and our children that are strong in their own culture have it, but I don't think we give our children, irrespective of their culture, enough sense of who they are as a New Zealander.'

[Lisa]

What is poignant about Lisa's narrative is that the vision she holds of a good life for her family, is the same vision she has for every child that she comes across; regardless of culture. Having a strong sense of self is her aim for each child, and notably for Pasifika children, this includes being able to relate to their dual identity as both a Pacific Islander, and New Zealander. Again, we see the notion of being able to belong, and participate, in 'both worlds'. However for Lisa, it is not enough to merely understand whakapapa and have a sense of belonging. What stands out about her vision, is that she wants children to be 'fiercely proud' of their identity; who they are, and where they belong.

Charmaine spoke of her husband's experiences as a Samoan man, describing a situation where someone has progressed through to adulthood without a strong sense of cultural identity: 
'My partner, he's Samoan ... for him success is getting money, looking after your parents. But he's lost his language growing up, and he doesn't know enough of it. So when we go to funerals or we go to weddings or fono, he doesn't know how to ... what's happening, or the structure of those kinds of things. And that makes him uncomfortable, and he feels like a plastic Samoan. And you don't ever want anyone who is ethnic feeling like a plastic, you know what I mean? So that's the biggest thing'

[Charmaine]

While her husband's measure of success, and a good life, focuses on financial independence and an ability to support his family, it is evident in Charmaine's narrative that his lack of cultural connection can make for an uncomfortable experience for him. For Charmaine, who has witnessed this, developing this strong sense of identity and cultural connection is invaluable to her vision of a good life for her community, for it avoids anyone feeling fake, or 'plastic', in a community where they belong.

Finally, one other participant looked to the unpredictability of the future, to emphasise her idea of a good life:

'What this place looked like for my kids won't be the same place that it looks like for me today. You know what I mean? It is about building resilience, it is about building confidence, it is about identity through who are you, where are you from, and a lot of these kids can't answer.'

[Participant A]

In highlighting the uncertainty of the future for both adults and children, this participant reminds us that we cannot prepare youth for every eventuality. She instead looks to supporting youth to develop a sense of identity as the answer. In her eyes, an understanding of who you are, can help grow confidence and resilience with which to meet the future. A good life for Participant $A$, is being able to greet whatever the future brings with strength, confidence and resilience. 
For these participants then, the essence of living a good life is based on having a strong sense of identity, and the resilience that emerges from this. Whilst developing cultural identity was the focus of these participants narratives, it was believed that not one culture should be the focus of cultural identity. These participants felt identity was not formed by a single culture, and being able to identify as both a Pacific Islander and a New Zealander, and to participate in both worlds, was essential to their vision of a good life.

\section{Education \& Passion}

Of all characteristics considered important in living a good life, perhaps the most eagerly discussed of all ideas, was the notion of obtaining a quality education, and discovering one's passion.

In reflecting on her time as a principal at Wainuiomata Intermediate, Pearl shared that a desire to see their children achieve in an academic sense was a strong theme that had emerged in discussions with Pasifika parents.

'What I found over the years was that a very big difference in what Pasifika parents wanted was educational achievement for their kids. They really wanted their kids to do well academically and it was really evident in all the surveys and fono's we did with parents. It was raising the reading, writing and numeracy in the first instance and then all the other stuff that went with it. It was different for Māori families. They often told me they wanted a little bit less of the academic stuff and more of the cultural stuff.'

[Pearl, former principal at Wainuiomata Intermediate]

In acknowledging the differences between what Pasifika and Māori parents seek from education, Pearl alludes to the very topic this thesis examines; the acknowledgement of different conceptions of what constitutes a good life, and the questioning of what is needed from education to achieve this. Her comments infer that in her experience, while Māori families would prefer schools to support them in connecting their children to their culture, for Pasifika whanau, the priority is academic achievement. 
The comments of other Pasifika parents interviewed; echoed Pearls observations, and indicated that academic achievement is seen as integral to setting children up for further study and well-paid jobs later in life.

'I'm not a rich person, but I invest in expensive school, like catholic school, because I know the outcome is very good. The reason why, because I want them to succeed. I want them to be doctors, and lawyers, and maybe not everyone, but aim high. If you fall, you still fall, but if you aim low, you will learn hard times in life. So that's my vision for my kids. We just invest in our kids, we don't have a bank account to invest our money but we invest in their school and learning. It's all about success.'

[Rev. Aneterea]

'I hope our children will receive a good education to enable them to progress and be successful in their chosen career/s'

[Toli, former WaiPESI Trustee]

'We like kids growing up focused with school. We want the kids to go to university and study more for their future, their better life. We don't want our kids to end up on the road everywhere without job, we want them to learn more and study hard and then go back after college to university and get more knowledge for their future and their lives. Not for us but for their better life.' [Miliama, parent]

The narratives of Rev. Aneterea and Miliama above demonstrate that whilst they believe achievement at primary and secondary level to be important for their children; they also want their children to take their educational journeys beyond this. Both reflect a desire for their children to aspire high, and continue to learn, ultimately gaining an education that will allow them to live a comfortable life. Rev. Aneterea in particular, reemphasised his hope that his children would have high expectations of themselves, and set their sights high. 
'So my focus for my kid is to aim high. Because if you aim high, and you fall, you are still on a high. But if you aim low, you fall to the ground you know! So that's what I told him, you pursue high.'

[Rev. Aneterea]

In discussions with other parents, ensuring that their children had opportunities within education to find and pursue their passions emerged as a stronger priority than that of academic achievement. For Trevor and Toli, education that opens their children's minds to a variety of career ideas, and supports them to discover what interests them, is their vision of an ideal education

'I want their mind is loaded with ideas, and when it's the time, whatever he's deciding to do, I'll support that.'

[Trevor]

'[Good education is when] the children are motivated and confident to discover their interests in education subjects and extra curricula (sports and hobbies).' [Toli]

The narratives of Leah and Louana also signal a belief in the importance of being able to pursue ones passion, in identifying this as integral to their perception of a good life for their whanau.

'A vision of a good life for them would be that the children are doing something they are passionate in, and they're happy'

[Louana]

'Good life ... Probably just stay in school. I know everyone's different, so it may not be all academic, but as long as they find a passion in something, that's my main thing. Whether it's sport, or art, or something to do with uni. Just encourage them to whatever their passion is, whatever they're good at.'

[Leah]

What is interesting about the perspectives of Louana and Leah, is that their focus is on their children finding their passion, and pursuing it. While they wish for their children to obtain an education, the purpose of this is not to gain skills for the development of 
human capital that will later provide a wealthy career. Instead, they hope that their children will discover their passion, and in Leah's case, that education will support them to find it.

\section{Living comfortably}

The final theme that emerged from discussions around what a good life constitutes, was that of having the ability to live a comfortable lifestyle. Comfortable, is an apt description of this communities' goals. They do not necessarily seek wealth, but do seek financial independence, as emphasized by loane and Emma below

'In NZ, financial independence is the bottom line.'

[loane]

'[Being equipped] to go out and live independently, know how to look after themselves and be able to provide for themselves ... definitely.' [Emma]

Other participants extended on what financial independence looks like for them, highlighting a desire to not need to live financially on a week-to-week basis

'So I think successful children who are in jobs ... and just living comfortably, you know you're not stressed about pay week to pay week, and you've got your family support'

[Lahraine, ex VUW PASI student, WaiPESI volunteer]

'A wonderful life for anyone would be no bills, maybe owning your own home and your cars for those that drive ... Home, car, good job, and not worrying about bills would be absolutely beautiful.'

[Traci] 
What is significant about the life that Traci and Lahraine depict, is that their hopes are not ostentatious and focussed on riches. Rather, they are emphasising having financial security, enabling one to have what they need to get by; as opposed to living a luxurious lifestyle. Lahraine extends on her vision of what is viewed as a necessity below:

'And then, once your parents hit retirement age, they retire, instead of working beyond retirement age. I think that's when children need to step in and then they are giving back.'

[Lahraine]

Lahraine takes her perspective of living comfortably one step further, to include ensuring financial security for parents as well; echoing the collective focus of Pasifika cultures.

\section{Summary}

This chapter has illustrated the various components Pasifika families suggest are integral to their vision of a good life. This vision is multi-faceted, and borders on an austere lifestyle, where greater focus is placed on following one's passion, and feeling that one belongs.

Participants suggest that a good life is having the ability to participate in one's community, while having access to support when required, and feeling a sense of belonging in their community, supported by normalisation of culture. It is also about retaining cultural identity and embracing diversity, whilst strengthening identity in Pasifika youth. Discovering and pursuing a passion is integral to this vision, in hope that it will support gaining financial independence and living a comfortable lifestyle.

It is evident that this is a vision driven by diverse needs, emphasising the need to examine local context and community aspirations if education is to facilitate this vision of development. 


\section{Chapter Seven: Thematic Analysis \#3: How can community involvement in education, progress this vision of development?}

The following chapter will examine the ways in which participants suggest the Wainuiomata community can further work to ensure every child has equal opportunity to succeed in their journey to living the 'good life' that has been narrated. It draws on examples of what WaiPESI has already achieved within their community, and suggests areas where help is still needed. Some ideas call for more responsibility on the part of schools, others focus on the role of WaiPESI but ultimately, participants acknowledged that the greatest progress would be made through partnership between families, schools and community.

Throughout the previous chapter, Pasifika narratives have built up a picture of what they deem to be a 'good life', for both themselves and their whanau. In essence, the life narrated by these participants is comfortable, and one where there is an opportunity to follow one's passion. Education, is considered a vital stepping stone to achieving both of these goals. Access and achievement in education increases employability, which in turn influences the amount an individual can earn to support both themselves and their family. This level of wealth then determines whether a person will be able to own their own home and live comfortably; or whether renting is the only option available, and living week-to-week is a struggle. Learning the right skills and succeeding in the necessary pre-requisites enhances the probability of entering a job of one's choice, the chance to pursue a career you love, and ultimately, follow one's passion.

However, as 'Thematic Analysis \#1: What have been the educational experiences of Pasifika families in Wainuiomata?' showed, the current education model is not supporting Pasifika youth to achieve to their potential, let alone setting them on a path to discover and succeed in their passion. How can a child who faces the challenges of deficit theorising, lack of encouragement and having their culture invalidated, be expected to have the confidence to aspire high and navigate their own pathway to success?

This is a distressing reality for many Pasifika students in Aotearoa, and a reality that the Wainuiomata community is seeking to change for their own youth. 
As the following narratives will show, work to change the educational outcomes for Pasifika youth in Wainui has truly been, a community effort. Over the past eight years, WaiPESI trustees, school teachers and leaders, community members, and parents and whanau alike have dedicated incredible time, funds and energy to the continued outputs of WaiPESI. Whilst WaiPESI has made a significant difference in the lives of a number of Pasifika youth, many still need help navigating their learning journey to succeed, and WaiPESI can not do this alone. Community buy-in has been critical, and exceptional.

\section{Start early}

1 firmly believe education starts from conception. It also starts in community. We've always prided ourselves in New Zealand on a quality public education system. It's always produced very good people. But the disconnect comes, when you see who gets to go to uni. Who ends up graduating? Who ends up going on to masters or postgrad? ... We have to start early. And we've got to look at a wider buy-in than just children being born. One, before they go to preschool, what happens, and two, in terms of pre-school, are we doing a good job in terms of preparing them for literacy, numeracy and into primary and into secondary.'

[Luamanuvao]

Luamanuvao's comments signal a belief in the responsibility of both parents and ECE centre's to ensure that Pasifika youth are prepared to engage in, and have access to, quality early childhood education.

While Luamanuvao's narrative here specifically refers to the years before pre-school, and the quality of education received when they attend, an underlying issue between these stages is the uptake of ECE services by Pasifika parents. The number of Pasifika children participating in ECE has increased exponentially in recent years, with Pasifika seeing the greatest growth in attendance of any ethnic group in Aotearoa over the past five years, as depicted in Table 1. However, the current attendance rate of $88.3 \%$ sits behind both Māori (95.2\%) and Pakeha (92.4\%), and therefore demonstrates there is still room for improvement, and still whanau to engage. The earlier a child can begin 
their educational pathway, the more likely they are to develop resilience, settle easily into the next stage of their schooling, and become life-long learners (MoE, 2017).

With Luamanuvao as patron, and Louana, a passionate early childhood educator at the helm, WaiPESI was able to draw on these beliefs, expertise and community connections to form what would be affectionately known in the community as WaiPESI Play Day's.

At each playdate, MoE, Kohanga Reo, kindergartens, playgroups, and home-based education providers would attend, with each organization having an activity for children set up at their stall, and volunteers helping parents to see what skills children were learning through participating in each activity. At the first event, Annie Roberts estimates they captured 11-14 families who were not already enrolled in ECE services, and exposed them to what was available to them. One parent, Leah, admitted she didn't fully understand the value of ECE until attending the first WaiPESI playdate.

'I always thought I wouldn't put my kids in to kindy, but being down there and seeing what they do, it made me ok with it. I liked what I saw. I thought it would be good for them; it's not just a playground sort of thing but about what they learn, and how they learn'

[Leah] 


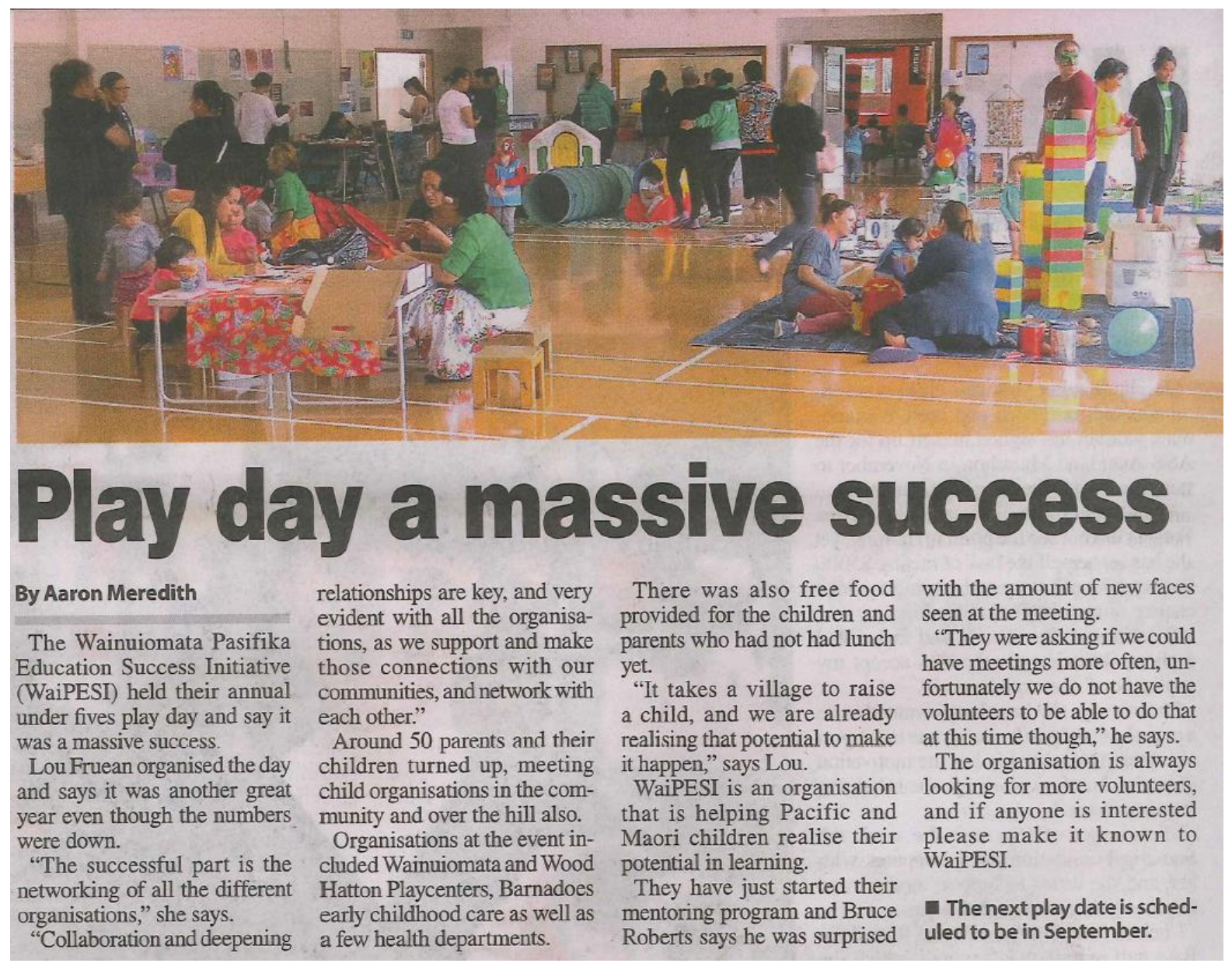

Figure 5. 'Play Day a Massive Success'; article featuring in the Wainuiomata News, $18^{\text {th }}$ March 2015

Whilst growing enrollment in ECE services was an exciting outcome of these Play Days, WaiPESI's wider focus was on making parents aware of the options that were available to themselves and their whanau and empowering them to make decisions armed with this knowledge.

'When we ran a play day, we had heaps of different organizations involved', said Louana. 'But at that play day, we made a mandate that actually you're not flying your own flag. It actually takes a village to raise a child'. Under Louana's instruction, no selfadvertising banners were permitted, and any brochures or advertising material organisations wanted to share would be put together at a second, separate information table, where parents could choose what they were interested in. In this way, WaiPESI was able to support parents to explore their options; yet empower them to make their own decisions without pressure. Jay, a former WaiPESI employee also 
noted the influence they were able to have beyond their early childhood focus. 'It's almost that sort of building the knowledge of Pasifika parents to understand the education context' (reference).

The success of, and attendance at, WaiPESI play days has been such that the group has continued to run these events on an annual or biennual basis. However, the extensive influence that these play days have had, is perhaps best reflected in the response of the community:

'But what has happened, is a lot of the ideas which were new ideas, are now becoming business as usual ... So for WaiPESI, it's been a huge success. The ideas, where they saw that there were gaps or needs, and they put in these programs to make change, the schools and the kindy's have now recognized themselves and taken that on board'

[Annie \#2, WaiPESI Trustee and Community Hub Manager ${ }^{22}$ ]

WaiPESI can say with pride that they have inspired other groups in the community, with other kindergartens reporting they have held their own version of the 'play day' event. This not only shows that WaiPESI's event was admired, but demonstrates that other groups in the community are now buying in to the vision of supporting their youth to become life-long learners, and in essence; owning their own development.

${ }^{22}$ Annie \#2 is a current WaiPESI Trustee and Wainuiomata Community Hub Manager, the site of many WaiPESI activities 


\section{Engaging community to pursue this vision}

'I firmly believe education starts from conception. It also starts in community' [Luamanuvao]

Discussions with participants revealed an unquestioning belief amongst many, that involving the community in children's education is critical; echoing the old phrase 'it takes a village to raise a child'. This belief would underpin the direction of WaiPESI, as loane shares below:

'In the early days of WaiPESI [it was about] mobilising the village, believing, normalising learning to be part of our children's daily lives, involving educationalists, families, church, sports coaches and anyone who is interested in supporting our children through their learning journey.'

[loane]

Vai pointed out that unless communities, parents and schools could work together to support their children's education, realities would not change, for no party could achieve this on their own.

'I knew, that unless we involved parents and the communities in the schools, then nothing was going to change... Whether it's the teacher and parent, teacher and child, parent and child. I knew it was important to reinforce this, because they can't do it on their own. If that relationship becomes a three, it becomes a strength. I just knew from my teaching experience that the more we connected with home the more successful the journey would be for the child, the student.'

[Vai]

Tute also echoed Vai's sentiments, explaining that even if schools were not progressing the way communities and parents felt they should, they were integral to the educational journey and therefore must be collaborated with. 
'Because you can't leave schools out of the picture, we're talking educational success and achievement. Early childhood to tertiary as Luamanuvao's original vision ... you can't leave the schools out. But in order to do that you actually have to pay some respect to the schools and what's going on there, not exclude them or be above them, but actually collaborate together so that the programmes you offer supports and empowers the Pasifika community to be engaged, to inform and drive what's happening in the school' [Tute]

It is clear from the above narratives, that a strong belief that it takes a village (or in this case, community) to raise a child exists amongst these participants. It is thought that the community has much to offer in the way of supporting youth and learning both inside and outside the classroom. This belief has shaped WaiPESI's direction, with the group acknowledging that working towards a common vision of success together makes it all the more likely to be achieved. 


\section{Support Pasifika youth to grow confident in their identity}

A further key idea that emerged when speaking to participants, was that the formation of a strong cultural identity early in a child's education, would build the confidence and resilience needed to face challenges as they grow older; both inside, and outside the classroom. Emma, a parent of children whom attended WaiPESI, expands on this below:

'But you know kids who do leave primary fully confident and very ... set in their own identity, do really well I think going through because they know I'm Tongan, I'm special, I'm unique, I can do whatever I want, all that kind of stuff. Because when you get to college, that's when you really do start to think about your future and where that culture takes a back seat. But if culture is already embedded as a norm from your formative years then you'll be better equipped, and it benefits your ability to appreciate other cultures. So that's why I think it's really important in the early years'

[Emma]

It was also expressed that schools have a key role to play in the development of this identity. Vai looked to teachers to play their part in helping children to find their sense of identity, and establish where they belong in the world.

'Identity has been part of teaching and learning for a few years now and it needs to be ... highlighted a lot more, and for all kids, so they have an identity, and they can see where they fit in to their community, their country' [Vai]

Pearl agreed with Vai's comments, and expanded on the way she shared this belief with her own teaching staff.

'The culture of the child cannot enter the classroom until it has first entered the consciousness of the teacher. And we had that written in the staffroom on the whiteboard and that was really for every child. Their language and their culture is really important, and you cannot separate the two' 
[Pearl]

Emma also spoke to the integral role schools have in shaping children's identity, but from a different angle. She believed that teachers were mentors and role models, and the presence, or lack thereof, of Pasifika staff influences how children perceive themselves.

'I mean a fulltime Pasifika resource at Fernlea would be amazing. We've had vacancies and I've always wanted a Pasifika male because teachers are role models, and if you are not ... if the minority are Pasifika people, then that's the norm for our Pasifika kids. They'll always see themselves as a minority. So it would be really healthy if there were more Pasifika people inside the school to build up that picture of normality for Pasifika kids. They'd be like oh yep, Mr or Mrs so and so is Samoan, she's one of the teachers. It's normal. But for all the teachers to be non-Pasifika, it kind of reduces a Pasifika child's view of what is normal.'

[Emma]

Although these narratives speak to the role schools have in developing cultural identity, the underpinning belief that a strong cultural identity is vital for youth was also central to the work of WaiPESI. While their events and activities were not explicitly focussed on expressions of Pasifika culture, common Pasifika values were embedded in much of the work they did. However, WaiPESI was also careful not to overdo it, as not to make any whanau who did not have strong knowledge of Pasifika culture uncomfortable.

'The most we're going to do Pacific wise is start with a prayer, end with a prayer. We'll eat, we'll laugh, we'll learn. Nothing exclusive about that. Might be the way of our style, or sometimes our subject matter might be in a Pacific way but you know that's cool, if you guys - if you're open to it, anyone's welcome'

[Annie]

The central message that emerged from the narratives above, is that school and community both have roles to play in developing the cultural identity of Pasifika youth. 
In working towards this, it is essential they collaborate to support the work of each other. 


\section{Help education feel more safe, approachable and enjoyable}

Ensuring that talking about, and engaging with education was a safe experience for families was one of WaiPESI's first steps. In Luamanuvao's words, "The thing that I really wanted to look at as a way to engage community and empower the families, is so that they can operate with principals and teachers as equals.'. For many parents, it is daunting to talk about what they don't know, and even more challenging to find the confidence to do this with their children's teachers.

'I don't know enough about how kids are at school, but I do know they get lost in the system. And here is a way to open it up for them ... and parents don't have a great time at school, they don't have great experiences at school, so that's a lot of parents in an environment where they aren't comfortable, where it should reflect their culture as well. And I need schools to be reflective, they're working on it but they're not there. So we were key in it because we had both education and culture.'

[Vai]

Here, Vai demonstrates how past experiences in Aotearoa's education system can make parents feel uncomfortable raising concerns about their children's schooling; for they are back in an environment in which they themselves were not encouraged or validated. She implies that the culture of these parents is still not embraced both in the classroom of their children, or in parent-teacher interactions, leading to a potential unwillingness to raise concerns, due to a lack of confidence. In contrast, WaiPESI sought to make their own interactions with parents as comfortable as possible, believing that the more confident the parent felt in their environment, the more safe they would feel speaking out with questions or concerns. 'I knew that it was so crucial when we came together that it was inviting and embracing' Vai continued. 'It was loving, a family feeling, culturally sensitive, and culturally aware' (Reference).

However, participants also suggested WaiPESI could take this support of parents a step further, by introducing some form of advocacy service to assist parents in asking questions of their child's education outside of WaiPESI.

'That was my thing, I really wanted to get that off the ground. Advocacy because as a parent I could advocate for my kids, easy. Because I was pretty 
staunch in what I thought. But with Pasifika parents they're respectful, it's all about respect. You don't want to rock the boat, you believe that the educators are going to do the right thing by your kids. But if you don't make enough noise nothing happens for those kids, they just sit in the back, and cruise through, then find out at the end they don't have what they need to carry on in their field.

[Louana]

Others suggested that if WaiPESI could help with creating a safe space for parents to also embark on a learning journey, this could be key in creating a positive cycle of educational achievement for whanau.

'I'd always had a vision Holly, that we've got a whole lot of Palagi people who have retired that used to teach, or are literate. You can actually mobilise that resource, to come in and maybe have an hour or two hours. And I wanted to see that community centre really thrive and have people come in and say I belong, this is my place. I can teach someone to cook, we can go and do a lesson of shopping... deep down, the idea was to empower these people so they could fall in love with learning and if some of those parents return to school who've dropped out of school then that has an impact on the next generation.'

[Luamanuvao]

What is striking about this narrative, is that it emphasizes collaboration between community and parents, to make learning an enjoyable experience for both, with the hope that this will be passed on to children. Luamanuvao's vision of a space where everybody belongs and can contribute, is not a one-way help system, but communitydriven and mutually beneficial, which is empowering in itself.

'I think the biggest thing is we do give the kids and their families confidence. And once they have that, once they believe in themselves, the world is open. And I think that's a big part of what we do. It might not be through any particular lesson, but the atmosphere we provide. In that learning can be fun. The world is open, just go find it' 


\section{[Bruce, WaiPESI Board Member ${ }^{23}$ ]}

However, empowerment cannot exist without confidence, which was a key attribute WaiPESI sought to instil in both parents and children, as Bruce describes above. Through the loving, family atmosphere Vai described, parents were able to ask questions about how the schooling system worked, arming themselves with the knowledge to understand whether their child was on track, or needed extra support. In this sense, schools have become more approachable for those parents who now know what is expected of their child, how well their child is progressing, and what is needed to help their children grow. For children, homework was no longer the boring after-school chore when it involved pizza, friends and guest speakers to endlessly question. Learning became fun.

\section{Support whanau to get involved - confidence to advocate, knowledge to question}

The goal of WaiPESI has always been to encourage families to get involved, and to create a new education story together. As has become evident throughout this thesis, WaiPESI has sought to achieve this in a number of ways, with one of the first steps being to share knowledge about how Aotearoa's education system works.

'It was really just how do we get that information to these families in a way that isn't too invasive of their privacy. We will give you the information that empowers you to make some choices and make some decisions'.

[Yvonne]

One notable way WaiPESI was able to impart knowledge in parents was through a weekly session they called Growing Stronger Together. These sessions catered to children from pre-school to secondary school, and at the same time, incorporated an opportunity for parents to discuss and learn about topics of their choice.

The success of these sessions lay in that they were driven by community needs, and it was about learning together. Each week, the focus for the evening would differ. Topics

${ }^{23}$ Bruce is a current WaiPESI Trustee and works as a Te Papa Museum Host, which has allowed him to take WaiPESI youth behind the scenes of the museums Pasifika exhibit on an annual basis. 
for learning were not predetermined, and at the close of each session a parent and student would again be invited to come to the front, to share what they had learned with everyone, followed by a discussion of ideas for the following week. Such discussion ensured that these sessions would be of genuine benefit to those attending.

'One of the topics was how do I transition my child from early learning, to primary, to intermediate, because some of the information I have about my child isn't transitioning to the intermediate. So how do I have that conversation, how do I start that? One parent was like how do I tackle reading with my child? Can you give me any tips? .... We found, it was simple little things. Like one of the early topics we talked about was how do I read these reports? How do I read a school report?'

[Annie \#1]

To ensure that no whanau missed out on attending these sessions due to fear of repercussion, the library staff held an 'amnesty', forgiving any old fines still against the whanau names.

'I love that we've transitioned to the library because some parents weren't coming in because they had books that were overdue at the library and we had an amnesty, the librarians had an amnesty and they were like don't worry, we just want you to come along, we'll forgive/clear the records, and start you afresh.'

[Annie \#1]

A common challenge faced by parents was the struggle to help children with homework and keep them on track at home. This was often fuelled by their belief that they were not smart enough to know the answers, for their schooling experiences had not been good, and therefore they had nothing to offer.

'And parents kept saying, I'm useless at maths so my child can't do maths. And we have to change that thinking'

[Pearl]

For Pearl and Vai, it became particularly important to show parents that they did not have to be teachers to help their children's learning. 
'So we invited parents to come work alongside their children in the school. We stayed back for six weeks, on a Wednesday night. We'd have something to eat, something to drink, and then do an hours work with parents and kids.

Teachers were staying back at school three nights a week with their various meetings. And we gave the parents worksheets on what they could do at home with their child'

[Pearl]

'I was very aware of ... allowing the parents to understand that they are not expected to be a teacher. We are just supporting and helping them in their parent role, with their children's learning. And there is so much they could gain, from discussions, and from the learnings that we have, about what they could do.'

[Vai]

One of the ways in which this was demonstrated, was a simple reading session with a small groups of parents and children.

'My favorite [topic] was the one where Vai did a session on how to read a book to the kids ... and the parents left there going oh my god, I feel so much better. And she was saying if you don't know what that word means, your child probably doesn't either so go look it up together, don't be embarrassed. And when you're reading the book, ask them, do you understand what it means? What do you think happens next? The parents left there buzzing, on something so special

[Annie \#1]

Vai was able to teach strategies for how to get through difficult words, and introduce simple questions to get children thinking analytically about the text, connecting it with their own world experiences, and getting parents and children connecting through these discussions. Understanding the difference they could make in their child's learning, despite not necessarily having finished school themselves was an empowering experience for parents, and part of what made WaiPESI special, as Alexia mentions below. 
'It's a real, real point of difference, because not only were they showing parents, this is what your kids can do, they were also educating the parents in how to help their kids achieve more.'

[Alexia]

This new-found confidence in parents encourages continued involvement in their children's schooling, through whatever means they can. Participating in small tasks together as early as possible, such as reading together or discussing a child's day at school, may initially seem inconsequential, but in reality make focusing on education an important and normal part of daily life.

'Adult/family participation from day 1 , developing the confidence to continue to be involved and normalising learning and achieving. Supporting students and families understand the system better means that we become better "players" and less content to be "spectators"'.

[loane]

The upshot of building parent's knowledge of the educational context, as loane points out, is not only that families are better equipped to engage in the system and ask questions of it. More importantly, it means with the knowledge behind them of how things can (and should be) for their children, parents are less satisfied with the status quo, and merely trusting the authority of educators.

However, participants also indicated that more progress could be made if parents were supported to take this new knowledge forward, and put it into action. As has already been mentioned, participants suggested WaiPESI could move into the space of empowering parents with not only the knowledge, but the confidence to advocate for the best education for their child:

'One thing that came out of here that we haven't really had a chance to address with the programme, was advocacy. And it came out of the very first sessions with the parents, having someone who could speak for our families.'

[Annie \#1]

'Because one of the things we've always thought, set up like an advocate group, so that the parents who struggled to go and have conversations with 
the principal, someone could go and support them. Someone could help them understand the process of what you do if your child's having a hard time at school, what do you do if your child's being bullied? What do you do if your child's not achieving? And having those people walk alongside parents ... even my role here, I see that we need that role, that kind of community champion that is kind of connected to our school, ideally like a third party' [Tute]

\section{Learning is not restricted to the classroom}

'I knew I wanted to ensure that kids were experiencing fun ... in their learning. And that learning didn't always have to be in the classroom. And that when it was learning outside the classroom they thought wow this is learning. And they were able to experience success, outside the classroom '

[Vai]

Vai's vision of imparting a love of learning through demonstrating that it could be fun, and was not restricted to the classroom, is a vision that has become central to the work of WaiPESI. Through the connections of volunteers, WaiPESI were able to offer opportunities for both students and their whanau to engage with learning outside the classroom. Back-of-house tours of Te Papa, Aotearoa's National Museum were an annual event hosted by Bruce, a WaiPESI trustee who worked as a Te Papa tour guide by day. Over the years that WaiPESI has run, several tours have taken place with each group demonstrating both keen interest, lively enthusiasm, and respect for both the knowledge and artefacts shared. For some students, it has been an opportunity to extend and enhance the knowledge they already hold of their ancestors and culture. For others, it is the first time they have visited the Pasifika exhibit and considered the connection it holds to their identity, resulting in realizations like those Bruce recalls below:

'As we were leaving, this one boy who was probably about 12 or 13 looked at me and said, 'I've never been so proud to be Samoan'. Because when we were 
looking at these objects, I'm saying these are your ancestors, aren't they clever? So that's another way we can connect them to their culture, and I have the unique opportunity to provide that.'

[Bruce]

These annual Te Papa trips have not only been about exposing children to their culture and providing them with an opportunity to explore outside of Wainuiomata, but creating an educational experience. Whilst on the trip, learning remains paramount. 'We look at the whole thing as education', said Bruce. 'We use it not just as a cultural opportunity, but an educational opportunity also. We'll ask things like "Who wants to be a tour guide at Te Papa?". Last time about twelve hands shot up!'

In 2018 this visit was extended to a tour of the neighbouring Circa Theatre, coinciding with the showing of The Still Life of Chickens, a performance by Pasifika playright D.F. Mamea. In partnership, Circa and Te Papa were able to provide this opportunity for 25 parents and children from WaiPESI to attend, with their travel, tickets and tours free of charge.

Experiencing a performance at Circa Theatre was not only a eye-opening experience for these youth, but a chance to meet further Pasifika role models, and increase their level of aspiration and belief in what they, as Pasifika youth can achieve. For parents, this was also a fantastic opportunity, given some parents in attendance had never been to anything beyond their children's school play. Learning remained a key focus throughout the visit, with discussions on the bus ride home revolving around questions such as 'Who wants to be an actor now you've seen the play? How could you get there?', and 'Who wants to be a director? Or a puppeteer?'.

'Everyone enjoyed it', said Louana. 'It gave the kids and parents another view of what different learning passions can look like within a successful view of life'

Through the collaborations of WaiPESI, Te Papa, Circa Theatre, and families, it is evident this community has been able to create their own incredible learning opportunity for their youth. Experiences such as these offer not only the chance to understand what learning can look like outside of the classroom, but to expand the horizons of both students and parents to careers and opportunities they would not otherwise have considered, or possibly, believed themselves capable of. 


\section{Aspire to Achieve}

One of WaiPESI's core goals was to raise the aspirations of youth in their community, and encourage them to look beyond Pasifika stereotypes, through widening their horizons as to what they can achieve. With this in mind, WaiPESI embarked on the creation of an annual careers evening that sought to involve students, their whanau, and the community.

'The big careers night they put on here was phenomenal. It was just really well organized, the people they had speaking and engaging. The stalls were informative; parents hung around and spoke to the right people. They had people here that dragged the community in, and we had big numbers though. And everyone was really positive ... [it was about] raising that level of aspiration, and just letting people see you know ... potential careers they might not have thought about. Just making sure they can see over the hill I guess. And that their parent's life doesn't have to be their life.'

[Craig, Current Principal at Wainuiomata Intermediate]

What stood out about the careers evening that Craig experienced, was the focus on raising student's level of aspiration, by exposing them to careers they had never thought of; and much less considered. The atmosphere was vibrant, with engaged parents and enthusiastic children encountering a diverse range of community mentors.

'But I remember now one of the other points of difference now, was the Passion, the career information, was exposing our kids not just to the things that they want, but some things they hadn't thought about... Get our kids thinking, these could be realities for them. There was one kid who was interested in being a pilot. Now how many kids in Wainui are going to have a chance to even speak to a pilot? And one of the people Lou had last year, a naval woman who worked in aviation? But she was also a marine biologist, so we want to expand the horizons. I'd love to have the kids have their world expanded, and be exposed to a wide range.'

[Yvonne] 


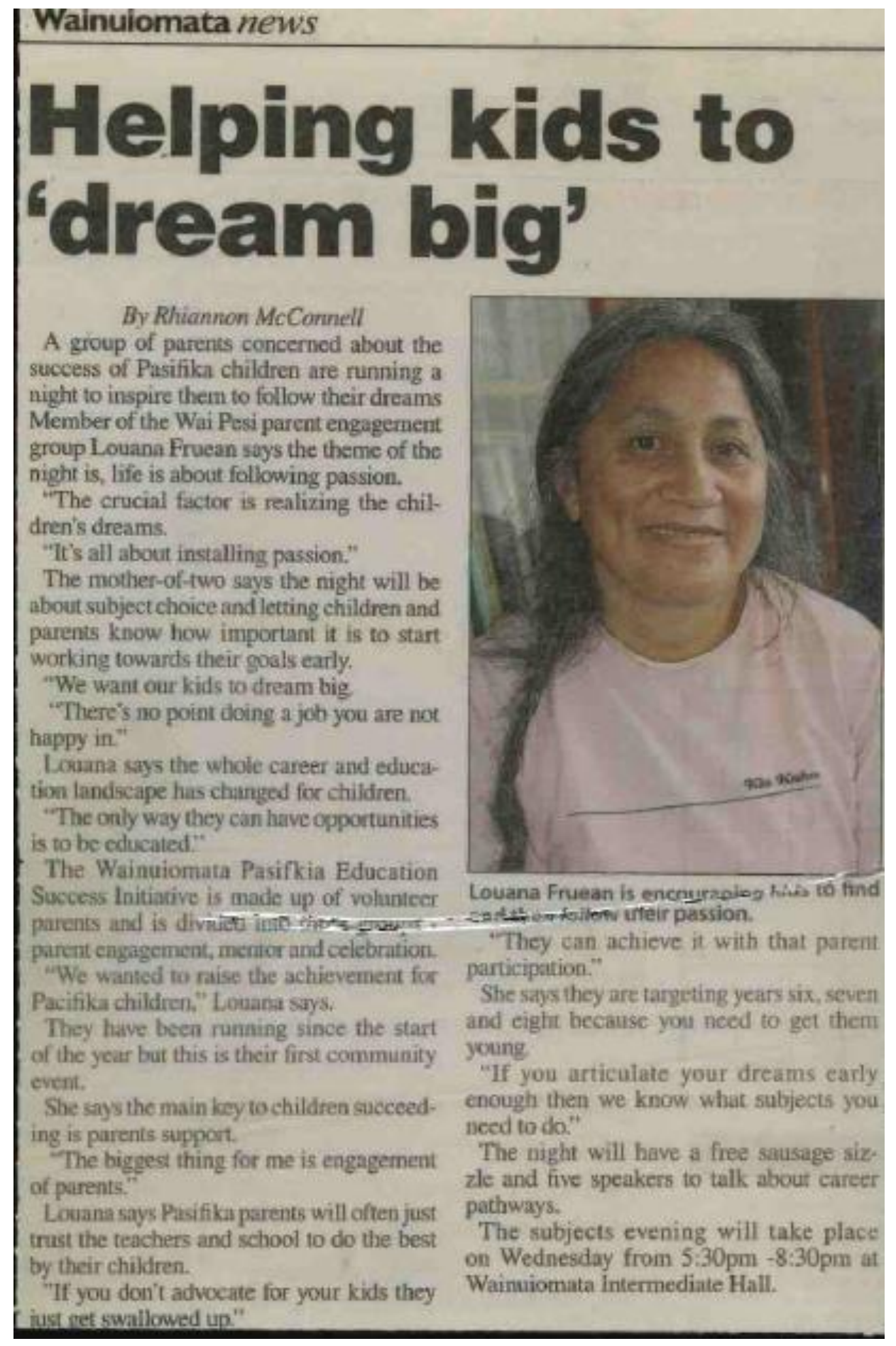

Figure 6. Careers Evening. Article in Wainuiomata News, helping to advertise WaiPESI's first Career Evening. 
However, these career evenings were not just about exposure, but instilling belief in both children and parents that whatever sparked passion in them, they could achieve. Through encouraging children to think about what excited them, and then discussing the steps they can take to do that, a belief that they can succeed in doing so is inherent in the conversation.

\author{
'Because often kids will say, "I'd really like to do be ... BUT". And then the \\ outcome is I'll never be able to do that. So WaiPESI is all about you, you want to \\ do that? Let's make it happen. What do we need to do for you to get to that \\ space? And for you think about what it is you want to do, and follow your \\ passion... Not just be a dentist, because it pays a lot. But following your \\ passions so that what you end up doing, is something that is meaningful for you \\ as a person.'
}

[Annie \#2]

Yet as Emma reflected, whether her primary-aged children choose to follow their new goal of becoming pilots or not, the most important outcome is that they now have vision they want to pursue, and they know it would be possible for them to achieve that. Better still, is the conversations it has incited with friends, who did not attend the evening, who are prompted to think about their dream job too.

'But it was good because it made them think about is it that they want.

Whether they become pilots or not it's for fun. But for me the absolute positive there is that they started the conversation. I think that's great because it starts the conversation. It's like a ripple effect. It starts conversations with his family, with their friends, with their friends' friends. I think it's positive and it did stem from WaiPESI.'

[Emma]

Coaxing students to think about what they would do if they could not fail, was a stepping stone to getting them thinking about the opportunities available to them. For some children, this was the first time they had considered what they could do, as opposed to what would be expected of them. For others, it was the first time they had voiced their vision to their whanau. 
'That very first information evening, was around passion... What is your passion? What is it you love doing? What do you wanna do? What do you dream about doing? You can hear Louana in all of this ... And we've had children open up. They've never shared it with their parents...

Sometimes we were the conduit between the parents and the kids. Like saying hey, this is your child's passion. This is what comes from this ... then have that conversation that there are lots of jobs they can have from that passion. Telling them the only way they are going to move forward, is being happy in what they are doing.'

[Annie \#1]

Annie's comments demonstrate the importance of WaiPESI's focus on involving the whole whanau, not just the children, in their events. In her experience, some children needed that extra bit of encouragement to voice their passions with their parents, and both child and parent benefited from discussing where this passion could take them. Such experiences reinforce the importance of making the careers-evening a familyfriendly event, so the whole family is welcome to engage, and support their children in their education story together. WaiPESI did their best to make the evening as welcoming as possible for all ages, as described below.

'Our model was very much focused not just on the high school students, because what we believed was one; parents didn't engage because the time the school set wasn't suitable for them and two, the high school thing really focused on students, not the family. And we felt that actually the family need to be part of that to understand and support their students. And we also wanted kids at a younger age to be exposed to that career evening, to be excited about learning, to see the purpose of education, and have some vision in their mind about what they wanted to be to then see the purpose of their learning. So it was very much about targeting families'

[Vai] 
Such has been the success of this careers evening, it has been noted by schools in the area that their students attitudes towards their future have changed. Craig, the principal of Wainuiomata Intermediate, recognised a shift in his students self-belief following their attendance at WaiPESI careers evenings:

'They [WaiPESI] are authentic about wanting those higher expectations for the kids so they aim up and don't narrow their focus. And that's reflected in what our kids talk about when we ask them about careers. They don't see limits' [Craig]

In order to maintain this influence on students, and continue to expand their horizons, Craig believes that continuing interactions that focus on normalising educational achievement is key.

'I think if they continue to provide role models like that and just I guess ... it comes back to the authentic word again. The more kids just see that as a normalized ... this is what's happening out there, these are just other Wainui/Pasifika people who are making a difference and have achieved at this level, then the more normal it just seems to our kids and the more expected that they can do that. Whereas if you make it a one off event and trawl out the same 3 or 4 people every year it loses its impact pretty quick'.

[Craig]

The key word in Craig's reflection, is 'normalising'. Make it normal to aspire high. Normal to achieve at school. Normal to find your passion, pursue it, and make a difference. If WaiPESI can continue to support youth to believe they can achieve, and that it is normal to do so, then these children will soar. 


\section{Connect children and whanau with their culture}

In order to build a stronger sense of cultural identity in Pasifika youth, participants suggested that WaiPESI could fill the space where parents are struggling, by acting as a cultural resource for schools. One participant, Emma, suggested that this may be the most effective use of WaiPESI's time and knowledge.

'Personally I think in order to see their resource succeed, they need to work with the schools, and the churches. But working with schools as in can we, as a Pasifika resource, come into your school and teach your kids a Samoan song... Because schools want that, they want the diversity, they want culture, they just don't have the funding to be able to do that. So I mean that would be ideal.'

[Emma]

Indeed, Emma looked to the work of Louana, a WaiPESI trustee, as an example of an influential teacher of Māori traditions, customs and values, and raised the idea that WaiPESI could offer a Pasifika resource to emulate her.

'I think it'd be really cool if WaiPESI could go in in that way, like how Louana has done it. She's gone in and has taught Kapa Haka which is awesome, and like at Fernlea, the kids love it. They perform the songs and if they just had a Pasifika version, that would be awesome. It's about where you kind of invest your time and money and at the end of the day the end result is you want to have successful kids who are fully equipped to tackle academia wherever they are, but the fundamentals of building and strengthening identity in kids first I think is important.'

[Emma]

Again we see in Emma's comments above, an underpinning belief that cultural identity strengthens resilience, forming a foundation for success.

Rev. Aneterea shares the same hope as Emma, that WaiPESI could step into the sphere of connecting children and whanau with their culture, but for different reasons. For Rev. Aneterea, WaiPESI teaching would reinforce what he is trying to instill in his own children, and youth at the church. 
'If they can do that, that is most of the kaumatua, the senior one, they will love that. Because sometimes we try to teach our culture but they are influenced by the culture outside, they go to school, they become different people, you know? So I wish that WaiPESI will help in that area.'

[Rev. Aneterea]

As he points out, whilst he and other elders can attempt to instil cultural values and knowledge in their children, it is easy for youth to put this to one side when this is not the dominant culture they must fit into and interact with daily. It is hard for him to emphasise the importance of understanding and respecting their island culture, when he is one of few making it so. In the context of both school and church then, it is apparent that having someone to share knowledge of Pacific Island cultures and affirm its values would be appreciated by other whanau who perhaps do not have the knowledge to impart themselves.

\section{Extra Academic Support}

Additional academic assistance was a further area identified as an opportunity for WaiPESI to support Pasifika youth. Parents agreed that having extra trained help was beneficial for their children, who may not receive this kind of extra attention in the classroom, where up to 30 other students can be competing for the help of a single teacher.

'There were times where teachers came in and they put ten minutes here, with the kid. But that's one thing I would've liked seeing more of, having qualified personnel. Just to lift up their learning.'

[Trevor]

'And I was also asking them if they can help to provide a teacher aide, for example English, maths, on that day, so I can invite young ones and say we're going to do some English today, and these young ones will come. You know, extra help outside of the classroom ... Because I definitely know, people would 
love to come to the church, the parents. And at the same time the parents will come and bring their children to the programme so they can learn'.

[Rev. Aneterea]

Charmaine also raised the idea of having extra support available to students if they felt they needed it, but was specific in what she felt would help.

‘Our Pasifika/Māori students struggle to get literacy and numeracy. So perhaps having standards they could work on there [WaiPESI], additional standards to safeguard them in case they don't get literacy and numeracy at school.'

[Charmaine]

NCEA achievement rates for Pasifika, although increasing, remain an area of concern which offers credit to Charmaine's idea. NCEA Level 2 is deemed the minimum requirement for entry into the workforce, and offering a safeguard to ensure this is achieved is both a sensible and considerate option. Identifying that not enough credits have been obtained usually occurs close to the end of the school year, putting additional stress on both teachers and students, the latter of whom are already dealing with the pressure of end-of-year exams.

\section{Connect whanau with other community opportunities}

As WaiPESI begins to explore what the needs remain in their community, and what space they can fill, the realisation has come that while WaiPESI has many connections; they have few volunteers on the ground to resource further events.

However, the outlook of WaiPESI has always been positive and strengths-based, and this situation is no different. In reflecting on their capabilities, Gail illustrates how WaiPESI recognised that they could work with their connections to deliver holistic whanau support, supporting a safe and comfortable home life for these children after a busy day at school.

'We'd already started the conversation about how could we work smarter with other groups, like-minded groups in our community. We don't need to reinvent the wheel, we can actually ask someone - we'd already started to outline who 
we could shoulder tap. Our families want to learn about banking, finance, retirement, getting in to your first home and all that. Could you come in and provide that? Maybe we can provide a cup of tea etc., but we don't have to run it. We don't have to do everything. And besides, we're less - there is less of us to do it. But to be sustainable, we need to buddy up, work smarter, and buddy up with other people

[Gail]

Connecting whanau with services that already exist in the community offers a dual benefit. For WaiPESI, less physical presence is required to ensure that families have an opportunity to learn and feel comfortable doing so, whilst still helping to address a need in their community. For these community services, they are reaching more whanau who need their assistance because of WaiPESI's encouragement to attend, and spreading word of the support they can offer. Again, a theme of collaboration runs through these ideas, drawing on the strengths of the community to help each other grow.

\section{Identify those who need support}

In order to build knowledge and confidence in parents, those who need support must first be reached, as several parents already involved in WaiPESI suggested. While attendance has been steady, it has generally remained limited to a core group of parents, who continue to return.

One WaiPESI parent, Emma, suggested that in order to extend their reach and offer as much support as possible to the community, WaiPESI could take a proactive approach in seeking out families who could benefit the most from their help.

'And also with WaiPESI going into the churches and working with churches to identify families that might need a little bit of extra help with their children's education, and kind of forming something around the gaps' 
[Emma]

Emma specifically mentions connecting with PI churches in Wainuiomata, as a good way to start. Approaching Pastors or Reverends to explain what WaiPESI could support families with, means that this information can be passed on by pastors themselves, whom families already trust and respect, in their own environment. Church leaders are also likely to be aware of families that would benefit from attending WaiPESI. Connecting with parents via the churches also means more families may be reached that may have heard of WaiPESI, but not understood that the support provided is free, or were too nervous to attend on their own.

Rev. Anterea, another parent already involved in WaiPESI, agreed with Emma. He wholeheartedly believes in WaiPESI's vision, having brought his children along, and offered to connect them with both his own church and other pastors in the community.

'One of the things I was talking to them [WaiPESI] about, I want them to engage more to the community. Like, coming to churches? Talking to them. Bring the programme to run in the church, like each church for maybe one day, or one week, and then move to another church. It's the idea of ... there are so many Pacific community churches here, but they don't know this programme. They don't know it's available, you know? And that's why I say that, is that it is the place of meeting for Pacific Island people, the church. They feel comfortable in that environment. That's where I told them, it would be lovely, and I can connect them to other pastors around here'

[Rev. Aneterea]

However, Rev. Aneterea also raised the importance of making WaiPESI a comfortable space for parents reached via churches, whether they met at a WaiPESI event or in their own environment. He pointed out that unless they were comfortable, families would not come, and removing language barriers would be a key part of this.

'And as I say hopefully there will be some time that there is a cultural thing, speaking maybe some Māori and Samoan, because there are some parents 
who are scared of coming around when they speak English too much. And they think oh if they talk to me what am I going to say? Because it's not their language. But having that there, that will feel those parents, you know, English is their second language, that will feel comfortable. If there is a need I can ask, because now I can speak my own language to this person. So these are the things I want to see to improve WaiPESI.'

[Rev. Aneterea]

Having coordinators who can speak some Māori or Samoan is not only a matter of comfort, but encouragement, Rev. Aneterea tells us. If WaiPESI is able to provide someone who can speak in families first languages, they are more likely to not only incite attendance, but engagement and active participation, which can only be to the benefit of both WaiPESI and whanau.

Although Emma and Rev. Aneterea's comments focus on how families can be encouraged to attend WaiPESI, it is heartening to note the sentiment underlying these comments. They signify that a belief that WaiPESI is invaluable, and an experience they want to share with others.

\section{Summary}

The story of WaiPESI is one of a grassroots initiative in Wainuiomata, that is succeeding in supporting children to achieve better educational outcomes, for what the Pasifika community deems as their vision of development; the good life that they want for their children. Pasifika families are actively involved with WaiPESI, and are seeking to support their children in their educational journey. They identify with the ethos of WaiPESI, supporting the need to start children's educational journey early, and to engage the community within this. However, they have also offered their ideas as to what direction and form they believe WaiPESI should take next, suggesting that education needs to be encouraged to support youth to aspire high, develop their cultural identity, and involve the whole whanau in the learning journey. 
In this sense, their success ${ }^{24}$ has been the result of collaboration between the home, community, and schools, emphasising the ownership this community has taken of their own development journey. While WaiPESI begun the path to community drivendevelopment, it has been the engagement of families and the community that have resulted in this community owning their own development.

\footnotetext{
${ }^{24}$ This success is particularly exemplified by the fact that other groups are beginning to emerge in Wainuiomata with a similar approach and ethos to WaiPESI, yet focussed on the community within a particular school. The model of WaiPESI is evidently admired; and one the community is seeing works.
} 


\section{Chapter 8: Conclusion}

This thesis has explored the ways in which Pasifika communities perceive and engage in education, for their own vision of development. Global academic and policy literature has asserted that education supports progress and development, yet it rarely questions the intricacies of this relationship between education and development. However, Post-development theorists have drawn attention to the need to consider problematic aspects of the notion of 'development' and have drawn attention to the importance of understanding diversity and local context. Drawing on these insights, this research highlights the need to question the relationship between education and development because scholars are yet to apply post-development critiques to education to ask what vision of development should guide educational strategies, and to question universal approaches to education.

Similarly, education has yet to be studied in Aotearoa from a development studies perspective to question what vision of development our education system aligns with. Such as task is important, given the disturbingly high rates of educational inequality (OECD, 2015). Applying a post-development lens to education in Aotearoa gives us the opportunity to explore alternative visions of development, rather than trusting that mainstream conceptions of development and subsequent approaches to education hold the answers to living a good life. A post-development lens highlights that we must we must give voice to community visions of development, and see value in existing community-driven education initiatives that support these visions.

The Pasifika community in Aotearoa is diverse, youthful and growing, constituting $8.1 \%$ of New Zealand's population at the time of the last census (Statistics New Zealand, 2019). However, this is also a community that faces many challenges, and is frequently seen to lag in measures of social 'progress'. With the belief that education is good for development in mind, despite the complexities of this relationship, it can be argued that obtaining a quality education has the power to turn this situation around. Yet, success in Aotearoa's education system which mirrors a universal approach to education, is the very thing Pasifika youth are struggling to attain, through little fault of their own. 
It is out of this context of educational inequality that WaiPESI emerged, with the aim of working to empower Wainuiomata's Pasifika families and community to seek the best educational outcomes possible for their youth. This research worked alongside WaiPESI, seeking to understand how they perceive and engage with education to fulfil their community aspirations.

Applying a post-development lens to this situation encourages us to look beyond the statistics and question whether the universal approach to education, embodied in the country's education system, is appropriate. It also reinforces a need to turn to the Pasifika community and understand this situation from a local context. It prompts us to ask what the educational experiences of Pasifika families have been, what they perceive as the objective of education, and how they are engaging with this vision. Embracing a diverse methodological approach to this research enabled me to appreciate the range of experiences, aspirations and actions undertaken by members of the Wainuiomata Pasifika community.

To reinforce the underlying research aim to understand the Wainuiomata community's vision of development, and the role they perceive education as having in progressing this vision, three secondary research questions were defined: .

1) What have been the educational experiences of Pasifika families in Wainuiomata?

2) What does a good life look like for Pasifika families in Wainuiomata?

3) How can community involvement in education, progress this vision of development?

\section{Key Findings}

The first question - What have been the educational experiences of Pasifika families in Wainuiomata? - offered insights into how Pasifika families perceived their educational experiences as students, and the experiences they continue to have as parents, grandparents and educators now. In reflecting on their own schooling, these families acknowledged that their experiences had generally not been positive. The loss of one's first language in an English-speaking education system emerged as a common experience amongst participants, and this has proved difficult to regain. These families have found themselves unable to pass their first language on to their children, and at 
times they have felt positioned as inferior to others in their culture who remain fluent in the language. Others remembered that encouragement to further their education beyond that of compulsory schooling levels was non-existent, reflective of a deficit perspective of Pasifika students. Those that did manage to overcome these challenges and succeed in New Zealand's education system, noted that progressing through tertiary studies could be a lonely experience due to a lack of Pasifika peers.

Observing their children and students progressing through the New Zealand education system now, these families remain frustrated that their children face similar challenges. They perceive Pasifika youth as being either ignored, or forgotten. They see the vibrant diversity of Pasifika cultures suppressed in a Eurocentric education system. Parents experience subtle, yet demoralising, racism as they seek better support for their children. For the majority of these families, the education system did not work to support them as youth; nor does it produce better educational outcomes for their own children today.

The second research question - What does a good life look like for Pasifika families in Wainuiomata?, - illustrated the vision of development that the Pasifika community in Wainuiomata aspires to. This vision is one that presents many contrasts with mainstream, Western conceptions of development that are typically materialistic and individualistic.

For Wainuiomata Pasifika families, the ability to be able to participate in their communities and feel a sense of belonging is critical to living a good life. Underpinning this sense of belonging, is a desire to see their diverse cultures retained, respected, and normalised within their community. To achieve this, participants also indicated that a good life for their families and community is one where there is opportunity to cultivate a strong sense of cultural identity in Pasifika youth.

Perhaps the most eagerly discussed characteristic of a good life however, was the notion of obtaining quality education that allows an individual to discover their passion. Belief in the importance of having the ability to pursue and grow one's passion into a career, is particularly strong in this community. Furthermore, this opportunity to follow one's passion seems to take precedence over financial gain, as families identified the ability to live comfortably as a further characteristic of a good 
life. For these families, living comfortably is about having financial independence, being able to pay the bills, and support one's family.

Thus, we see that 'development' is indeed a complex concept and diverse views are held by different groups. Just as post-development writers argue for 'diverse economies', it can be suggested that complex views about what a good life might be, call for 'diverse education' strategies (Flemming, 2015). The third and final research question asked 'How can community involvement in education, progress this vision of development?' To answer this question, focus was given to the ways participants suggest the Wainuiomata community can work to ensure every child has the support to live the 'good life' visions that were articulated. While participants drew on examples of what WaiPESI had already achieved to illustrate what they believed was successful community development, they also highlighted areas they believed that their Pasifika families still needed support in. Starting a child's journey through education early, and involving the whole family in this journey from the beginning, emerged as a key idea that would become central to the work of WaiPESI. These participants also suggested that through partnerships with the community that help take children outside the classroom to learn, children could identify that education is not restricted to the classroom, and begin to fall in love with learning. These experiences would have the dual benefit of widening their horizons to consider passions and careers they had not previously conceived. Families also suggested that through collaboration with both schools and community resources, education could be utilised as a tool to teach both children and their families about their culture. They also said if you 'look after the home, you look after the children'.

Inherent in each of these ideas is the belief that to achieve these visions of development, working in unison and partnership between the community, schools and families is vital. Furthermore, these responses suggest that succeeding in this vision requires involving the whole whanau in the educational journey. 


\section{Emerging Themes}

Several wider themes emerged beyond these research questions, that offer further insight into the way education is perceived and engaged in within this Pasifika community, and situate their experiences within broader academic literature.

Countering deficit thinking. It has become evident throughout this research journey, that the Wainuiomata community are exceptionally passionate about working together to create better educational outcomes for Pasifika youth. What makes their attitude exceptional however, is that despite the disappointing experiences these participants have had as students and parents in Aotearoa's education system, they are still choosing to work with the system, in the hope of creating change for Pasifika students today. Through WaiPESI, these families are engaging with educators to learn how they can work together to better support their children at school, whilst voicing their own concerns and questions regarding their child's learning.

While frustrated by their own experiences, these families have not become disenchanted with the notion of education itself, and still place significant emphasis on achieving in education in their vision of a good life, as demonstrated in Chapter 6 . The opportunity to obtain a quality education is viewed as critical to helping a one discover their passion and pursue this as a career, and to living what these families deem a comfortable life.

Such active engagement counters the wider deficit views of Pasifika that position them as marginalised and powerless to effect change. Rather than simply asking the state system to do more to accommodate Pasifika children within the national system, the efforts of WaiPESI are seeking to bring about change from below, to equip children with confidence, support and skills to succeed. The efforts reflect a Pasifika community that is passionate about education, is strongly engaging in community partnerships, and is actively working to create a better future for their young people.

Alternative concepts of development. When examining what the research participants envisage as a good life for their families, it became apparent that these 
visions are not simply grounded in mainstream conceptions of development, yet are not entirely separate from them. Mainstream perspectives of development, are founded on Western values which prioritise the agency of the individual, and where progress is frequently determined by material wealth. The drive for development within neoliberal political economies involves universal ideas and standards of 'progress' and 'development' to which all countries should supposedly aspire.

Yet what this community is telling us, is that their vision of development, as understood by what they envisage as a good life, is different to this imposed universal model. For these Pasifika families and educators, the retaining and normalisation of their culture in the society they live in, is key. They want their children to grow up with a strong sense of identity and affiliation with their culture, while able to fully participate in Aotearoa's western society and economic systems. This desire to create a greater awareness in youth of their identity and surroundings alludes to Freirean conceptualizations of education, yet does not seek conscientisation in its entirety. In aspiring for their children to embrace their cultural identity, Pasifika communities want their children to be encouraged to embrace the diversity that is contradictory to the very nature of development, while being able to participate in both worlds.

The ability to live comfortably, with financial independence and the capital to support one's family was a further element of what characterised a good life for this Pasifika community. In this respect, the value placed on financial wealth aligns with western conceptions of progress. However, in taking a step back and examining how one accumulates financial wealth in each of these perspectives, Pasifika voices were adamant that having the opportunity to discover one's passion and pursue this as a career was also important in a good life for their youth.

It is evident then, that similarities and contrasts exist between what this community perceives as a good life for them, and what mainstream development dictates should be aspired to in the name of progress. The emergence of these complexities support post-development's critique of mainstream development for imposing a homogenous vision of development and progress across diverse communities. 
Diverse education for diverse 'development'. Whilst Pasifika participants in this research were strongly supportive of the general role of education in achieving a good life for themselves and their children, they were aware that the relationship between education and development is complex. The participants indicated that they believed education was conducive to obtaining a good job, and living comfortably. As previously stated, such a perspective aligns with the school of thought that determines education is good for development due to its ability to stimulate growth in GDP, and raise the wages of individuals thereby supporting them to avoid poverty (see Chapter 2:

Education for Economic Growth).

However, this community also saw the development of cultural identity as a core characteristic of a good life for them, and believed education had the potential to support this. Education, they envisioned, could be a tool that not only connected children to their culture via Pasifika teachers and resources, but validated and celebrated that culture. Thus, education has to perform multiple roles - economic and material, as well as cultural and psychological - if it is to empower Pasifika children to straddle different worlds and succeed in both. This suggests that we need to move beyond universal and homogenising concepts of education for development and recognise the importance of multiple cultural and social contexts for development and thereby inform and support diverse and bespoke educational strategies for different communities.

To conclude, when we conceptualise development as a good life, we get different understandings of the purpose of education, and therefore different signposts to the way education should be conceived, delivered and evaluated. Above all, it is critical to highlight the role communities have in this process. The example of WaiPESI has demonstrated that an active, informed and proactive community can do much to articulate and institute alternative approaches to education. 


\section{References}

Andrews, T. (2012). What is social constructionism? The Grounded Theory Review, 11(1). pp. 39-46.

http://groundedtheoryreview.com/2012/06/01/what-is-socialconstructionism/

Allen, J. M., \& Bruce, T. (2017). Constructing the Other: News media representations of a predominantly 'brown' community in New Zealand. Pacific Journalism Review: Te Koakoa, 23(1), 225-244. https://doi.org/10.24135/pjr.v23i1.33

Auckland Council. (2019). Pacific Auckland. Who are Pacific people? Retrieved April 05, 2019, from the Auckland Council website: https://www.aucklandcouncil.govt.nz/plans-projects-policies-reportsbylaws/our-plans-strategies/auckland-plan/about-the-aucklandplan/Pages/pacific-auckland.aspx

Berentson-Shaw, J. (2018). Telling a new story about "child poverty" in New Zealand. [Report]. Retrieved 04 July, 2019, from The Workshop and The Policy Observatory website: https://thepolicyobservatory.aut.ac.nz/ data/assets/pdf file/0011/206678/T elling-a-New-Story-About-Child-Poverty-in-New-Zealand.pdf

Berryman, M., Kerr, L., Hikairo Macfarlane, A., Penetito W., \& Hingangaroa Smith, G. (2012). Education for Māori: Context for our proposed audit work until 2017. (Parliamentary Paper No. B.29[12g]). Retrieved June 21, 2019, from the Controller and Auditor-General website: https://www.oag.govt.nz/2012/education-for-Māori/docs/education-forMāori.pdf

Blackburn, J. (2000). Understanding Paulo Freire: reflections on the origins, concepts, and possible pitfalls of his educational approach. Community Development Journal, 35(1), 3-15. https://doi.org/10.1093/cdj/35.1.3

Brende, B. (2015). Why Education is the Key to Development. Retrieved 17 February, 2020, from the WeForum website: https://www.weforum.org/agenda/2015/07/why-education-is-the-key-todevelopment/

Bulloch, H. (2014) 'Contending developments: Local notions of development on Siquijor Island, Philippines' Journal of International Development 26, 177-186 https://doi.org/10.1002/jid.1818

Bulloch, H. (2017) In Pursuit of Progress: Narratives of Development on a Philippine Island. Honolulu: University of Hawai'i Press 
Careers NZ. (2017a). The Future of Work. Retrieved April 18, 2018 from Careers NZ website:

https://www.careers.govt.nz/jobs-database/whats-happening-in-the-jobmarket/the-future-of-work/\#cID 439

Cerdan, P. (2013). Post-Development and Buen Vivir: An approach to development from Latin-America. International Letters of Social and Humanistic Sciences, 10(1), 15-24.

https://doi.org/10.18052/www.scipress.com/ILSHS.10.15

Chambers, R. (1997). Whose reality counts?: putting the first last. London: Intermediate Technology Publications Ltd.

Collins Dictionary. (2020) Palagi. Retrieved January 15, 2020, from Collins Dictionary website:

https://www.collinsdictionary.com/dictionary/english/Palagi

Corak, M. (2006). Do Poor Children Become Poor Adults? Lessons from a Cross-Country Comparison of Generational Earnings Mobility. Research on Economic Inequality, 13, 143-188.

https://doi.org/10.1016/S1049-2585(06)13006-9

Cram F. (2016). Kaupapa Māori Research. Retrieved May 27, 2019, from the Katoa Ltd. website:

http://www.katoa.net.nz/kaupapa-Māori

Crang, M., \& Cook, I. (2007). Doing ethnographies. London, United Kingdom: SAGE.

Creswell, J. (2014). Research design: Qualitative, quantitative, and mixed methods approaches ( $4^{\text {th }}$ ed.). Thousand Oaks: SAGE Publications.

Cunliffe, A. L. (2003). Reflexive inquiry in organizational research: Questions and possibilities. Human Relations, 56(8), 983-1003. https://doi.org/10.1177/00187267030568004

Dunn, K. (2005). Interviewing. In I. Hay (Ed.), Qualitative research methods in human geography (pp. 50 - 82). Oxford: Oxford University Press.

Earle, D. (2010). How can Tertiary Education deliver better value to the Economy?

(Tertiary Education Occasional Paper 2010/08). Ministry of Education.

Retrieved November 22, 2018, from the Education Counts website:

https://www.educationcounts.govt.nz/ data/assets/pdf file/0004/86980/val ue-of-tertiary-education.pdf

Education Counts. (2016a). Number and percentage of students achieving at or above the National Standard for mathematics (2012-2016) [Data File]. Retrieved April 18, 2018, from Education Counts website:

https://www.educationcounts.govt.nz/ data/assets/excel doc/0009/148977/ 2016-Mathematics-Pangarau-Data-Tables.xlsx 
Education Counts. (2016b). Number and percentage of students achieving at or above the National Standard for reading (2012-2016) [Data File]. Retrieved April 18, 2018, from Education Counts website:

https://www.educationcounts.govt.nz/ data/assets/excel doc/0007/149272/ 2016-Reading-Panui-Data-Tables.xlsx

Education Counts. (2016c). Number and percentage of students achieving at or above the National Standard for reading (2012-2016) [Data File]. Retrieved April 18, 2018, from Education Counts website:

https://www.educationcounts.govt.nz/ data/assets/excel doc/0006/149307/ 2016-Writing-Tuhituhi-Data-Tables.xlsx

Education Counts. (2016d). Median weekly income (\$) for the population aged 15 and over by highest qualification and ethnic group 1998-2016 [Data File]. Retrieved April 18, 2018, from Education Counts website:

https://www.educationcounts.govt.nz/ data/assets/excel doc/0008/104399/ Income.xlsx

Education Counts. (2017). Prior participation in early childhood education of children starting school by ethnic group and year, 2000-2017 [Data File, PPN1].

Retrieved May 14, 2018 from Education Counts website:

https://www.educationcounts.govt.nz/statistics/early-childhoodeducation/participation

England, K. V. (1994). Getting personal: Reflexivity, positionality, and feminist research. The Professional Geographer, 46(1), 80-89.

https://doi.org/10.1111/i.0033-0124.1994.00080.x

Epstein, J. (2010). School/Family/Community Partnerships: Caring for the Children We Share. Phi Delta Kappan, 92(3), pp. 81-96. https://doi.org/10.1177/003172171009200326

Farrelly, T. \& Nabobo-Baba, U. (December, 2012). Talanoa as Empathic Research. Paper presented at the International Development Conference: Integrating Research, Policy and Practice, Auckland. Retrieved May 14, 2019, from the DevNet website:

https://devnet.org.nz/wpcontent/uploads/2018/07/Farrelly,\%20Trisia\%20\&\%20Nabobo-

Baba,\%20Unaisi\%20Talanoa\%20as\%20Empathic\%20Research\%20\%5Bpaper\%5 $\underline{\text { D 0.pdf }}$

Fleming, K. (2015). Diverse Education for Diverse Economies: The relevance of Rural Training Centres in the Solomon Islands (Master's Thesis, Victoria University of Wellington). Retrieved October 01, 2019, from the Victoria University of Wellington website:

http://researcharchive.vuw.ac.nz/bitstream/handle/10063/4266/thesis.pdf?se quence $=2$ 
Fowler, T. (2018). Māori and Pasifika achievement is a learner success issue. Retrieved November 16, 2019, from the Tertiary Education Commission website: https://www.tec.govt.nz/news-and-consultations/archived-news/Māori-andPasifika-achievement-learner-success-issue/

Frankel, J. (2012). Pacific Islands and New Zealand. Retrieved February 19, 2020, from Te Ara - the Encyclopaedia of New Zealand website: https://teara.govt.nz/en/pacific-islands-and-new-zealand/page-2

Freire, P. (2017). Pedagogy of the Oppressed. London: Penguin Modern Classics.

Fa'avae, D., Jones, A., \& Manu'atu, L. (2016). Talanoa'I A E Talanoa - Talking about Talanoa. ALTERNATIVE, 12(2), 138-150. https://doi.org/10.20507/AlterNative.2016.12.2.3

Gadotti, M., Torres, C.A. (2009). Paulo Freire: Education for Development. Development and Change, 40(6), 1255-1267. https://doi.org/10.1111/j.1467-7660.2009.01606.x

Gaw, K. (June 08, 2016). The Story Behind the Four Asian Tigers. [Blog post]. Retrieved March 26, 2019, from iDeals website:

https://www.idealsvdr.com/blog/the-four-asian-tigers/

Gegeo, D. (1998) 'Indigenous epistemologies and empowerment' The Contemporary Pacific 10(2), 289-315.

Gibson-Graham, J. K. (2005). Surplus possibilities: Postdevelopment and community economies. Singapore Journal of Tropical Geography, 26(1), 4-26.

https://doi.org/10.1111/j.0129-7619.2005.00198.x

Global Partnership For Education. (2015). Education and the Global Goals. Global Partnership for Education. Retrieved February 08, 2020, from Global Partnership For Education website:

https://www.globalpartnership.org/news/infographic/education-and-globalgoals

Global Partnership for Education. (2020). Benefits of Education. Retrieved February 18, 2020, from Global Partnership for Education website: https://www.globalpartnership.org/benefits-of-education

Gregson, S., Terceira, N., Mushati, P., Nyamukapa, C., \& Campbell, C. (2004). Community group participation: Can it help young women to avoid HIV? An exploratory study of social capital and school education in rural Zimbabwe. Social Science \& Medicine, 58(11), 2119-2132. https://doi.org/10.1016/j.socscimed.2003.09.001

Gudynas, E. (2011). Buen Vivir: Today's tomorrow. Development, 54(4), 441-447. https://doi.org/10.1057/dev.2011.86 
Hammond, S. A. (2013). The Thin Book of Appreciative Inquiry. ( $3^{\text {rd }}$ Edition). Bend OR.: The Thin Book Publishing Co.

Hall, S. (1992). The West and the Rest: Discourse and Power. In S. Hall \& B. Gieben (Eds.), Formations of Modernity (pp. 184 - 227). Cambridge: Polity Press, in association with the Open University.

Harris, B. I. (1996). Children in Jeopardy: Can we break the cycle of Poverty? New Haven: Yale University Press.

Helu Thaman, K. (1993). Culture and the curriculum in the South Pacific. Comparative Education, 29(3), pp. 249-60.

https://doi.org/10.1080/0305006930290303

Helu Thaman, K. (2003). Decolonizing Pacific studies: Indigenous perspectives, knowledge, and wisdom in higher education. The Contemporary Pacific, 15(1), 1-17.

http://hdl.handle.net/10125/13690

Hook, G.R. (2006). A future for Māori education Part I: the dissociation of culture and education. MAl Review, Issue 1, 1-14.

http://www.review.mai.ac.nz/index.php/MR/article/view/8/197

Hotere-Barnes, A. (2015). Generating 'Non-stupid Optimism': Addressing Pākehā Paralysis in Māori Educational Research. New Zealand Journal of Educational Studies, 50 (1).

https://doi.org/10.1007/s40841-015-0007-y

Human Rights Commission. (2016). The stereotype of "Dumb, Fat, Violent" Pacific Islanders are wrong. Here's why. Retrieved February 17, 2020, from the Human Rights Commission website:

https://www.thatsus.co.nz/the stereotype of dumb fat violent are wrong here s why

Kamehameha Schools. (2014). Language Builds Identity and Perpetuates Culture. Retrieved May 05, 2018 from Kamehameha Schools website: https://apps.ksbe.edu/kaiwakiloumoku/node/605

Kapoor, I. (2005). Participatory Development, Complicity and Desire. Third World Quarterly 26(8), 1203-1220. https://doi.org/10.1080/01436590500336849

Kendall, N., Kaunda, Z., Friedson-Rideneur, S. (2015). Community Participation in International Development Education Quality Improvement Efforts: Current Paradoxes and Opportunities. Educational Assessment, Evaluation and Accountability, 27(1), 65-83.

https://doi.org/10.1007/s11092-015-9210-0 
Kids Matter. (2013). Why cultural identity matters to children's wellbeing. Retrieved May 14, 2018 from Kids Matter Website:

https://www.kidsmatter.edu.au/health-and-community/enewsletter/culturalidentity-matters-children\%E2\%80\%99s-wellbeing

Kindon, S., Pain, R., \& Kesby, M. (2007). Participatory action research: origins, approaches and methods. In S. Kindon, R. Pain, \& M. Kesby (Eds.), Participatory action research approaches and methods: Connecting people, participation and place (pp. 9-18). London: Routledge.

Loto, R., Hodgetts, D., Chamberlain, K., Waimarie Nikora, L., Karapu, R., \& Barnett, A. (2006). Pacific in the news: the portrayal of Pacific peoples in the New Zealand press. Journal of Community \& Applied Social Psychology, 16, 100-118. https://doi.org/10.1002/casp.848

Love Wainuiomata. (2016a). Wainuiomata. The Valley with a lot of heart. Retrieved December 26, 2019, from the Love Wainuiomata website: https://www.lovewainuiomata.co.nz/

Love Wainuiomata. (2016b). Facts and Figures. Retrieved December 26, 2019, from the Love Wainuiomata website: http://lovewainuiomata.com/facts-figures

Maclean, C. (2016). Wellington places - Eastern ranges. Retrieved February 24, 2019, from the Te Tera - the Encyclopaedia of New Zealand website: https://teara.govt.nz/en/wellington-places/page-12

Mahuika, R., Berryman, M., Bishop, R. (2011). Issues of culture and assessment in New Zealand education pertaining to Māori students. Assessment Matters, Issue 3, 183-198. https://search.informit.com.au/documentSummary; $d n=516054067390993 ;$ res $=$ IELHSS; type $=$ pdf

Māori Dictionary. (2020) hōhā. Retrieved February 02, 2020, from Māori Dictionary website:

https://Māoridictionary.co.nz/search?idiom=\&phrase=\&proverb=\&loan=\&histL oanWords=\&keywords=hoha

McConnell, R. (2013). Helping kids to 'dream big'. Wainuiomata News, p.11. Retrieved May 04, 2018, from issue website: https://issuu.com/the.star/docs/213240wn

McGrath, S. (2018). Education and Development. London: Routledge.

McGrath, S. (2010). The role of education in development: An educationalist's response to some recent work in development economics. Comparative Education 46(2), 237-253. https://doi.org/10.1080/03050061003775553 
McIntyre, A. (2007). Participatory action research (Qualitative research methods; v.52). Los Angeles: Sage Publications.

McMichael, P. (2017). Development and Social Change. (6 ${ }^{\text {th }}$ Edition). Pine Forge: Thousand Oaks.

Meredith, A. (March, 18, 2015). Play day a massive success. Wainuiomata News, p. 04. Retrieved May, 04, 2018, from issue website: https://issuu.com/the.star/docs/215076wn

Ministry for Culture and Heritage. (2017). History of the Māori language. Retrieved November 21, 2019, from the New Zealand History website: https://nzhistory.govt.nz/culture/Māori-language-week/history-of-the-Māorilanguage

Ministry for Pacific Peoples. (2016). Contemporary Pacific Status Report: A snapshot of Pacific peoples in New Zealand. Wellington: Retrieved February 18, 2020, from Ministry for Pacific Peoples website: https://www.mpp.govt.nz/assets/Uploads/Contemporary-Report-Web.pdf

Ministry of Business, Innovation \& Employment. (2016). Labour Market Terms Explained. Retrieved April 17, 2018 from MBIE website: http://www.mbie.govt.nz/info-services/employment-skills/labour-marketreports/pacific-peoples-labour-market-trends/june-2016/terms-explained

Ministry of Business, Innovation \& Employment. (2017c) Not in Employment, Education and Training. Retrieved April 02, 2018, from MBIE website:

http://www.mbie.govt.nz/info-services/employment-skills/labour-marketreports/pacific-peoples-labour-market-trends/june-2017/neet

Ministry of Business, Innovation \& Employment. (2019). Pacific Peoples in the Labour Market - June 2019 Year. Retrieved December 20, 2019, from the MBIE website:

https://www.mbie.govt.nz/assets/pacific-peoples-labour-market-report-june2019.pdf

Ministry of Business, Innovation \& Employment. (2017b). People employed, unemployed, and not in the labour force [Data file]. Retrieved March 27, 2018, from StatsNZ website:

https://www.stats.govt.nz/assets/Uploads/Labour-market-statistics/Labourmarket-statistics-December-2017-quarter/Download-data/household-labourforce-survey-december-2017-quarter-tables.xlsx

Ministry of Education. (2017). Benefits of early childhood education. Retrieved July 04, 2019, from the Ministry of Education website:

https://parents.education.govt.nz/early-learning/early-childhoodeducation/benefits-of-early-childhood-education/ 
Ministry of Education. (2020). New Zealand Curriculum. Retrieved February 03, 2020, from the Ministry of Education website:

https://parents.education.govt.nz/primary-school/learning-at-school/newzealand-curriculum/

Ministry of Education. (2018). Our purpose and vision. Retrieved February 20, 2018, from the Ministry of Education website:

https://www.education.govt.nz/our-work/our-role-and-our-people/ourpurpose-and-vision/

Ministry of Education (n.d.) Pasifika Education Community. Retrieved May 14, 2019, from the Ministry of Education website:

http://Pasifika.tki.org.nz/Media-gallery/Engaging-with-Pasifika-parentsfamilies-communities/Diversity-and-identity\#video-transcript

Ministry of Education. (2010). Teu Le Va: Relationships across research and policy in Pasifika education. Retrieved February 18, 2020, from Ministry of Education website:

https://www.educationcounts.govt.nz/publications/Pasifika/teu-le-varelationships-across-research-and-policy-in-Pasifika-education/appendices

Nakhid, C. (2003). "Intercultural" Perceptions, Academic Achievement, and the Identifying Process of Pacific Islands Students in New Zealand Schools. The Journal of Negro Education, 72(3), 297-317. https://doi.org/10.1016/10.2307/3211249

Noy, C. (2008). Sampling Knowledge: The Hermeneutics of Snowball Sampling in Qualitative Research. International Journal of Social Research Methodology 11 (4), 327-344.

https://doi.org/10.1080/13645570701401305

NZ's education gap among the worst in the developed world. (2018, October 30). The Dominion Post. Retrieved June 23, 2019, from the Stuff website: https://www.stuff.co.nz/national/education/108204490/nzs-education-gap-isamong-the-worst-in-the-developed-world-and-poverty-makes-it-worse

NZQA. (2016). Annual Report on NCEA and New Zealand Scholarship Data and Statistics (2016) [Electronic Report]. Wellington: Retrieved May 05, 2018 from NZQA website: http://www.nzqa.govt.nz/assets/About-us/Publications/statsreports/ncea-annualreport-2016.pdf

NZQA. (2018). Secondary Statistics Consolidated Data Files for 2017 - National by Ethnicity [Data File]. Retrieved May 14, 2018 from NZQA website: http://www.nzqa.govt.nz/studying-in-new-zealand/secondary-school-andncea/find-information-about-a-school/secondary-schoolstatistics/consolidated-files/data-files-for-2017/ 
OECD. (2015). Universal Basic Skills: What Countries Stand to Gain. OECD Publishing. Retrieved February 17, 2020, from the OECD website:

https://doi.org/10.1787/9789264234833-en

Office of the Children's Commissioner. (2018). Education matters to me: Key Insights.

[Report]. Retrieved May 25, 2019, from the Office of the Children's

Commissioner website:

https://www.occ.org.nz/assets/Uploads/OCC-STA-Education-Matters-to-MeKey-Insights-24Jan2018.pdf

Olaniyan, D.A., \& Okemakinde, T. (2008). Human Capital Theory: Implications for Educational Development. Pakistan Journal of Social Sciences, 5(5), 479-483. http://medwelljournals.com/abstract/?doi=pjssci.2008.479.483

Overton, J., Stupples, P., Murray, W.E., Gamlen, A. \& Palomino-Schalscha, M. (2020) 'Learning journeys: Five paradigms of education for development' Asia Pacific Viewpoint (in press).

Pasefika Proud. 2016. The profile of Pacific peoples in New Zealand. Wellington:

Retrieved April 16, 2018, from Pasefika Proud website:

http://www.pasefikaproud.co.nz/assets/Resources-fordownload/PasefikaProudResource-Pacific-peoples-paper.pdf

Pieterse, J.N. (2000). After Post-Development. Third World Quarterly, 21(2), 175-191. https://doi.org/10.1080/01436590050004300

Pihama, L., Cram, F., \& Walker, S. (2002). Creating methodological space: A literature review of Kaupapa Māori research. Canadian Journal of Native Education, 26(1), 30-43.

Potter, R., Binns, T., Elliott, J. Etienne, N., \& Smith, D. (Eds.). (2018). Geographies of Development: An Introduction to Development Studies (4th ed.). London: Routledge

Prescott, S. M. (2008). 'Using Talanoa in Pacific Business Research in New Zealand: Experiences with Tongan Entrepreneurs', AlterNative: An International Journal of Indigenous Scholarship, 4(1): 127-48.

https://doi.org/10.1177/117718010800400111

RacismNoWay. (2015). The importance of culture, language and identity. Retrieved August 22, 2018 from the RacismNoWay website:

https://www.racismnoway.com.au/about-racism/understanding-racism/theimportance-of-culture-language-and-identity/

Rist, G. (2014). History of Development: From Western Origins to Global Faith. (4 $^{\text {th }}$ Edition). London: Zed Books. 
Rivas, C. (2017). Finding Themes in Qualitative Data. In Seale, C. (Ed), Researching Society and Culture (4 ${ }^{\text {th }}$ Edition), (pp. 431-457). Thousand Oaks: SAGE Publishing.

Royal, T.A.C. (2012). Politics and knowledge: Kaupapa Māori and matauranga Māori. New Zealand Journal of Educational Studies, 47(2), 30-37.

https://search.informit.com.au/documentSummary;dn=446746674901479;res $=$ IELHSS

Roy, E.A. (2018). Has the 'New Zealand dream' turned sour for Auckland's Pacific Islanders? The Guardian. Retrieved November 11, 2019, from https://www.theguardian.com/cities/2018/nov/19/has-the-new-zealanddream-turned-sour-for-aucklands-pacific-islanders

Sachs, W. (2010). The development dictionary: A guide to knowledge as power $\left(2^{\text {nd }}\right.$ ed.). London, United Kingdom: Zed Books.

Sanga, K. (2001). A case for integrity in development assistance partnerships. Journal of Pacific Studies, 25(1), 231-52.

Sanga, K., and Taufe'ulungaki A. (2005). International Aid Impacts on Pacific Education. Wellington: He Pārekereke, Institute for Research and Development in Māori and Pacific Education, Victoria University; Suva: Institute of Education, University of the South Pacific.

Shuayb, M., Sharp, C., Judkins, M., \& Hetherington, M. (2009). Using Appreciative Inquiry in Educational Research: Possibilities and Limitations. (Report No. AEN01). Retrieved May 29, 2019, from the National Foundation for Education Research website: https://www.nfer.ac.uk/publications/aen01/aen01.pdf

Sin, I., Ormsby, J. (2019). The settlement experience of Pacific migrants in New Zealand: Insights from LISNZ and the IDI (Working Paper No. 19-02). Motu Economic and Public Policy Research. Retrieved February 19, 2020, from the Motu website:

http://motu-www.motu.org.nz/wpapers/19 02.pdf

Smith, G.H. (2009). Mai I te Maramatanga, ki te Putanga Mai o te Tahuritanga: From Conscientization to Transformation. In Andrzejewski, J., Baltodano, M.P. \& Symcox, L (Eds.). Social Justice, Peace and Environmental Education: Transformative Standards (pp. 19-28). New York, Routledge.

Spiller, L. (2012). 'How can we teach them when they won't listen?' How teacher beliefs about Pasifika values and Pasifika ways of learning affect student behaviour and achievement'. Set, 3, 58-66.

https://www.nzcer.org.nz/nzcerpress/set/articles/how-can-we-teach-themwhen-they-won-t-listen"-how-teacher-beliefs-about-pasi 
Spoonley, P. \& Butcher, A. (2009). Reporting superdiversity. The mass media and immigration in New Zealand. Journal of Intercultural studies 30(4), 355-372. https://doi.org/10.1080/07256860903213638

Statistics New Zealand. (2014a). 2013 Census QuickStats about culture and identity Ethnic Groups in New Zealand. Retrieved April 10, 2018, from StatsNZ website: http://archive.stats.govt.nz/Census/2013-census/profile-and-summaryreports/quickstats-culture-identity/ethnic-groups-NZ.aspx

Statistics New Zealand. (2019). New Zealand's population reflects growing diversity. Retrieved February 19, 2020, from StatsNZ website: https://www.stats.govt.nz/news/new-zealands-population-reflects-growingdiversity

Statistics New Zealand. (2018). Use of childcare by Māori and Pacific children takes off. Retrieved May 10, 2018 from StatsNZ website: https://www.stats.govt.nz/news/use-of-childcare-by-Māori-and-pacificchildren-takes-off

Story of a suburb: Where people are proud to be Wainuiomartins. (2010, February 10). The Dominion Post. Retrieved December 21, 2018, from the Stuff website: http://www.stuff.co.nz/dominion-post/news/3310091/Story-of-a-suburbWhere-people-are-proud-to-be-Wainuiomartians

Sultana, F. (2007) Reflexivity, Positionality and Participatory Ethics: Negotiating Fieldwork Dilemma in International Research. ACME: An International Journal for Critical Geographies, 6 (3), 374-385. https://acme-journak.org/index.php/acme/article/view/786

Tamasese, K., Peteru, C., \& Waldegrave, C. (1997). Ole taeao afua: the new morning: A qualitative investigation into Samoan perspectives on mental health and culturally appropriate services: A research project carried out by The Family Centre. Lower Hutt, Wellington, New Zealand: The Family Centre.

Teaiwa, T.K. (2011). Preparation for deep learning: A reflection on 'teaching' Pacific Studies in the Pacific. Journal of Pacific History, 46(2), 214-20. https://www.jstor.org/stable/41343799

Te Taura Whiri i te Reo Māori (n.d.) History of Te Re Māori. 1800 Tātai Kōrero. Retrieved May 16, 2019, from Te Taura Whiri i te Reo Māori|Māori Language Commission website:

https://www.tetaurawhiri.govt.nz/en/te-reo-Māori/history/1800/

The Education Hub. (2019). Four strategies to effectively support Pasifika students. Retrieved June 09, 2019, from The Education Hub website: https://theeducationhub.org.nz/wp-content/uploads/2019/08/Four-strategiesto-effectively-support-Pasifika-students.pdf 
Tilak, J. (2002). Education and Poverty. Journal of Human Development, 3(2), 191-207. https://doi.org/10.1080/14649880220147301

Tolich, M. (2002). Pākehā "Paralysis": Cultural Safety for Those Researching the General Population of Aotearoa. Social Policy Journal of New Zealand, 19, -. Retrieved November 27, 2019, from Ministry of Social Development website: http://www.msd.govt.nz/about-msd-and-our-work/publicationsresources/journals-and-magazines/social-policy-journal/spj19/pakehaparalysis19-pages164-178.html

Townsin, J. (2019). Introduction to Appreciative Inquiry. Retrieved January 03, 2020, from the Al Commons website: https://appreciativeinquiry.champlain.edu/learn/appreciative-inquiryintroduction/

Tucker, J., Van Teijlingen, E., Philip, K., Shucksmith, J., \& Penney, G. (2006). Health demonstration projects: Evaluating a community-based health intervention programme to improve young people's sexual health. Critical Public Health, 16(3), 175-189.

https://doi.org/10.1080/09581590600986358

Tupper, M. (2001). Community Participation in Conservation: Involving Hill Tribes in Developing Environmental Education in Vietnam (Unpublished Master's thesis). University of British Columbia, Canada.

Van Den Berg, H. (2001). Economic Growth and Development ( $1^{\text {st }}$ Ed.). New York: McGraw-Hill.

UNICEF Office of Research (2018). 'An Unfair Start: Inequality in Children's Education in Rich Countries', (Innocenti Report Card 15). Retrieved May 15, 2019, from the UNICEF Office of Research website:

https://www.unicef-irc.org/publications/995-an-unfair-start-educationinequality-children.html

United Nations. (n.d.a). 17 Goals to Transform Our World. Retrieved February 12,2020, from United Nations website:

https://www.un.org/sustainabledevelopment/

United Nations. (n.d.b). 4 Quality Education. Retrieved February 12, 2020, from United Nations website:

https://www.un.org/sustainabledevelopment/education/

United Nations. (2019). Progress of Goal 4 in 2019. Retrieved February 12, 2020, from https://sustainabledevelopment.un.org/sdg4

United Nations Development Programme. (2018). Sustainable Development Goals. Retrieved August 10, 2018, from the UNDP website: https://www.undp.org/content/undp/en/home/sustainable-developmentgoals.html 
Van Der Meer, J. (2011). Māori and Pasifika students' academic engagement: What can institutions learn from the AUSSE data? In: Radloff, A. (Ed.) Student engagement in New Zealand's universities (1-11). Ako Aotearoa: Wellington.

Vanhulst, J., Beling, A. (2014). Buen Vivir: Emergent discourse within or beyond sustainable development?. Ecological Economics, 101, 54-63.

https://doi.org/10.1016/j.ecolecon.2014.02.017

Vaioleti, T. (2006) Talanoa research methodology: A developing position on Pacific research. Waikato Journal of Education, 12, 20-34.

https://hdl.handle.net/10289/6199

Wainuiomata Pasifika Education Success Initiative. (2016). Cover photo [Picture]. Retrieved January 30, 2020, from @waipesi Facebook page: https://www.facebook.com/waipesi/photos/a.229489710552497/6581732576 84138/?type=1\&theater

Whyte, W. (1991). Participatory Action Research. Thousand Oaks, California: SAGE Publications, Inc.

https://doi.org/10.4135/9781412985383

Wylie, C., Hodgen, E., Hipkins, R., Vaughan, K. (2008). Competent Learners on the Edge of Adulthood: A summary of key findings from the Competent Learners @ 16 project [Report]. Wellington: Retrieved April 28, 2018 from Education Counts website:

http://www.educationcounts.govt.nz/ data/assets/pdf file/0004/47686/Onthe-Edge-of-Adulthood-Summary-Report.pdf

World Bank Group. (2011). Education is Fundamental to Development and Growth. Retrieved February 12, 2020, from the World Bank website: https://blogs.worldbank.org/education/education-is-fundamental-todevelopment-and-growth

World Economic Forum. (2015). Why education is the key to development. Retrieved February 12, 2020 from the World Economic Forum website:

https://www.weforum.org/agenda/2015/07/why-education-is-the-key-todevelopment/

Ziai, A. (September, 2014). Post-Development concepts? Buen Vivir, Ubuntu and Degrowth. Paper presented at the Degrowth Conference. Leipzig. https://www.degrowth.info/en/catalogue-entry/post-development-conceptsbuen-vivir-ubuntu-and-degrowth/ 


\section{Appendices}

Appendix A: Sustainable Development Goals

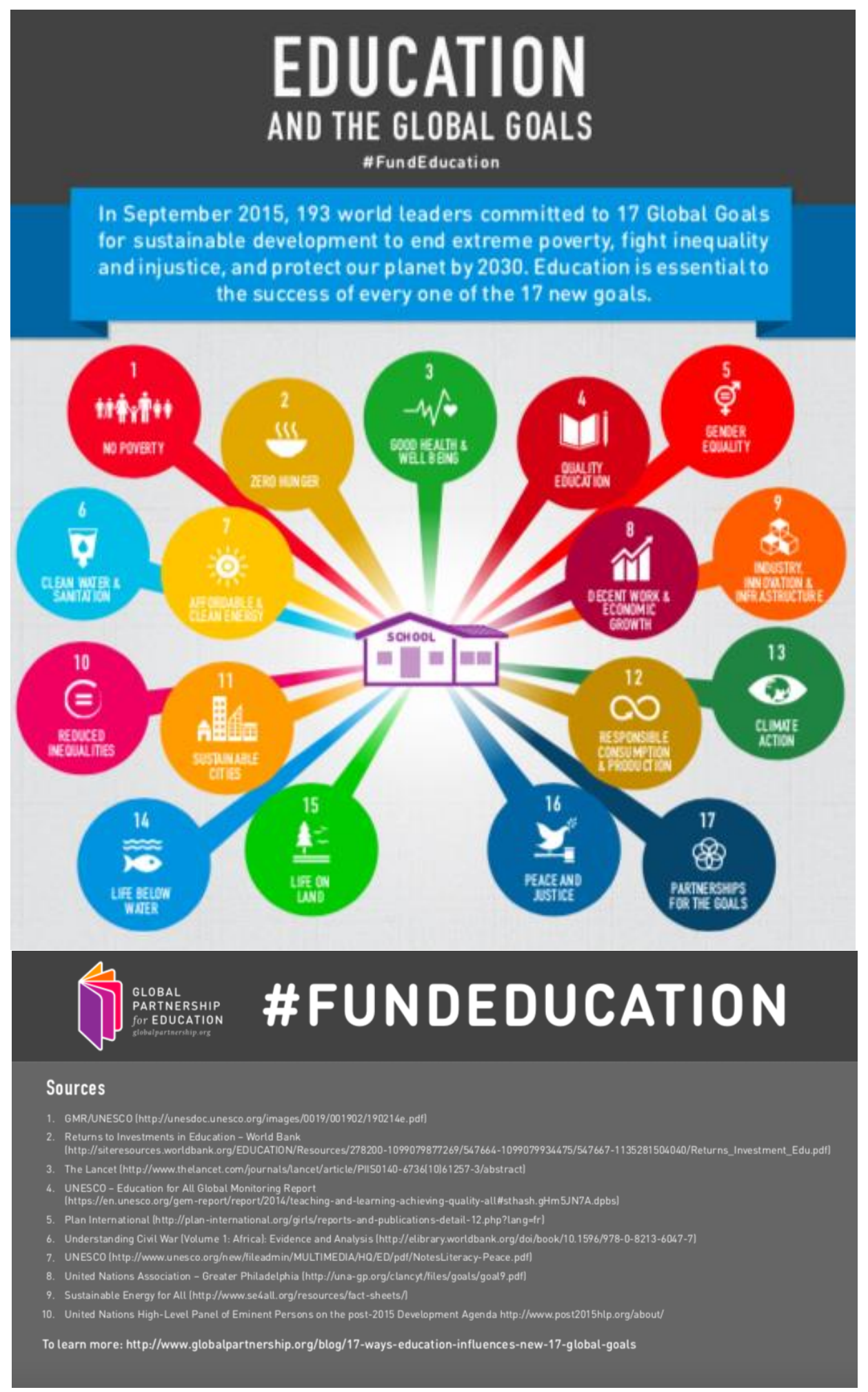




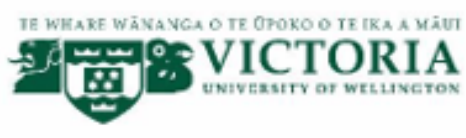

Voices of WaiPESI

\section{INFORMATION SHEET FOR PARTICIPANTS}

You are invited to take part in this research. Please read this information before deciding whether or not to take part. If you decide to participate, thank you. If you decide not to participate, thank you for considering this request.

\section{Who am I?}

My name is Holly McLeod and I am a Masters student in the Development Studies programme at Victoria University of Wellington. This research project is work towards my Master's thesis and a joint report for WaiPESI, and the Pasifika Office at Victoria University.

\section{What is the aim of the project?}

This project wants to hear about your experiences with WaiPESI thus far, our education system, and your hopes for your community's future. This research has been approved by the Victoria University of Wellington Human Ethics Committee [Reference \#26040].

\section{How can you help?}

You have been invited to participate because you have previously engaged with WaiPESI meetings or taken part in activities run by WaiPESI. If you agree to take part I will interview you at the Wainuiomata Public Library, or at a location you agree with. I will ask you questions about your experiences engaging with WaiPESI. The interview will take approximately one hour. I will audio record the interview with your permission and write it up later. You can choose to not answer any question or stop the interview at any time, without giving a reason. You can withdraw from the study by contacting me at any time before $30^{\text {th }}$ September 2018 . If you withdraw, the information you provided will be destroyed or returned to you.

What will happen to the information you give?

Due to the aim of this research being to give voice to your stories and experiences, the research is not confidential, and you will be named in the thesis and final report. However, should you not want to be identified by name but still take part in the research, you may specify this on the consent form that follows. If you choose this option, you will be referred to by a name such as 'Participant $\mathrm{X}$ '.

Only my supervisor and I will read the notes or transcript of the interview. The identified interview transcripts, summaries and any recordings will be kept securely and destroyed in five years, on the $1^{\text {st }}$ of May, 2023. 
What will the project produce?

The information from my research will be used in Master's thesis and a report for WaiPESI that illustrates the journey of WaiPESI thus far, drawn from the voices of yourself and other research participants. This report will also be used to advise the Pasifika office at Victoria University of Wellington. You will have access to both of these documents upon their completion.

This information may also be used in associated academic work, such as the publication of an academic journal article or a conference presentation.

\section{If you accept this invitation, what are your rights as a research participant?}

You do not have to accept this invitation if you don't want to. If you do decide to participate, you have the right to:

- choose not to answer any question;

- $\quad$ ask for the recorder to be turned off at any time during the interview

- $\quad$ withdraw from the study before $30^{\text {th }}$ September, 2018

- ask any questions about the study at any time;

- read over and comment on a written summary of your interview

- be able to read any reports of this research by emailing the researcher to request a copy.

If you have any questions or problems, who can you contact?

If you have any questions, either now or in the future, please feel free to contact either:

Student: Supervisor: Other Researcher:

Name: Holly McLeod Name: John Overton Name: AProf Hon.

Email: Professor of the School of Assistant Vice-Chancellor

Holly.Mcleod@vuw.ac.nz Geography, Environment and (Pasifika) Earth Sciences

Phone: 044635281

Phone: 044636152

Email:

Email:

John.Overton@vuw.ac.nz_Winnie.Laban@vuw.ac.nz

\section{Human Ethics Committee information}

If you have any concerns about the ethical conduct of the research, you may contact the Victoria University HEC Convenor: Dr Judith Loveridge. Email hec@vuw.ac.nz or telephone +644-463 6028 . 


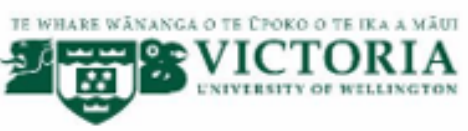

Voices of WaiPESI

\section{CONSENT TO INTERVIEW}

This consent form will be held for five years.

Researcher: Holly McLeod, School of Geography, Environment and Earth Sciences, Victoria University of Wellington.

- I have read the Information Sheet and the project has been explained to me. My questions have been answered to my satisfaction. I understand that I can ask further questions at any time.

- I agree to take part in an audio-recorded interview.

Yes $\square$ - I agree to take part in an audio-recorded interview

No $\square-$ I agree to take part in an interview, but do not want this to be audio recorded.

I understand that:

- I may withdraw from this study at any point before $30^{\text {th }}$ September 2018 and any information that I have provided will be returned to me or destroyed.

- The identifiable information I have provided will be destroyed 1st May 2023.

- Any information I provide will be kept confidential to the researcher and their supervisor

- I understand that the results will be used for Master's thesis and a report for WaiPESI that will also inform Pasifika office at the university.

Yes $\square$ No $\square$-I agree this information can be used for a Masters thesis, and any associated academic work

Yes $\square$ No $\square$-I agree this information can be used for a report about WalPESI, which will also inform the Pasifika office at Victoria University 
- Please select one of the below:

I consent to information or opinions which I have given being $\quad$ Yes $\square$ attributed to me in any reports on this research

OR

I do not wish for any information or opinions that I have given to be attributed to me by name.

Yes $\square$

- I would like a summary of my interview:

Yes $\square$

No $\square$

- I would like to receive a copy of the final reports and have added my Yes $\square$

No $\square$ email or postal address below.

Signature of participant:

Name of participant:

Date:

Contact details: 


\section{Appendix C: Interview Guide}

\section{Semi-structured interview guide}

- Introduce myself as a reseorcher supported by WoipEsl but independent of the group itself.

- Explain my aims - o thesis about whot a good life looks like for Posifika people, giving voice to experiences with WoiPESI, and colloting these stories into o report

- Research outputs include a report to be shared with WaiPESV/AVC Pasifika office to illustrate the journey of Waipes/ thus for, and community aspirations.

- Prefoce each interview with reminding porticipants that / want to heor the story of both their involvement with WoiPESI, and their experiences with our education system in Aoteoroo. Emphosise that there are no right or wrong answers here, as this is about their story.

\section{AVC Pasifika report focused:}

1) How did your involvement in WaipesI begin?

2) What made you want to be involved?

3) What have some of the highlights of your involvement been?

4) Where do you see WaipEsl going from here, over the next couple of years?

5) What is the long-term vision you hope it will achieve?

6) What sort of education do you hope your family will receive?

\section{Thesis focused:}

1) What does the word 'development' mean to you?

2) What does a good life look like for you? For your whanau? For your community?

3) What role do you think education has in achieving this vision of a good life? 
Alexia is the Children and Teens Librarian at Wainuiomata Community Hub, who was involved in running WaiPESI's Growing Stronger Together sessions at the Community Hub

Rev. Aneterea is a parent of children whom attended WaiPESI activities, and Pastor at the local Samoan Revival Church of the Nazarene.

Annie \#1 is a current WaiPESI Trustee and Acting Board Chair

Annie \#2 is a current WaiPESI Trustee and Wainuiomata Community Hub Manager, the site of many WaiPESI activities

Bruce is a current WaiPESI Trustee and works as a Te Papa Museum Host, which has allowed him to take WaiPESI youth behind the scenes of the museums Pasifika exhibit on an annual basis

Charmaine is a teacher at Wainuiomata High School, and acted as a volunteer at WaiPESI 'Growing Stronger Together' sessions

Craig is the current principal of Wainuiomata Intermediate, which has hosted WaiPESI Career Evenings and has a number of students currently attending WaiPESI

Emma is a parent of children who attend WaiPESI activities

Gail is a current WaiPESI Trustee who acts as both Treasurer and Secretary. Gail's work with WaiPESI also forms part of her role as Executive Officer to AVC (Pasifika) at Victoria University of Wellington

Hon. Luamanuvao Dame Winnie Laban is the Assistant Vice-Chancellor (Pasifika) at Victoria University of Wellington. A founding member of WaiPESI and their patron to this day, Luamanuvao is passionate about the educational outcomes for Pasifika youth and community empowerment. Luamanuvao is also known for making history in 1999 when she was appointed as the New Zealand's first female Pasifika MP, serving for the Labour Party.

loane is a former WaiPESI trustee and former deputy-principal at Wainuiomata High School, and was considered by other WaiPESI leaders to be instrumental in the genesis of WaiPESI

Jay is an ex-employee of WaiPESI, who was involved in both behind-the-scenes work and actively involved in organising both WaiPESI's weekly activities and core events

Lahraine is a former tertiary student who interned with WaiPESI as part of her Development Studies degree.

Leah is a parent of children who attend WaiPESI activities 
Lisa is a grandparent of children who attend WaiPESI activities, and in her capacity as a teacher at Konini Primary, helped lead teaching sessions herself.

Louana is a current WaiPESI trustee and former Board Chair. Louana's connections as an ECE teacher and energy were integral in the initiating of WaiPESI's Play Days to encourage participation in Early Childhood Education. She is also known as Whaea Louana, who visits schools in Wainuiomata and teaches elements of Māori culture and Kapa Haka.

Miliama is a parent of children who attend WaiPESI activities

Osuvale is a parent of children who attend WaiPESI activities

Participant A was formerly involved in WaiPESI

Pearl is the former-principal of Wainuiomata Intermediate School, which was incredibly supportive of WaiPESI in it's early years, through teachers volunteering their time to assist with after school sessions, and encouraging students to attend.

Toli was formerly involved in the organisation of WaiPESI

Traci is a parent of children who attend WaiPESI activities

Trevor is a grandparent of children who attend WaiPESI activities

Tute is the current Deputy Principal at Wainuiomata Primary School, and a former WaiPESI trustee. Tute was considered by other WaiPESI leaders to be instrumental in the genesis of WaiPESI

Vai is a former assistant-principal at Wainuiomata Intermediate School who was considered by other WaiPESI leaders to be instrumental in the genesis of WaiPESI

Yvonne is a former WaiPESI trustee 
